Prepared for the U.S. Department of Energy

under Contract DE-AC05-76RL01830

\title{
The Role of Energy Storage in Commercial Building
}

\section{A Preliminary Report}

MC Kintner-Meyer

$\mathrm{K}$ Subbarao

N Prakash Kumar

G Bandyopadhyay

C Finley

V S Koritarov
J C Molburg

J Wang

F Zhao

L Brackney

AR Florita

September 2010

Pacific Northwest

NATIONAL LABORATORY

Proudly Operated by Battelle Since 1965 


\title{
DISCLAIMER
}

This report was prepared as an account of work sponsored by an agency of the United States Government. Neither the United States Government nor any agency thereof, nor Battelle Memorial Institute, nor any of their employees, makes any warranty, express or implied, or assumes any legal liability or responsibility for the accuracy, completeness, or usefulness of any information, apparatus, product, or process disclosed, or represents that its use would not infringe privately owned rights. Reference herein to any specific commercial product, process, or service by trade name, trademark, manufacturer, or otherwise does not necessarily constitute or imply its endorsement, recommendation, or favoring by the United States Government or any agency thereof, or Battelle Memorial Institute. The views and opinions of authors expressed herein do not necessarily state or reflect those of the United States Government or any agency thereof:

\author{
PACIFIC NORTHWEST NATIONAL LABORATORY \\ operated by \\ BA'T"TELLE \\ for the \\ INITED STATFS DEPARTMFNT OF ENFRGY \\ under Contract DE-AC05-76RL01830
}

\author{
Printed in the United States of America \\ $\Lambda$ vailable to DOE and DOE contractors from the \\ Office of Scientific and Technical Information, \\ P.O. Box 62, Oak Ridge, TN 37831-0062; \\ ph: (865) $576-8401$ \\ fax: $(865) 576-5728$ \\ email: reports@adonis.osti.gov

\begin{abstract}
Available to the public from the National Technical Information Service, U.S. Department of Commerce, 5285 Port Royal Rd., Springfield, VA 22161 ph: (800) 553-6847 fax: $(703) 605-6900$ email: orders(a)ntis.fedworld.gov online ordering: http://www.ntis.gov/ordering.htm
\end{abstract}

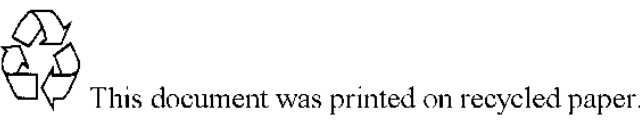




\title{
The Role of Energy Storage in Commercial Buildings
}

\section{A Preliminary Report}

\author{
MC Kintner-Meyer ${ }^{1}$ \\ $\mathrm{J} \mathrm{C} \mathrm{Molburg}^{4}$ \\ K Subbarao ${ }^{1}$ \\ J Wang ${ }^{4}$ \\ N Prakash Kumar ${ }^{1}$ \\ F Zhao \\ G Bandyopadhyay ${ }^{1}$ \\ C Finley ${ }^{3}$ \\ L Brackney ${ }^{2}$ \\ AR Florita ${ }^{3}$ \\ V S Koritarov ${ }^{4}$
}

September 2010

Prepared for

the U.S. Department of Energy

under Contract DE-AC05-76RL01830

Pacific Northwest National Laboratory

Richland, Washington 99352

\footnotetext{
${ }^{1}$ Pacific Northwest National Laboratory

${ }^{2}$ National Renewable Energy Laboratory

${ }^{3}$ University of Washington

${ }^{4}$ Argonne National Laboratory
} 



\section{Executive Summary}

\section{Motivation and Background of Study}

This project was motivated by the need to understand the full value of energy storage (thermal and electric energy storage) in commercial buildings, the opportunity of benefits for building operations and the potential interactions between a building and a smart grid infrastructure.

On-site or local energy storage systems are not new to the commercial building sector; they have been in place in US buildings for decades. Most building-scale storage technologies are based on thermal or electrochemical storage mechanisms. Energy storage technologies are not designed to conserve energy, and losses associated with energy conversion are inevitable. Instead, storage provides flexibility to manage load in a building or to balance load and generation in the power grid. From the building owner's perspective, storage enables load shifting to optimize energy costs while maintaining comfort. From a grid operations perspective, building storage at scale could provide additional flexibility to grid operators in managing the generation variability from intermittent renewable energy resources (wind and solar). To characterize the set of benefits, technical opportunities and challenges, and potential economic values of storage in a commercial building from both the building operation's and the grid operation's view-points is the key point of this project.

The research effort was initiated in early 2010 involving Argonne National Laboratory (ANL), the National Renewable Energy Laboratory (NREL), and Pacific Northwest National Laboratory (PNNL) to quantify these opportunities from a commercial buildings perspective. This report summarizes the early discussions, literature reviews, stakeholder engagements, and initial results of analyses related to the overall role of energy storage in commercial buildings. Beyond the summary of roughly eight months of effort by the laboratories, the report attempts to substantiate the importance of active DOE/BTP R\&D activities in this space.

The entire research effort was originally scoped for a period of two years. The first year plan focused on development of essential tools and models to address a set of research questions about the value and relevance of energy storage in commercial buildings. The three laboratories refocused the project scope during the latter part of the Summer of FY10 in response to DOE/BTP guidance. The reduced scope was intended to provide preliminary results in the first year, rather than in the $2^{\text {nd }}$ year as planned. This required an abbreviated model development effort by the 3 laboratories with less rigor to free time for preliminary analyses. The analyses are still on-going as of the writing of this preliminary report, which

provides a snapshot of the current state of the work. A final report is planned for submission in December 2010.

\section{Role of Energy Storage in Commercial Buildings in the Context of a Modern Electricity Supply System}

Energy storage is a means to provide operational flexibility within a building or in the broader context of the electric grid. In the past, commercial building owners invested in ice or cold-water storage equipment for the sole reason of reducing the demand charge and electricity cost during peak periods. The storage was charged during low-cost off-peak periods and then discharged during peak periods. In 
almost all cases, thermal energy storage was used to reduce the electricity bill by moving air-conditioning loads to low-cost night hours. A widely held view exists that energy storage in buildings remains a load management tool to generate value for the electricity service provider in exchange for a financial reward for the building owner. All electricity customers generally share the benefits of storage in the system or within certain distribution system feeders. Key benefits are higher utilization of the energy infrastructure, higher reliability, and more effective load and outage management. Infrastructure investment deferment may delay a rate increase or slow down the rate at which electricity rates may increase in the future.

In the past, the values that thermal energy storage systems created were two-fold. Firstly, the total demand of building electricity could be limited or reduced, which in densely populated downtown areas could amount to a large value by avoiding expensive distribution system upgrades. From the building owner/operator's point of view, peak limiting strategies reduce the demand charge component of the electricity bill. Secondly, peak load shifting could shift a block of energy from peak to off-peak periods, creating value proportional to the difference between the wholesale value of electricity during peak and off-peak periods. As long as the retail utility passes on the varying cost of electricity to the customer, there is an incentive to maximize the rate differential between peak and off-peak. However, for customers with a flat electricity rate, energy storage for load shifting is not a viable option.

There is future value in energy storage directly linked to the intermittency problem associated with increased penetration of wind and solar renewable energy into the North American grid. As a mitigation measure to smooth the minute-to-minute variability, grid operators will need to procure more balancing services and reserve resources. Energy storage of any kind is expected to play into this growing marketplace. The most direct way to accommodate balancing services includes battery energy storage that can inject and absorb electric energy to and from the grid. This may also be accomplished indirectly through a customer who has installed a thermal energy storage system. In this case, the end-use load (i.e., the chiller) would modulate its output in accordance with cooling load requirements and grid needs.

The market forces to integrate more renewable energy resources are in place. Twenty-nine states (including the District of Columbia) have laws in place that impose renewable portfolio standards (RPS). Grid operators in these jurisdictions are making plans to accommodate these new generation technologies. Studies perform for the California ISO and the Bonneville Power Administration indicated that the regulation requirements (part of the ancillary services to operate the grid safely) would need to be doubled.

The transition of today's grid to a modern energy infrastructure will both enable and require much more active participation of load customers in the energy and ancillary services markets. Ubiquitous communications technologies and advanced controls will transform resources in the demand sectors from passive to active elements on the grid. "Smart" commercial buildings will not be the sole active demand side participants on the emerging smart grid, as sophisticated home energy management systems will enable the residential building sector and smart charging strategies will link in the electric vehicle fleet. Likewise bulk energy storage technologies, smaller community energy storage systems, and on-site battery storage are also likely to compete in these new markets. Modern commercial buildings are uniquely positioned for this new opportunity with large, intrinsic, thermal masses that may be leveraged by advanced controls and demand response mechanisms. Inherent thermal mass may also be augmented with active thermal energy storage to increase the building's resource. 
Drastic improvements of building energy efficiency, even by relatively optimistic goals of 50-70\% above ASHRAE Standard 90.1-2004, suggest reductions in the total carbon emissions attributable to commercial buildings. However, population and economic growth will continue to increase total commercial and residential floor area, making the total reduction of emissions an even harder goal to reach. Achieving long-term carbon reduction targets by 2050, is inextricably linked to our ability to decarbonize the energy supply to the US building stock. The building sector is perfectly positioned, not only to contribute by drastically improving energy efficiency on the demand side, but also to contribute to the supply side by providing grid services with potentially no carbon emissions penalties.

\section{Need for Energy Storage R\&D in the Building Sector}

DOE's energy R\&D portfolio is diverse, including a broad range of supply and demand side technologies that will help address the nation's energy, climate, and energy security concerns. Of equal importance are the spaces between these technologies, and the cost-effective system integration opportunities that are easily overlooked. Building energy storage and the broader value proposition falls in this area. If affordability of future energy supply is taken into consideration when designing the R\&D agenda for the US building stock then an overall system perspective should be applied that includes both buildings and the electricity infrastructure.

Over decades of research in the energy efficiency space, we have recognized the power of systems analysis in the buildings sector and the importance of defining the right problem. There has been recognition of diminishing returns associated with continued $R \& D$ investment in individual building component technologies, and increased emphasis placed on the cost-effectiveness of holistic system engineering approaches. The analysis of integration issues in the buildings research context offers great promise in improving the overall efficiency of whole building systems relative to continued emphasis on specific components.

Just as we have recognized the importance of defining system boundaries and interactions to address the commercial building energy efficiency challenge, there are opportunities that the building sector may provide in the broader system context of the electric grid. In this expanded context, current thinking associated with the performance and value of certain building technologies shifts substantially.

Technologies that don't make economic sense for a building owner suddenly do have significant value at the community scale or larger, and become viable. The challenges and opportunities of interaction between buildings and the supply system are the subject of this analysis. Energy storage is not the only solution to the energy, climate, and security issues, but it could provide a significant value and contribution to this long-term energy-climate challenge. Not quantifying the whole-system benefits of building energy storage may delay the realization of novel concepts and opportunities in a time of heightened urgency.

\section{Preliminary Results}

A number of joint and individual activities took place during the eight month period of performance that the three laboratories worked on the project. All three laboratories contributed to an initial literature review and information gathering from key stakeholders to better understand the state of technologies and market perceptions. The outcomes of this collaboration were two individual reports published by PNNL and NREL. PNNL published the first report titled: "Literature Review in Support of the Project: 
Commercial Buildings, Local Energy Storage and the Electric Grid”, March 2010. NREL published the second report titled: "Expert Insights and Opinions Related to Energy Storage Applications in Commercial Buildings and the Electric Power Grid”. NREL/MP 550-48923. August 2010.

\section{Key Literature Review Insights}

Key insights gained by the literature review on thermal and electric energy storage systems for buildings include:

- Thermal energy storage (TES) is a proven technology, with the choice of technology dependent upon space-availability. If space is available, cold-water storage is preferred because of high chiller efficiency. Ice-storage is preferred in space constrained applications.

- Integrated phase change materials are emerging but unproven technologies that are attractive, as they require no additional installation footrprint.

- A number of proven battery chemistries are commercially available for building applications. The most common applications for buildings are uninterruptable power supplies (UPS) in data centers or sensitive processes.

- The integration of batteries for load time-shifting strategies is uncommon and requires high cost custom system design.

\section{Key Stakeholder Perceptions}

The following conclusions were drawn from discussions with building owner/operators, researchers, utility representatives, and regulators:

- Stakeholders indicated potential of battery storage for buildings applications, but did not see a nearterm business model to support it. Furthermore, the ownership model for batteries is unclear. (Should the utility own the resource, and is it located inside or outside a building?)

- There is little experience using batteries for time-shifting or balancing services, and the O\&M cost associated with frequent cycling is unknown.

- Thermal energy storage is proven technology and control strategies exist to integrate use into building energy management systems, and is significantly less expensive for time-shifting than batteries.

- Little effort has been made to explore the viability of thermal energy storage for intermittent renewable smoothing.

\section{Individual Laboratory Accomplishments}

Following these joint activities, the three laboratories performed individual work in accordance to their particular strengths and core capabilities. The available eight-month period of performance provided sufficient time to build new or enhance existing capabilities to address relevant questions for DOE/BTP in year two. Due to the redirection of emphasis at the DOE/BTP office, all three laboratories attempted to generate some preliminary results by the end of FY2010, demonstrating the capabilities of the tools and models developed. By no means are the relevant questions of the role of on-site energy storage in commercial buildings fully explored, and this report merely reflects a snapshot of the current status. 


\section{ANL Accomplishments}

ANL's objective for this study was to investigate present and future interactions between commercial buildings and the power sector. As dynamic electricity prices will have an impact on the demand in commercial buildings, the demand response actions by building owners and operators will, in turn, have an impact on the power system. The various demand response actions and load control strategies (with and without energy storage) employed by commercial buildings will result in reduced electricity demand during the peak hours, more economical operation of the power system and lower electricity prices.

To study these complex interactions, ANL chose to develop an agent-based modeling and simulation (ABMS) modeling framework. By representing commercial buildings as intelligent agents that react to electricity price signals from the electricity market and decide on appropriate demand response and load control actions, the ABMS modeling framework allows for a realistic simulation of the behavior of commercial building owners and operators. Building agents can have different load control mechanisms and operation strategies for performing their demand response actions. In the study, they have been divided into three main categories: load reduction actions, load shifting without energy storage, and load shifting with energy storage. For the analysis, the commercial building stock was represented using ten building agent types and hourly Typical Meteorological Year (TMY) weather data.

A prototypical ABMS model has been developed and several test cases have been studied.

Preliminary results show that there is noticeable interaction between commercial buildings and the power grid, with the building agents using different demand response options and load adjustment strategies to minimize their energy costs in response to dynamic electricity prices. Preliminary results also show that demand response actions of the commercial building stock have a significant impact on the power grid by reducing the need for peaking units and, consequently, reducing the level of electricity prices.

\section{ANL Recommendations}

Further study with more realistic simulation cases will be needed to provide a better assessment of the real potential for mutual interactions between the commercial building sector and the power grid. The next step would be to implement prototype building agent framework into Argonne's Electricity Market Complex Adaptive Systems (EMCAS) model. The EMCAS modeling platform would allow for more realistic studies of commercial buildings behavior in response to electricity price signals since it includes a detailed representation of the electric power system and calculates locational marginal prices of electricity for each node or zone within the power grid. In addition to energy management strategies and load shifting actions for price arbitrage, the commercial buildings (especially those equipped with energy storage devices) may also provide additional ancillary services (e.g., spinning reserve) to the power grid, thus generating additional financial revenues. With the advance of smart grid and building EMS technologies, the commercial building sector will inevitably change its role from a relatively passive and inelastic demand to a very active and flexible player in the electricity market. The possibilities and potential for various interactions between the power sector and its largest consumer, the commercial building sector, are tremendous. This is a very significant development and a very important area for research. 


\section{PNNL Accomplishments}

PNNL focused on the technical capabilities of on-site thermal energy storage in solving the intermittency problem of renewable energy resources. This analysis required consideration of time scales shorter than one hour to properly capture the intermittency characteristic of wind and solar energy resources (generally requires minute-by-minute or - at least - sub-hourly analysis). PNNL's accomplishments encompasses the development of an assessment framework that allows the analyst to address both broad technical potential questions, such as how much of the US commercial building sector would need thermal or battery energy storage equipment to accommodate variability of the new wind and solar generation capacity that is expected to be built by 2030, as well as, highly time-resolved optimization computations that trade-off the use of thermal energy storage to meet cooling loads and reduce the volatility in the energy output from wind and solar technologies.

To demonstrate the utility of the assessment framework PNNL explored the technical capabilities of cold energy storage for smoothing the output of a hypothetical wind plant. Several control strategies were explored with respect to maintaining comfort while providing value and benefit to the grid. An optimization technique was used to minimize a cost function for satisfying the building's cooling loads while maximizing a utility function that provides service to the grid. Cooling loads and wind generation for a whole month were used for the analysis. The results clearly indicate that thermal energy storage in a typical commercial building can provide significant smoothing capabilities as expressed by:

- reduced total cooling demand for the building during high-cost peak periods

- reduced ramping rates of the electricity fed into the grid or drawn from the grid for cooling purposes

- and improved capacity credit for the wind plant, a measure that values the wind power plant ability to deliver electricity during peak periods consistently.

\section{PNNL Recommendations}

PNNL plans to extend this analysis under the current funding to address the following questions:

What is the technical potential of thermal energy storage in buildings to meet all of the additional regulation services that are necessary to integrate a 30\% RPS into a selected western region? Determined will be the fraction of commercial floor area and the size of the thermal energy storage necessary to meet all of the future balancing requirements if the RPS requirements are met by wind generation. With additional funding for FY2011, PNNL will expand this regional analysis to a national assessment taking the regional diversity in the cooling requirements and wind energy developments and fluctuations of wind generation into considerations. This assessment will provide DOE insights into the potential contribution of the US building stock on the renewable energy integration issue. For the commercial building industry it will provide first order estimates on potential revenue streams in return for providing grid services. It will also reveal practical issues associated with the control strategies between meeting the building load requirements and serving the grid. 


\section{NREL Accomplishments}

NREL was responsible for the detailed building simulations necessary for ANL's agent behavior definition of the building stock. NREL also engaged with John Deere Corporation, a member of the Commercial Building Partnership (CBP), on a case study that involved a mid-sized $\left(12,000 \mathrm{ft}^{2}\right.$.) commercial building in Des Moines, Iowa, an on-site wind turbine, and a ground source heat pump used as a storage mechanism. NREL modeled the commercial building with the ground source heat pump system and wind power plant to study heat pump sizing and control strategies that would maximize the value of the combined wind turbine-building system.

A preliminary control strategy recharges the ground storage in the night hours when there is very little load in the building. The stored energy is then utilized to reduce the electricity demand in the early morning hours during start-up of the heating system (6:00 to 8:00 a.m.) shifting about 10\% of the heating loads to the night hours. The current research has focused on identifying optimal set points for HVAC control that manage storage charge and discharge for heating and cooling. The following conclusions can be drawn from the preliminary results:

\section{NREL Recommendations}

Initial experience with the detailed John Deere building, storage, and wind generation model suggests a number of practical next steps. In addition to studying the impact of storage sizing and control parameters on comfort and grid benefit, an optimization study focusing on life-cycle cost/benefit analysis would identify the amount of excess production that would necessitate the purchase of auxiliary equipment such as boilers and fluid coolers. Although it is evident that conversion of electricity to thermal storage can reduce the next day's daily electrical demand, it is important to quantify the value this has for the utility. 



\section{Acronyms and Abbreviations}

$\mathrm{AC}$

O\&M

SAF

$\mathrm{AA}$

AMRA

CALMAC

CES

DC

DOD

EES

HVAC

IEEE

IP

JCI

MW

MWh

$\mathrm{NaS}$

O\&M

PCM

R\&D

SAF

SAFT

SI

SLI

$\mathrm{T} \& \mathrm{D}$

TES

UPS

VRB

$\mathrm{ZnBr}$
Air-conditioning or air conditioner

Operation and Maintenance

Storage Assessment Framework

type-AA battery

Automatic Meter Reading Association

CALMAC Manufacturing Corporation

Community Energy Storage

direct current

Department of Defense

Electric Energy Storage

heating, ventilating and air conditioning

Institute of Electrical and Electronics Engineers

Intellectual Property

Johnson Controls, Inc.

megawatt

megawatt hour

sodium-sulfur

operation and maintenance

phase-change material

Research and Development

Storage Assessment Framework

Saft Group, a battery manufacturer

international system of units

starting-lighting-ignition

transmission and distribution

thermal energy storage

uninterruptible power supply

vanadium-redox battery

zinc-bromine 



\section{Contents}

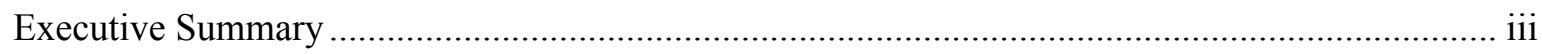

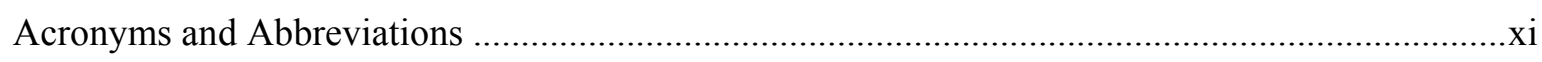

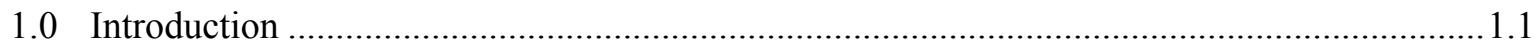

1.1 What Role Could Energy Storage Play in Commercial Buildings in the Context of a Modern Electricity Supply System? ..........................................................................

1.2 The Need for Energy Storage R\&D in the Commercial Building Sector ...................... 1.3

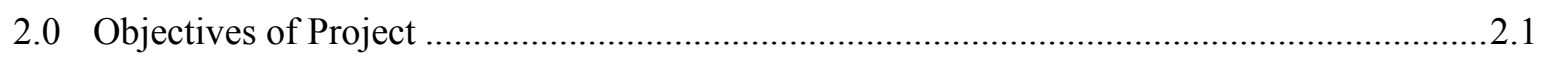

3.0 Outcomes of Year-1 Activities ........................................................................................... 3.1

3.1 Literature Review of Current State-of-the-Art Energy Storage in Buildings

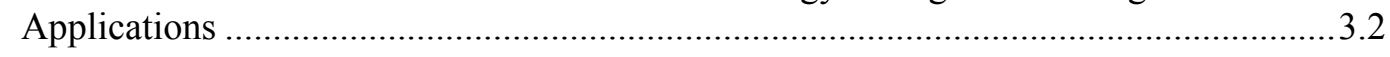

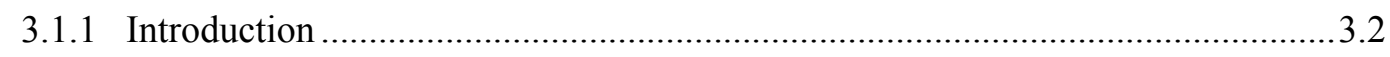

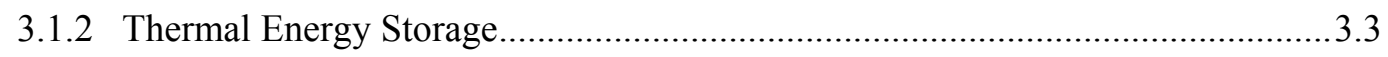

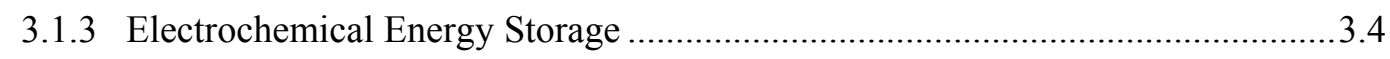

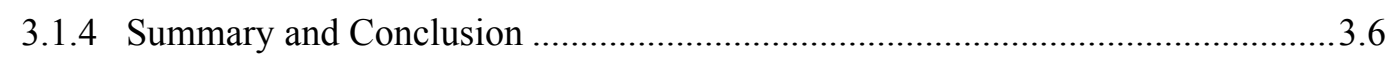

3.1.5 Bibliography of the Literature Review......................................................... 3.10

3.2 Stakeholder Engagement: Discussion on the Needs and Role of Energy Storage in

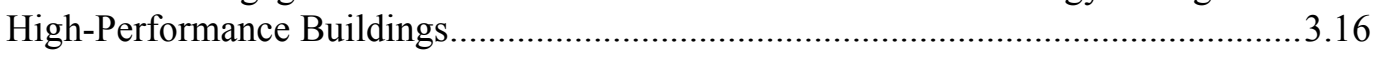

3.2.1 Experience with On-Site Energy Storage ..........................................................

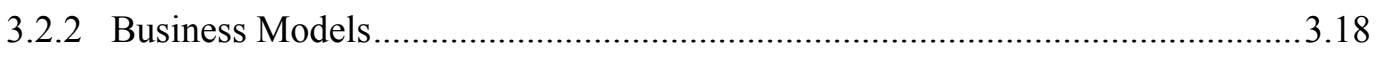

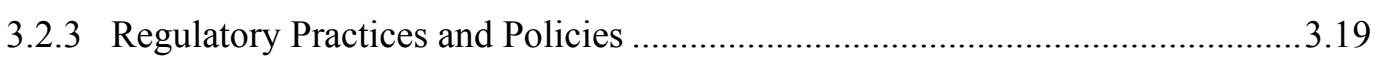

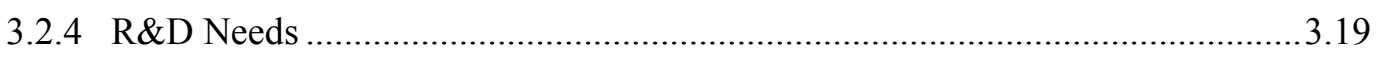

3.2.5 Conclusions on Perceived Need and Role of Energy Storage in Commercial

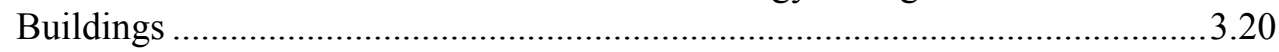

3.3 ANL's Accomplishments: Agent-Based Modeling of Commercial Buildings .............3.20

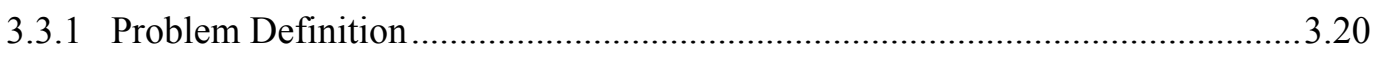

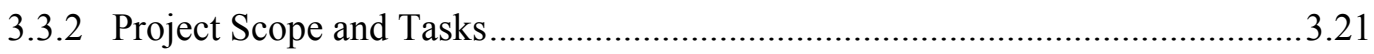

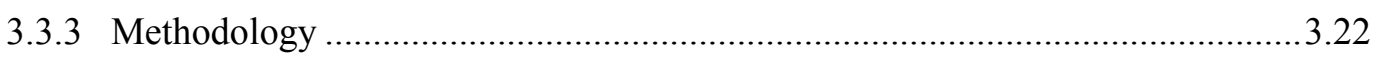

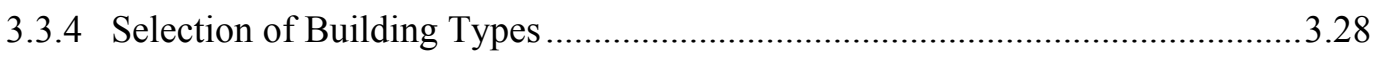

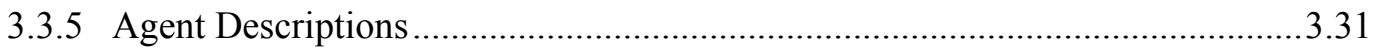

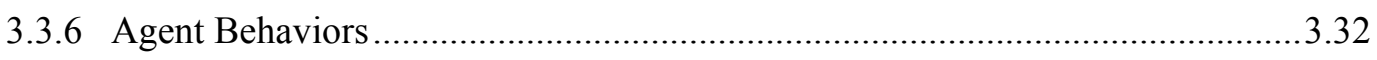

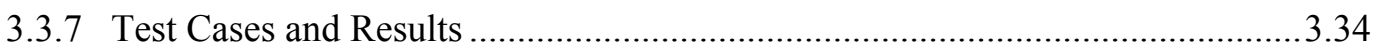

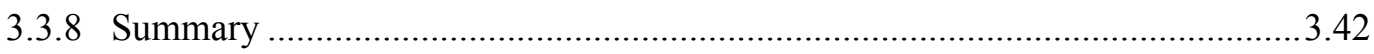

3.4 PNNL's Accomplishments: Development of an Assessment Framework to Analyze Opportunities of Building Thermal Energy Storage to Smooth Wind Power.................3.42

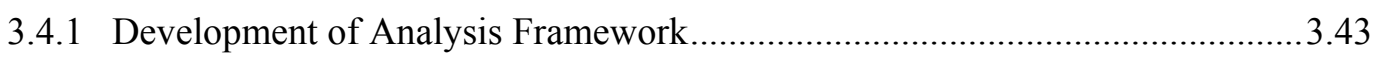

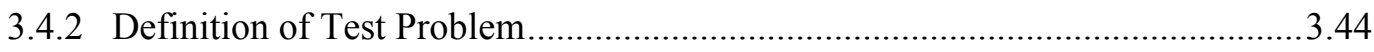

3.4.3 Results and Discussion on the Potential Contribution by Buildings ....................45

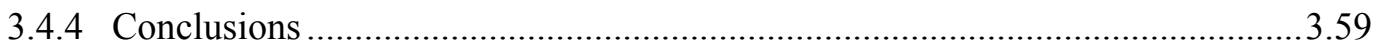


3.5 NREL's Accomplishments: Support of Building Simulations and Case Study with

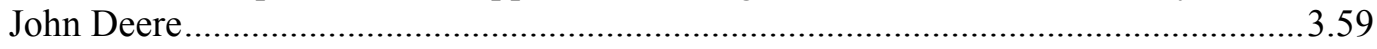

3.5.1 The Value of Energy Storage in Commercial Buildings ......................................60

3.5.2 Load Profiles for Prototypical Buildings.............................................................63

3.5.3 Case Study: Role of Energy Storage as Part of a Renewables Energy Portfolio3.71

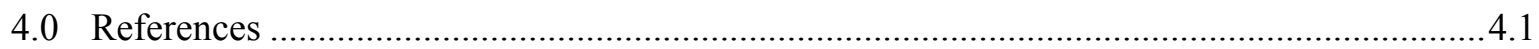




\section{Figures}

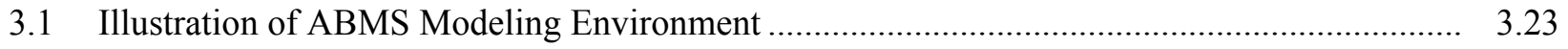

3.2 Thermal R-C Model of the Simple Hourly Method .............................................................. 3.26

3.3 Agent-Based Building Stock Energy Simulation Process.................................................. 3.27

3.4 Conceptual Relationship between Building Agents, Regions, and Transmission Lines............ 3.31

3.5 Agent Behavior 1: Load Reduction.................................................................................. 3.33

3.6 Agent Behavior 2: Load Shifting without Energy Storage .................................................. 3.33

3.7 Agent Behavior 3: Load Shifting with Energy Storage .................................................... 3.34

3.8 Typical Hourly Electricity Price Profile............................................................................ 3.35

3.9 Office Agent Electricity Demand Profile Before and After Load Reduction Actions,

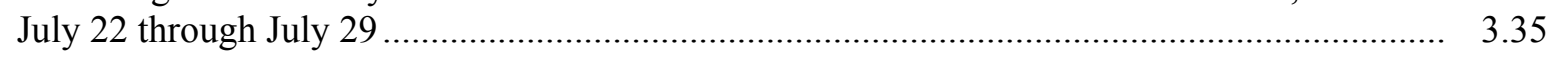

3.10 Office Agent Hourly Electricity Cost Before and After Load Reduction Actions,

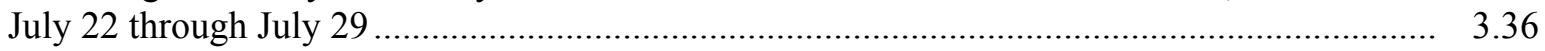

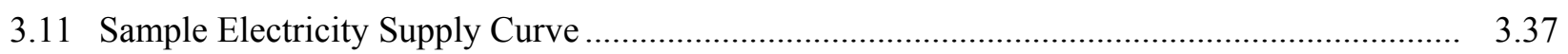

3.12 Estimated Electricity Load Profile - Baseline ….............................................................. 3.38

3.13 Estimated Electricity Price Profile: Baseline ................................................................. 3.38

3.14 Commercial Building Stock Electricity Demand Before and After Reduction Actions,

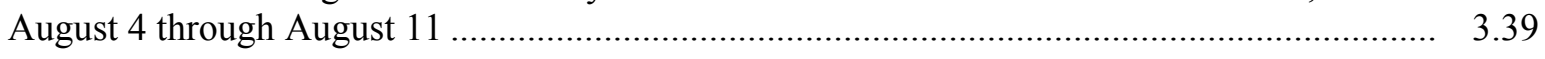

3.15 Test Case 2: Electricity Price Reduction ........................................................................... 3.39

3.16 Electricity Price Volatility Reduction .......................................................................... 3.40

3.17 Building Stock with and without Electricity Storage ...................................................... 3.41

3.18 Building Stock Battery Storage Hourly Status ................................................................. 3.41

3.19 Building Stock Total Utility Cost with and without Storage ............................................. 3.42

3.20 A Plot of Wind Generation and Cooling Profiles for the Period of Analysis ........................... 3.45

3.21 A Plot of Net Electricity Flows to or from the Grid with No Storage..................................... 3.47

3.22 A Plot of Net Electricity Flow to or from the Grid with a Storage of 10, Controlled to Minimize the Power Draw from the Gri.

3.23 A Plot of Net Electricity Flow to or from the Grid with Storage of 10, Controlled to Minimize the Power Draw from the Grid and Maximize Power Feed into the Grid; Peak Hours are More Heavily Weighted than Off-peak Hours.

3.24 A Plot of Net Electricity Flow to or from the Grid, Controlled to Minimize the Power Draw from the Grid and Maximize Power Feed into the Grid while Constraining the Maximum Flow; Peak Hours are more Heavily Weighted than Off-peak Hours. ....

3.25 A Plot of Net Electricity Flow to or from the Grid, Controlled to Minimize the Power Draw from the Grid and Maximize Power Feed into the Grid as well as Minimizing Ramps While Constraining the Maximum Flow; Peak Hours are more Heavily Weighted than Off-peak Hours...

3.26 A Plot of Net Electricity Flow to or from the Grid, Controlled to Minimize the Power Draw from the Grid and Maximize Power Feed into the Grid as well as Minimizing Ramps While Constraining the Maximum Flow; No Distinction is made Between Peak and Off-peak Hours. 
3.27 A Plot of Net Electricity Flow to or from the Grid ........................................................... 3.53

3.28 A Plot of Net Electricity Flow to or from the Grid ............................................................ 3.54

3.29 Histograms of the Number of Hours in the Month that the Grid Experiences the Power Flow for the Bin

3.30 Histograms of the Number of Hours in the Month that the Grid Experiences the Ramp Rate for the Bin

3.31 Total Energy Flow to and from the Grid Separately Aggregated over all Peak and Off-peak Hours.

3.32 Pareto Frontiers for the Dual Objectives of Maximizing Energy and Grid Benefits, for Various Storage Values

3.33 The Value of Energy Storage in Commercial Buildings, from a Purely Physical

Perspective, Utilizing Renewable Generation....

3.34 Comparison of Two Electrcal Load Profiles from the 4,820 Varieties.....

3.35 An Example Cluster Dendrogram Showing how Similar Buildings are Classified

3.36 The Discrete Wavelet Transformation Process.

3.37 Building \#1 Discrete Wavelet Transformation

3.38 Building \#103 Discrete Wavelet Transformation

3.39 Bayesian Hierarchical Clustering

3.40 The EnergyPlus Model of the Preliminary Designed Medium-Sized Office Building...........

3.41 Electric Demand and Production of the Medium-Sized Office Building.

\section{Tables}

Table 3.1. Summary of Cool Thermal Storage Technologies ................................................... 3.8

Table 3.2. Range of Performance and Cost Characteristics of Various Battery Technologies........3.9

Table 3.3. The 10 Building Types Modeled as Agents...............................................................2.28

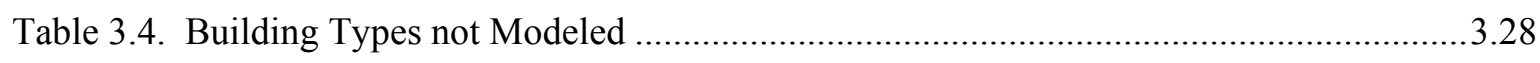

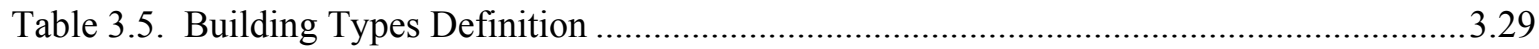

Table 3.6. Required Input Parameters for Each Building Agent ...............................................3.32

Table 3.7. Building Stock Specification for Test Case 1 .............................................................3.34

Table 3.8. Agent Load-Reducing Actions and Electricity Price .................................................3.35

Table 3.9. Utility Savings of the Demand Reduction Actions for the Test Case 1 Building Stock3.36

Table 3.10. Building Stock Specifications in Test Case 2 ........................................................3.37

Table 3.11. Agent Load-Reducing Actions and Electricity Price ..............................................3.39 


\subsection{Introduction}

On-site or local energy storage systems are not new to the commercial building sector, and have been in place in buildings in the United States (US) for decades. Most building-scale storage technologies are based on thermal or electrochemical storage mechanisms. Energy storage technologies are not designed to conserve energy, and losses associated with energy conversion are inevitable. Instead, storage provides flexibility to manage load or generation at building or grid scales. Building storage at scale can provide grid operators the flexibility in grid operation to increase the integration of additional intermittent renewable energy capacity and defer capital investment for upgrading transmission and distribution infrastructure. From the building owner's perspective, storage enables load shifting to optimize energy costs while maintaining comfort.

Renewed interest in energy storage is primarily driven by the convergence of national energy security and climate change drivers and improvements of the cost-effectiveness, safety, and reliability of storage technologies. The US has made large investments to position the country as a key technology provider for energy storage, to the emerging smart grid infrastructure and developments in the electric transportation sector. In the past two years, research and development (R\&D) funding for stationary electric energy storage systems has increased in response to concerns regarding forecasted increases in intermittent renewable energy resources contributing to the total generation mix. Bulk energy storage has been viewed as an important enabler of the future electricity infrastructure that can cost-effectively address the intermittency problem of the wind and solar energy resources. Taken in aggregate, the inherent thermal capacitance in buildings or specific building scale storage technologies effectively become a "bulk storage" capability when coordinated via demand response mechanisms.

Given the elevated and sharpened focus on energy storage technology R\&D for transportation and utility applications in the US and elsewhere, the question naturally arises, "What is the complete value proposition of exploring opportunities of energy storage in buildings?" This value proposition potentially benefits building owners and utilities alike, and impacts the attractiveness of both R\&D and capital investment.

In early 2010, Argonne National Laboratory (ANL), National Renewable Energy Laboratory (NREL), and Pacific Northwest National Laboratory (PNNL) initiated a research effort to quantify these opportunities from a commercial buildings perspective. This report summarizes the early discussions, literature reviews, stakeholder engagements, and initial results of analyses related to the overall role of energy storage in commercial buildings. Beyond the summary of roughly 8 months of effort by the laboratories, the report attempts to substantiate the importance of active U.S. Department of Energy (DOE)/Building Technologies Program (BTP) R\&D activities in this space.

The entire research effort was originally scoped for a two-year period. The first year plan focused on development of essential tools and models to address a set of research questions about the value and relevance of energy storage in commercial buildings. The three partner laboratories refocused the project scope during the summer of FY 2010 in response to DOE/BTP guidance. The reduced scope was intended to provide preliminary results in the first year, rather than in the second year, as planned. This required an abbreviated model development effort, with less rigor to free time for preliminary analyses. The analyses are still on-going as of the writing of this preliminary report, which provides a snapshot of the current state of the work. A final report is planned for submission in December 2010. 


\subsection{What Role Could Energy Storage Play in Commercial Buildings in the Context of a Modern Electricity Supply System?}

Energy storage can provide operational flexibility within a building or in the electric grid. In the past, commercial building owners invested in ice or cold-water storage equipment for the sole reason of reducing the demand charge and electricity cost during peak periods. The storage was charged during low-cost off-peak periods and then discharged during peak periods. In almost all cases, thermal energy storage was used to reduce the electricity bill by moving air-conditioning loads to low-cost night hours. In some cases, thermal energy storage was used to provide auxiliary cooling capacity when direct cooling equipment was insufficient to meet demand during peak periods. Some papers argue that marginal energy efficiency improvements may be claimed in buildings by reducing the air-velocity and supply air temperature set points in conjunction with ice-storage. A widely held view exists that energy storage in buildings remains a load management tool to generate value for the electricity service provider in exchange for a financial reward for the building owner. All electricity customers generally share the benefits of storage in the system or within certain distribution system feeders. Key benefits are higher utilization of the energy infrastructure, higher reliability, and more effective load and outage management. Infrastructure investment deferment may delay a rate increase or slow down the rate at which electricity rates may increase in the future.

In the past, the value that thermal energy storage systems created was two-fold. Firstly, the total demand of building electricity could be limited or reduced, which in densely populated downtown areas could amount to a large value by avoiding expensive distribution system upgrades. From the building owner/operator point of view, peak limiting strategies reduce the demand charge component of the electricity bill. Secondly, peak load shifting could shift a block of energy from peak to off-peak periods, creating value proportional to the difference between the wholesale value of electricity during peak and off-peak periods. Since the retail utility passes on the varying cost of electricity to the customer, there is an incentive to maximize the rate differential between peak and off-peak.

There is future value in energy storage directly linked to the intermittency problem, which is associated with increased penetration of wind and solar renewable energy. As a mitigation measure to minute-to-minute variability, grid operators will need to procure more balancing services and reserve resources. Energy storage of any kind is expected to play into this growing market place. The most direct way to accommodate balancing services includes battery energy storage that can inject and absorb electric energy to and from the grid. This may also be accomplished indirectly through a customer who has installed a thermal energy storage system. In this case, the end-use load (i.e., the chiller) would modulate its output in accordance with cooling load requirements and grid needs.

The market forces to integrate more renewable energy resources are in place. Twenty-nine states (including the District of Columbia) have laws in place that impose renewable portfolio standards (RPS). Grid operators in these jurisdictions are making plans to accommodate these new generation technologies. Studies perform for the California ISO and the Bonneville Power Administration indicated that the regulation requirements (part of the ancillary services to operate the grid safely) would need to be doubled compared to today's requirements (BPA, 2008; CAISO, 2010).

The transition of today's grid to a modern energy infrastructure will both enable and require much more active participation of load customers in the energy and ancillary services markets. Ubiquitous communications technologies and advanced controls will transform resources in the demand sectors from 
passive to active elements on the grid. "Smart" commercial buildings will not be the sole active demand side participants on the emerging smart grid, as sophisticated home energy management systems will enable the residential building sector and smart charging strategies will link in the electric vehicle fleet. Likewise bulk energy storage technologies, smaller community energy storage systems, and on-site battery storage are also likely to compete in these new markets. Modern commercial buildings are uniquely positioned for this new opportunity with large, intrinsic, thermal masses that may be leveraged by advanced controls and demand response mechanisms. Inherent thermal mass may also be augmented with active thermal energy storage to increase the building's resource.

Drastic improvements of building energy efficiency, even by relatively optimistic goals of $50-70 \%$ above ASHRAE Standard 90.1-2004, suggest reductions in the total carbon emissions attributable to commercial buildings. However, population and economic growth will continue to increase total commercial and residential floor area, making the total reduction of emissions an even harder goal to reach. Achieving long-term carbon reduction targets by 2050 is inextricably linked to our ability to decarbonize the energy supply to the US building stock. The building sector is perfectly positioned to not only contribute by drastic energy efficiency reduction on the demand side, but also contributed to the supply side by providing grid services with potentially no carbon emissions penalties.

\subsection{The Need for Energy Storage R\&D in the Commercial Building Sector}

DOE's energy R\&D portfolio is diverse, including a broad range of supply and demand side technologies that will help address the nation's energy, climate, and energy security concerns. Of equal importance are the spaces between these technologies, and the cost-effective system integration opportunities that are easily overlooked. Building energy storage and the broader value proposition falls in this area. If affordability of future energy supply is taken into consideration when designing the R\&D agenda for the US building stock then an overall system perspective should be applied that includes both buildings and the electricity infrastructure.

Over decades of research in the energy efficiency space, we have recognized the power of systems analysis in the buildings sector and the importance of defining the right problem. There has been recognition of diminishing returns associated with continued R\&D investment in individual building component technologies, and increased emphasis placed on the cost-effectiveness of holistic system engineering approaches. The analysis of integration issues in the buildings research context offers great promise in improving the overall efficiency of whole building systems relative to continued emphasis on specific components.

Just as we have recognized the importance of defining system boundaries and interactions to address the commercial building energy efficiency challenge, there are opportunities that the building sector may provide in the electric grid. In this expanded context, current thinking associated with the performance and value of certain building technologies shifts substantially. Technologies that don't make economic sense for a building owner suddenly do have significant value and viability for a community-scale project. The challenges and opportunities of interaction between buildings and the supply system are the subject of this analysis. Energy storage is not the only solution to the energy, climate, and security issues, but it could provide a significant value and contribution to this long-term energy-climate challenge. Not quantifying the whole-system benefits of building energy storage may delay the realization of novel concepts and opportunities in a time of heightened urgency. 


\subsection{Objectives of Project}

Argonne National Laboratory (ANL), the National Renewable Energy Laboratory (NREL), and Pacific Northwest National Laboratory (PNNL) will conduct this project as a collaborative effort. The objective of the research is to develop a foundational understanding of issues and interactions between energy storage and the power grid as related to the commercial buildings environment. Specifically, the research will examine the potential of various energy storage options and technologies (thermal and electric) and how these can contribute to a more flexible, dynamic, and efficient interaction between buildings and the power grid, thus paving the way for maximizing the combined value of high performance buildings and smart grid technologies. In 2009, a multi-year research effort was proposed to perform jointly and collaboratively by ANL, NREL, and PNNL, utilizing the specific strengths of each laboratory in the areas of buildings simulations, understandings of grid market dynamics, and the interactions between the electric grid and end-users.

ANL was tasked to develop agent-based representations for a range of commercial buildings and investigate various operating strategies for energy storage and their impact on the electricity market. This approach attempts to emulate unpredictable, real-life, behavior that accounts for uncertainty in pricing expectations and the variety of strategies that may be used by different building agents. PNNL was commissioned to employ an alternate optimization-based approach to investigate storage sizing and control strategies as well as the cost-effectiveness of energy storage systems for various regions in the US. These complementary analysis methods will be supported with EnergyPlus modeling and optimization capability at NREL to characterize building agents and their baseline load profiles, so that all three collaborators use a consistent set of building parameters.

A set of key questions were defined at the outset of the 2009 phase. They included:

- What is the role of energy storage in supporting DOE's goal of net-zero energy buildings in 2025 ?

- What are the key values of energy storage located in buildings to the building owner and the grid?

- How will the building owner maximize the utility of energy storage? Could there be conflicting control strategies of energy storage for maximizing the owner's benefit versus that of the grid?

- How does the need and the performance characteristics of the energy storage as well as the overall control strategy changes with the specific renewable energy technology implemented at the building?

- What are the impacts of flexible and dynamic commercial buildings electric load on the power grid and electricity prices at high penetration of energy storage?

- What will be the emerging behavior and strategies of commercial buildings with regard to electricity demand and price responses?

As mentioned in the previous section, the entire research plan was based on a two-year execution cycle, with the first year planned to develop essential tools and models to address a set of research questions about the value and relevance of energy storage in commercial buildings. The three laboratories refocused their efforts during the latter part of the summer of 2010 when the DOE/BTP indicated that the effort could potentially be discontinued. Thus, only a fraction of the key questions above could be addressed. 


\subsection{Outcomes of Year-1 Activities}

This section describes the outcomes of the three-laboratory research activities generated over an eight-month period - from February 2010 through September 2010. The initial work that calibrated the research questions and provided a directional sense of the research focus was performed jointly by all 3 laboratories. The outcomes of that work will be summarized in detail in this report. It included a literature review on energy storage technologies (thermal and electric), control strategies, and integration of the control strategies within the context of overall climate control in buildings. In addition, phone interviews were performed to discern industry professionals' perceived opinions on the state-of-the-art in storage technology, lessons-learned operating energy storage, and the potential opportunities of storage that may lay ahead as nationwide significant investment is flowing into the smart grid technology deployment. Two individually detailed reports were generated as work products. PNNL published a report titled: Literature Review in Support of the Project: "Commercial Buildings, Local Energy Storage and the Electric Grid", March 2010. NREL published the second report titled: "Expert Insights and Opinions Related to Energy Storage Applications in Commercial Buildings and the Electric Power Grid". NREL/MP 550-48923. August 2010.

Following these joint activities, the three laboratories performed individual work in accordance to their particular strengths and core capabilities. The available 8-month period of performance provided sufficient time to build or enhance existing capabilities to address relevant questions for DOE/BTP in the second year. Due to the redirection of emphasis at the DOE/BTP office, all three laboratories attempted to generate some preliminary results demonstrating the capabilities of the tools and models developed. By no means are the relevant questions of the role of on-site energy storage in commercial buildings fully explored. The report on the 8-months accomplishments reflects a snap-shot of the current status.

ANL explored the impacts of demand response and on-site storage on the wholesale market behavior in a regional US power grid. Building on ANL's existing EMCAS model, which uses an agent-based simulation approach, to simulate restructured electricity markets, new agent behavior was augmented to EMCAS to model the price responsiveness of the commercial building sector. As described below, preliminary results were generated that indicate the commercial building sector's ability to dampen the price volatility in the electricity wholesale markets and to impose a downward pressure on the peak prices. This analysis was performed based on hourly simulations of both the generation dispatch and the thermal behavior of commercial buildings.

PNNL focused on the value of on-site storage to solve the intermittent problem of renewable energy resources. This analysis required to look at time steps shorter than one hour. The intermittency characteristic of wind and solar energy resources generally requires minute-by-minute or sub-hourly analysis. PNNL's accomplishments over the 8-month period encompasses the development of an assessment framework to address both broad technical potential questions, such as how much of the US commercial building sector would need thermal energy storage or battery storage equipment to accommodate the variability of the new wind and solar generation capacity that is expected to be built by 2030, as well as highly time-resolved optimizations computations that trade-off the use of thermal energy storage to meet cooling loads as well as to dampen the volatility in the energy output from wind and solar technologies as well as reducing operating cost. The technical potential of thermal energy storage as it is currently applied in commercial buildings in the US, and how it would need to be controlled to smooth and firm output of wind generation will be discussed below. 
NREL was responsible for the detailed building simulations necessary for ANL's agent behavior definition of the building stock. NREL also provided a 'reality-check' of the viability of future storage concepts by utilizing their relationship to a member of the Commercial Building Partnership (CBP). NREL provided valuable insights from a case study with the CBP member on how to utilize a groundsource heat pump system for an office campus to the output of a small wind power installation. This case study furnished insights into the operational challenges for designing and implementing control strategies that would extend the general scope of buildings operations. It also addresses some of the economic challenges for such an integration endeavor.

\subsection{Literature Review of Current State-of-the-Art Energy Storage in Buildings Applications}

\subsubsection{Introduction}

The project team reviewed existing literature on thermal energy storage (TES) and electric energy storage (EES) technologies and systems that are currently commercially available or likely to be available by 2025. The literature review captures current baseline performance and efficiency metrics for TES and EES systems that will be used in the system models to be developed under this research program. The primary objective of this task was to examine the range of available data on performance metrics and parameters for use in the models and also identify any quality and reliability issues of the data. The results were also used as discussion points during the structured phone interview and discussions with the stakeholders (discussed subsequently Section 3.1.5 below) and for developing the storage assessment framework requirements and design (discussed in Section 0).

The review is focused on the cost and performance of energy storage suitable for commercial buildings applications. The team was interested in storage technologies that can contribute to achieving the goals of the BTP. Technologies included in this review are those that are capable of shifting electric or thermal loads from peak to off-peak periods or are able to cycle frequently between charging and discharging in accordance to the regulation signals from grid-operators to smooth out the variability from wind or solar energy resources.

The literature survey was not a rigorous comparative assessment of all existing and future TES and EES technologies and options. Rather, it was intended to map the range of performance for mature commercial technologies currently available in the market or technologies under active development or demonstration and expected to be commercialized within the next decade or so. Performance parameters of interest include storage capacity, charging rate, discharge rate, storage density and lifetime chargedischarge cycle capability. Both first costs and operations and maintenance (O\&M) costs were of interest.

The literature review covered both subject areas: 1) end-use TES and 2) electro-chemical energy storage. Thermal storage options include both sensible-heat and latent-heat options. Sensible-heat options include storage in the elements of building construction (structural and non-structural) and hot or chilled

water storage. Latent-heat options are expected to be dominated by ice storage, but could include systems with other phase-change materials (PCM), including PCMs incorporated into the building envelope components. Electrical storage options include both conventional and flow batteries. Results were 
compiled and presented at a technology-category level, i.e., classes of technologies were presented rather than individual products.

\subsubsection{Thermal Energy Storage}

Thermal Energy Storage (TES) is an on-site storage option that has the advantage of direct use in achieving building space conditioning. Storage density, expressed in energy units per unit volume, is a critical parameter for the practical application of any storage option in buildings as they are often space constrained. If the temperature range experienced during charging and discharging spans the fusion temperature of the storage medium, the TES technology is referred to as latent-heat storage. For latentheat storage, the storage medium is referred as a phase change material (PCM). If no phase change occurs, the storage is referred as sensible-heat storage.

\subsubsection{Sensible TES}

Currently available sensible TES includes:

- Building Thermal Mass Storage

- Ground (Seasonal) Thermal Storage

- Chilled-Water Storage

By pre-cooling the building, it may be possible for the operator to successfully shift cooling-related thermal loads to off-peak time periods without compromising occupant thermal comfort (Rabl and Norford 1991). The manipulation of the zone air temperature setpoint during unoccupied hours allows usage of the building's thermal mass and enables dynamic response to utility rate incentives within the constraints of occupant comfort and indoor air quality. ASHRAE has funded significant research on optimal control strategies using building thermal mass summarized in ASHRAE's handbook (ASHRAE 1999).

Since the near surface ground maintains a nearly constant temperature throughout the year, one approach is to use the ground surrounding and/or underneath the building for seasonal thermal energy storage. Rejected heat is stored in the ground during the summer and is used during the winter. In the winter the ground is cooled using outside winter ambient conditions and the stored 'cool' energy is used for cooling the building interior during summer. One major impediment to this method of storage is high first cost of construction of the ground heat exchangers.

Chilled water storage is sometime used in commercial buildings as a matured technology. The large footprint of the water tank makes the chilled water storage less desirable in a commercial building where floor space is highly valuable. Space constraint is usually an issue with most commercial buildings, which can favor ice-storage technologies because of the higher energy density. Due to its simplicity and low first cost, chilled-water storage is still used in some commercial buildings. Cost of chilled water storage is about $\$ 9-\$ 20$ per $\mathrm{kWh}$. 


\subsubsection{Latent Heat TES}

Latent heat storage systems are system utilizing a phase change material (PCM). PCM is a substance with a high heat of fusion which, melting and solidifying at a certain temperature, is capable of storing and releasing large amounts of energy.

Ice is the most commonly used PCM for latent heat TES. With a specific heat of fusion of water of about $333 \mathrm{~kJ} / \mathrm{kg}$, compared to the specific heat of water of about $4 \mathrm{~kJ} /\left(\mathrm{kg}^{*} \mathrm{~K}\right)$, a chilled water tank requires a volume that is about water 8-10 times as large as that of an ice storage assuming a water temperature differential between the chilled water supply and return temperature of 8-10 degrees $\mathrm{C}$.

Ice storage systems are commercially available in a wide variety of distinct technologies from a number of vendors that differ in the heat exchanger configurations, method of ice containment, and other engineering details. Broadly the categories include internal-melt ice on coil, external-melt ice on coil, encapsulated, ice harvester, and ice slurry technologies. While the above systems are suitable for operation with conventional chillers, an integrated system has been specially developed for use with rooftop and other direct expansion systems. The ice making system essentially deploys internal melt ice on coil configuration.

The chiller cost for the Ice harvester systems are higher at about $\$ 340-470 /$ ton. For all other Ice TES systems the chiller cost ranges from $\$ 60-170 /$ ton. The storage costs are lower for the ice harvester systems at approximately $\$ 6-8 / \mathrm{kWh}$. For all other Ice TES systems the storage cost ranges from $\$ 15-$ 22/kWh.

\subsubsection{Other PCM-based Energy Storage}

There have been substantial efforts for developing TES systems with non-ice PCMs that would freeze above the melting point of ice. The PCM materials chosen were usually salt hydrates. However no commercial systems are currently available. PCMs have been proposed and tested for enhancement of the thermal mass of envelope components for many years. However, their widespread adoption has been impeded by high initial cost, gradual deterioration of the phase-change properties, material leakage, and corrosion. Wallboards with embedded, encapsulated PCM are quite suitable for thermal storage applications in buildings. However no PCM-enhanced wall board is still commercially available.

\subsubsection{Electrochemical Energy Storage}

Electrochemical energy storage can broadly be classified into conventional and flow batteries. Both have been covered in the literature review. Conventional batteries include lithium-ion, nickel-metalhydride, nickel-cadmium, lead-acid, and sodium-sulfur batteries. Flow batteries include zinc-bromine and vanadium-oxide batteries. Flow batteries are normally considered for relatively large ( $1 \mathrm{kWh}$ - many MWh) stationary applications.

\subsubsection{Lithium Ion Battery (Li-ion)}

The main advantages of Li-ion batteries, compared to other advanced batteries, are (Divya and Ostergaard 2009):

- High energy density (225-375 Wh/L, 90-150 Wh/kg) 
- Room for further improvement with high voltage cathodes and electrolyte

- High efficiency (80-85\% DC to DC)

- Diverse chemistry to target different operation regimes (high power vs. high energy)

- Long cycle life (3000 cycles at 80\% DOD).

While Li-ion batteries took over $50 \%$ of small portable market in a few years, there are some challenges for making large-scale Li-ion batteries. The main hurdles are the high cost (above $\$ 600 / \mathrm{kWh}$ ), complex battery management circuitry, and safety issues related to thermal management.

\subsubsection{Nickel Metal Hydride Battery (NiMH)}

Compared to the lithium-ion cell, the specific energy is lower (Energizer 2010). Its tolerance to high temperature excursions is also quite poor, and it has a high self discharge rate, with loss of up to $50 \%$ of its capacity after 6 months of storage. Hence this battery does not appear to be a good candidate for large batteries used in stationary applications. No major demonstrations have been carried out for this technology in utility applications.

\subsubsection{Nickel Cadmium Battery (Ni-Cd)}

Ni-Cd batteries are very rugged, have a high power density, and are used in power tools. In the high energy space, they are being replaced by Ni-MH batteries (Linden 1995). While cylindrical Ni-Cd batteries are used in consumer electronics and power tools, large industrial batteries are prismatic. DC to DC efficiency for Ni-Cd batteries ranges from 60 to $70 \%$. Flooded batteries, while rated to last 10 to 15 years, last longer. Sintered plate Ni-Cd batteries provide 3500 cycles at $80 \%$ DOD. Their self-discharge rate is $5 \%$ per month, which is $\sim$ approximately five times higher than that for lead acid batteries. Large battery systems include active thermal management along with hydrogen sensing and ventilation.

\subsubsection{Lead Acid Battery}

Lead-acid is one of the oldest and most developed battery technologies (Linden 1995). Its application for energy management, however, has been very limited due to its short cycle life at high depth of discharge (1000 cycles vs. 3000 cycles for Li-Ion) and low specific energy and energy density. Lead acid batteries are used for starting, lighting and ignition (SLI) with high power and shallow depth of discharge, for traction purposes with deep depth of discharge, and also in stationary applications. Round trip efficiencies range from $75 \%$ to $85 \%$ DC to DC. The cycle life at $100 \%$ DOD varies from 100 for SLI batteries to 1000 for deep cycle batteries.

\subsubsection{Sodium Sulfur (Na-S) Battery}

Na-S battery cells (Ibrahim, Ilinca et al. 2008) have a DC to DC efficiency of $80 \%$. The Na-S battery can provide above its rated power output within thermal limits constraint by thermal management. For instance, the Na-S battery can deliver $500 \%$ of rated power over five minutes, $400 \%$ of rated power over 15 minutes, and $260 \%$ over one hour, with power rated at the seven-hour rate. Hence the maximum DOD at the 1-hour rate is only $37 \%$. This limitation may be overcome by incorporating better thermal management to prevent cell temperature from exceeding safety limits. The cycle life as a function of 
depth of discharge varies from 4000 cycles at $90 \%$ DOD to 43,000 cycles at $10 \%$ DOD. The only supplier for this technology is NGK Insulators, Ltd. The price of NGK $50 \mathrm{~kW} / 350 \mathrm{kWh}$ modules was $\$ 75 \mathrm{~K}$, which corresponds to $\$ 1500 / \mathrm{kW}$ or $\$ 210 / \mathrm{kWh}$. The total installed capacity in the year 2007 was $270 \mathrm{MW}$, which is slated to increase to $630 \mathrm{MW}$ by the end of 2010 . About $45 \%$ of the installed systems are used for load leveling, and $40 \%$ for load leveling and emergency power/uninterrupted power system, with about $13 \%$ used to firm up renewable energy.

\subsubsection{Flow Batteries}

\section{Zinc Bromine Flow Battery}

The $\mathrm{Zn}-\mathrm{Br}$ battery can be split into a power module consisting of cell stack and electrolyte circulation, and an energy system module which consists of electrolyte storage tanks (de Leon, Frias-Ferrer et al. 2006). Since the power and energy modules are independent, high power systems can be built by increasing stack active area, while high energy systems at a fixed power can be built by increasing electrolyte storage volume.

The DC to DC round trip efficiency for $\mathrm{Zn}-\mathrm{Br}$ Flow Battery is $70 \%$ to $80 \%$. $\mathrm{Zn}$-Br batteries selfdischarge at the rate of $1 \%$ per hour due to bromine crossover. Mitigation of self-discharge can be done by stopping electrolyte flow, which can lead to a rise in temperature due to poor thermal management. The price for a $\mathrm{Zn}-\mathrm{Br}$ system is $\$ 325 / \mathrm{kWh}$ and $\$ 650 / \mathrm{kW}$. However, the price would vary depending on the energy to power ratio for the system.

\section{Vanadium Oxide ("Vanadium Redox Battery" VRB) Flow Battery}

The net efficiency of this battery can be as high as $85 \%$, with a range of 70 to $85 \%$. Like other flow batteries, the power and energy ratings of VRB are independent of each other. The use of Vanadium Oxide Flow Batteries has continued to increase due to independence of power and energy subsystems (Gattrell, Park et al. 2004). The shortcomings of VRB batteries are low energy density (20-30 WH/L; 15 $23 \mathrm{WH} / \mathrm{kg}$ ), low power density, high self discharge rate, high bipolar plate cost, high membrane and reactant cost. However, VRB systems have a very fast response time. It has a cost range of $\$ 800 / \mathrm{kW}$ to $\$ 1460 / \mathrm{kW}$ and $\$ 150 / \mathrm{kWh}$ to $\$ 290 / \mathrm{kWh}$.

\subsubsection{Summary and Conclusion}

The technical landscape of thermal energy storage technologies and their respective cost-performance characteristics are shown in Table 3.1. Cost and performance characteristics for electro-chemical storage are shown in Table 3.2. Insights gained during this literature review can be summarizes as follows:

- TES is proven technology. Choice of the TES dependence on space-availability of storage tank. If space is available, cold-water storage is preferred because of high chiller efficiency. If ice-storage is desirable because of space constraints, than chiller efficiency is likely to be reduced because of larger delta $\mathrm{T}$ or low chilled water temperature.

- Phase change materials integrated into building materials is novel technology- not currently used. Advantage would be that it storage would not require dedicated location and footprint for storage tank. 
- There are many proven battery chemistries in commercially available systems applicable for buildings applications. Most batteries have been used for uninterruptable power supply (UPS) in data centers or for other high-sensitive processes in buildings. UPS is rarely used only when line power fails. The integration of batteries for load time-shifting strategies are not common and would need to be custom-designed at high cost.

- Battery storage systems on-site in commercial buildings for applications other than dedicated UPS applications are NOT common. Although there is no technical barrier that would limit the use of battery storage for time-shifting of buildings loads and/or supporting integration of intermittent renewable technologies, the cost are very high rendering such application economically not viable. 
Table 3.1. Summary of Cool Thermal Storage Technologies (Adapted from ASHRAE publication on "Cool Store Design Guide")

\begin{tabular}{|c|c|c|c|c|c|c|c|c|c|c|c|c|c|}
\hline \multirow[t]{2}{*}{ Parameter } & \multirow{2}{*}{$\begin{array}{l}\text { Units } \\
\text { Range }\end{array}$} & \multicolumn{2}{|c|}{ Chilled Water } & \multicolumn{2}{|c|}{ Ice harvester } & \multicolumn{2}{|c|}{ External melt ice } & \multicolumn{2}{|c|}{ Internal melt ice } & \multicolumn{2}{|c|}{$\begin{array}{l}\text { Encapsulated } \\
\text { ice }\end{array}$} & \multicolumn{2}{|c|}{$\begin{array}{l}\text { Phase-change } \\
\text { material }\end{array}$} \\
\hline & & Low & High & Low & High & Low & High & Low & High & Low & High & Low & High \\
\hline \multirow{2}{*}{ Chiller Cost $\mathrm{t}^{\mathrm{a}}$} & $\$ /$ ton & 200 & 300 & 1100 & 1500 & 200 & 500 & 200 & 500 & 200 & 500 & 200 & 300 \\
\hline & $\$ / \mathrm{kW}$ & 57 & 85 & 313 & 427 & 57 & 142 & 57 & 142 & 57 & 142 & 57 & 85 \\
\hline \multirow{2}{*}{ Tank Volume } & $\mathrm{ft} 3 /$ ton-hr & 11 & 21 & 3 & 3.3 & 2.8 & 2.8 & 2.4 & 2.8 & 2.4 & 2.8 & 6 & 6 \\
\hline & $\mathrm{m} 3 / \mathrm{kWh}$ & 0.089 & 0.169 & 0.024 & 0.027 & 0.023 & 0.023 & 0.019 & 0.023 & 0.019 & 0.023 & 0.048 & 0.048 \\
\hline \multirow{2}{*}{$\begin{array}{l}\text { Storage Installed } \\
\text { Cost }^{\mathrm{b}}\end{array}$} & \$/ton-hr & 30 & 100 & 20 & 30 & 50 & 70 & 50 & 70 & 50 & 70 & 100 & 150 \\
\hline & $\$ / \mathrm{kWh}$ & 8.53 & 28.4 & 5.7 & 8.5 & 14.2 & 19.9 & 14.2 & 19.9 & 14.2 & 19.9 & 28.4 & 42.7 \\
\hline \multirow{2}{*}{$\begin{array}{l}\text { Charging } \\
\text { Temperature }\end{array}$} & $\operatorname{deg} F$ & 39 & 42 & 15 & 24 & 15 & 25 & 22 & 26 & 22 & 26 & 40 & 42 \\
\hline & $\operatorname{deg} \mathrm{C}$ & 3.9 & 5.6 & -9.4 & -4.4 & -9.4 & -3.9 & -5.6 & -3.3 & -5.6 & -3.3 & 4.4 & 5.6 \\
\hline \multirow{3}{*}{$\begin{array}{l}\text { Chiller Charging } \\
\text { Efficiency Indicators }\end{array}$} & $\mathrm{COP}$ & 5 & 5.9 & 2.7 & 3.7 & 2.5 & 4.1 & 2.9 & 4.1 & 2.9 & 4.1 & 5 & 5.9 \\
\hline & $\mathrm{kW} /$ ton & 0.6 & 0.7 & 0.95 & 1.3 & 0.85 & 1.4 & 0.85 & 1.2 & 0.85 & 1.2 & 0.6 & 0.7 \\
\hline & $\mathrm{kW} / \mathrm{kW}$ & 0.171 & 0.199 & 0.27 & 0.37 & 0.242 & 0.398 & 0.242 & 0.341 & 0.242 & 0.341 & 0.171 & 0.199 \\
\hline \multirow{2}{*}{$\begin{array}{l}\text { Discharge } \\
\text { Temperature }\end{array}$} & $\operatorname{deg} F$ & 40 & 46 & 34 & 36 & 34 & 36 & 34 & 38 & 34 & 38 & 48 & 50 \\
\hline & $\operatorname{deg} C$ & 4.4 & 7.8 & 1.1 & 2.2 & 1.1 & 2.2 & 1.1 & 3.3 & 1.1 & 3.3 & 8.9 & 10 \\
\hline Discharge Fluid & & \multicolumn{2}{|c|}{ Water } & \multicolumn{2}{|c|}{ Water } & \multicolumn{2}{|c|}{ Water } & \multicolumn{2}{|c|}{ Coolant } & \multicolumn{2}{|c|}{ Coolant } & \multicolumn{2}{|l|}{ Water } \\
\hline \multicolumn{2}{|l|}{ Tank Interface } & \multicolumn{2}{|c|}{ Open Tank } & \multicolumn{2}{|c|}{ Open Tank } & \multicolumn{2}{|c|}{ Open Tank } & \multicolumn{2}{|c|}{ Closed system } & \multicolumn{2}{|c|}{$\begin{array}{l}\text { Open or closed } \\
\text { system }\end{array}$} & \multicolumn{2}{|c|}{ Open Tank } \\
\hline \multicolumn{2}{|l|}{ Strengths } & \multicolumn{2}{|c|}{$\begin{array}{l}\text { Use existing } \\
\text { chillers; fire } \\
\text { protection duty }\end{array}$} & \multicolumn{2}{|c|}{$\begin{array}{l}\text { High } \\
\text { instantaneous } \\
\text { discharge rates }\end{array}$} & \multicolumn{2}{|c|}{$\begin{array}{l}\text { High instantaneous } \\
\text { discharge rates }\end{array}$} & \multicolumn{2}{|c|}{$\begin{array}{l}\text { Modular tanks } \\
\text { good for small or } \\
\text { large installations }\end{array}$} & \multicolumn{2}{|c|}{$\begin{array}{l}\text { Tank shape } \\
\text { flexible }\end{array}$} & $\begin{array}{l}\text { Use ex } \\
\text { chiller }\end{array}$ & ing \\
\hline
\end{tabular}

Notes: a: Costs are for chiller or refrigeration plant only, and do not include installation. All costs, except ice harvesters, are per nominal ton. Derating for actual operating conditions may be required.

b: Costs are for storage only, and include tank, internal diffusers, headers, and heat transfer surface.

c: Typical minimum temperatures, with appropriate sizing of storage capacity. Higher temperature can be obtained from each medium. 
Table 3.2. Range of Performance and Cost Characteristics of Various Battery Technologies

\begin{tabular}{|c|c|c|c|c|c|c|c|c|}
\hline \multirow{10}{*}{$\begin{array}{l}\text { Performance } \\
\text { Data }\end{array}$} & & $\mathrm{Li}$ ion & $\begin{array}{l}\text { Ni metal } \\
\text { Hydride }\end{array}$ & $\begin{array}{c}\text { Nickel } \\
\text { Cadmium }\end{array}$ & Lead Acid & $\begin{array}{l}\text { Sodium } \\
\text { Sulfur }\end{array}$ & $\begin{array}{l}\text { Zinc Bromine } \\
\text { Flow }\end{array}$ & $\begin{array}{l}\text { Vanadium oxide } \\
\text { flow }\end{array}$ \\
\hline & Energy density $\left(\mathrm{kWh} / \mathrm{m}^{3}\right)$ & 225-375 & $175-275$ & $100-175$ & $60-125$ & $145-150$ & 60 & $15-25$ \\
\hline & Specific energy (Wh/kg) & $90-190$ & $60-120$ & $40-80$ & $25-50$ & 90 & 70 & $5-25$ \\
\hline & Specific power (W/kg) & $80-2000$ & $200-1500$ & $200-500$ & $80-300$ & 150 & 100 & \\
\hline & Response time & Instant & Instant & Instant & Instant & Millisecond & Millisecond & Millisecond \\
\hline & Charge time ${ }^{1}$ (best) & $3 \mathrm{hrs}$ & $1 \mathrm{hr}$ & $1 \mathrm{hr}$ & 8-36hrs & & $\mathrm{n} / \mathrm{a}$ & $\mathrm{n} / \mathrm{a}$ \\
\hline & Discharge rate $^{2}$ (best/peak) & $1 \mathrm{C} / 30 \mathrm{C}+$ & $0.5 \mathrm{C} / 5 \mathrm{C}$ & $1 \mathrm{C} / 20 \mathrm{C}$ & $0.2 \mathrm{C} / 5 \mathrm{C}$ & & $\mathrm{n} / \mathrm{a}$ & $\mathrm{n} / \mathrm{a}$ \\
\hline & Round trip efficiency (\%) & $85-95 \%$ & $70 \%$ & $70-90 \%$ & $75 \%$ & $85 \%$ & $70-75 \%$ & $65-75 \%$ \\
\hline & Self-discharge $^{3}$ (\% per month) & $5-10 \%$ & $30 \%$ & $20-25 \%$ & $5 \%$ & None & Insignificant & Insignificant \\
\hline & $\begin{array}{l}\text { Life Cycle Number of } \\
\text { charges/discharges cycled to } \\
80 \% \text {, depth of discharge }\end{array}$ & $\begin{array}{l}300- \\
1000+\end{array}$ & $300-500$ & $1500-2,000$ & $200-500$ & $3,000-5,000$ & $10,000+$ & Up to 10,000 \\
\hline \multirow[t]{3}{*}{ Cost } & Capital cost $(\$ / \mathrm{kWh})$ & $\begin{array}{l}\$ 600- \\
\$ 1200\end{array}$ & $\$ 500-\$ 700$ & $\$ 500-\$ 600$ & $\$ 175-\$ 250$ & $\$ 350-\$ 500$ & $\$ 150-\$ 250$ & $\$ 350-\$ 500$ \\
\hline & $\begin{array}{l}\mathrm{O} \& \mathrm{M} \text { cost (exclusive of } \\
\text { power) }\end{array}$ & & & & & & & \\
\hline & O \& M service intervals & None & 60-90 days & 30-60 days & $\begin{array}{l}3-6 \\
\text { months }\end{array}$ & & & \\
\hline
\end{tabular}

\footnotetext{
${ }^{1}$ The charge time depends upon the battery chemistry and charging algorithm. The algorithm may include several stages, such as initial rapid charge followed by constant voltage or constant current topping charge.

${ }^{2}$ Increasing the rate of discharge increases the batteries internal resistance, decreasing both voltage and efficiency. Electronic protections may be added to the battery limiting the rate of discharge. Specifically, this is the case for lithium ion batteries which contain protections restricting full discharge to 30 minutes or longer, depending upon the exact battery.

${ }^{3}$ The rate at which a battery self-discharges usually increases with temperature.
} 


\subsubsection{Bibliography of the Literature Review}

"Battery University" http://www.batteryuniversity.com/

"Electricity Storage Organization." http://www.electricitystorage.org/ESA/home/

"Mathworks 2010" http://www.mathworks.com/

ASHRAE, 1999. HVAC Applications, Chapter 40: Supervisory control strategies and optimization. American Society for Heating, Refrigeration and Air-Conditioning Engineers, Atlanta, GA.

Ahkil A., Zaininger H., Hurwitch J., Badin J., 1993, Battery energy storage: A preliminary assessment of national benefits (the Gateway Benefits Study). Sandia Rep. SAND93-3900-UC212, Sandia Natl. Labs., Albuquerque, NM

AMRA/IEEE SCC31, 1996, Utility industry end device data tables: Tables Version 0.1, Document version 1.9. AMRA/IEEE SCC31 End Device subcommittee, January 8, 1996.

Andresen, and Brandemuehl M. J. , 1992, "Heat Storage in Building Thermal Mass: A Parametric Study," ASHRAE Transactions, 98(1), pp. 910-918.

Ashok S., and Banerjee R. , 2003, "Optimal cool storage capacity for load management," Energy, 28(2), pp. 115-126.

Athienitis A. K., Liu C., Hawes D., Banu D., and Feldman D. , 1997, "Investigation of the thermal performance of a passive solar test-room with wall latent heat storage," Building and Environment, 32(5), pp. 405-410.

Bahnfleth W. P., and Joyce W. S. , 1994, "Energy use in a district cooling system with stratified chilledwater storage," ASHRAE Transactions, New Orleans, LA, USA, pp. 1767-1778.

Bansal N. K., and Buddhi D. , 1992, "Performance equations of a collector cum storage system using phase change materials," Solar energy, 48(3), pp. 185-194.

Beier R. A., and Smith M. D. , 2003, "Minimum duration of in-situ tests on vertical boreholes," ASHRAE Transactions, Kansas City, MO, United states, pp. 475-486.

Bernier M. A. , 2001, "Ground-coupled heat pump system simulation," ASHRAE Transactions, Atalanta, GA, pp. 605-616.

Bisio G., and Rubatto G., 1991, "Refrigeration systems based on short-term storage by means of ice banks," Energy and Buildings, 17(1), pp. 1-6.

Braun J. E. , 1990, "Reducing Energy Costs and Peak Electrical Demand Through Optimal Control of Building Thermal Storage," ASHRAE Transactions, 96(2), pp. 876-887.

Braun J. E. , 2007, "A Near-Optimal Control Strategy for Cool Storage Systems with Dynamic Electric Rates (RP-1252).," HVAC\&R Research, 13(4), pp. 557-580.

Braun J. E. , 2007, "Impact of Control on Operating Costs for Cool Storage Systems with Dynamic Electric Rates.," ASHRAE Transactions, 113(2), pp. 343-354.

Braun J. E., and Lee K. , 2006, "Assessment of Demand Limiting Using Building Thermal Mass in Small Commercial Buildings," ASHRAE Transactions, 112(1), pp. 547-558.

Buddhi D., Sawhney R. L., and Sodha M. S. , 1988, "SOLAR THERMAL STORAGE SYSTEMS USING PHASE CHANGE MATERIALS.," International Journal of Energy Research, 12(3), pp. 547-555. 
Caldwell J. S., and Bahnfleth W. P. , 1998, "Identification of mixing effects in stratified chilled-water storage tanks by analysis of time series temperature data," ASHRAE Transactions, Toronto, Can, pp. 366-376.

Cavallo A. J. , 2001, "Energy Storage Technologies for Utility Scale Intermittent Renewable Energy Systems," Journal of Solar Energy Engineering, 123(4), pp. 387-389.

Chandra D., Reilly J. J., and Chellappa R., 2006, "Metal Hydrides for Vehicular Applications : The State of the Art HYDROGEN STORAGE," System, (February).

Chatterji D. , 1976, "Development of sodium-sulfur batteries for utility application."

Chen C., Guo H., Liu Y., Yue H., and Wang C. , 2008, "A new kind of phase change material (PCM) for energy-storing wallboard," Energy and Buildings, 40(5), pp. 882-890.

Conniff P. , 1991, "Strategies for Reducing Peak Air-Conditioning Loads by Using Heat Storage in the Building Structure," ASHRAE Transactions, 97(1).

Dell R. M., and Rand D. A. , 2001, "Energy storage — a key technology for global energy sustainability," Journal of Power Sources, 100, pp. 2-17.

Denholm P. , 2004, "Life cycle energy requirements and greenhouse gas emissions from large scale energy storage systems," Energy Conversion and Management, 45(13-14), pp. 2153-2172.

EPRI, 2007, Market Driven Distributed Energy Storage System Requirements for Load Management Applications, Palo Alto, CA., 1014668.

Eskilson P. , 1987, "Thermal analysis of heat extraction boreholes."

Evers A. C., Medina M. A., and Fang Y., 2010, "Evaluation of the thermal performance of frame walls enhanced with paraffin and hydrated salt phase change materials using a dynamic wall simulator," Building and Environment, In Press, , pp. - .

Faiman D. , 1980, "KINETIC WALL FOR WINTER SPACE HEATING.," Energy and Buildings, 4(2), pp. 191-194.

Feldman D., Banu D., Hawes D., and Ghanbari E. , 1991, "Obtaining an energy storing building material by direct incorporation of an organic phase change material in gypsum wallboard," Solar energy materials, 22(2-3), pp. 231-242.

Fiorino D. P. , 1994, "Energy conservation with thermally stratified chilled-water storage," ASHRAE Transactions, New Orleans, LA, USA, pp. 1754-1766.

Fong K. F., Chow T. T., and Hanby V. I. , 2005, "Development of optimal design of solar water heating system by using evolutionary algorithm," International Solar Energy Conference, Orlando, FL, United states, pp. 333-341.

Gansler R. A., Reindl D. T., and Jekel T. B. , 2001, "Simulation of Source Energy Utilization and Emissions for HVAC Systems," ASHRAE Winter Meeting CD, Technical and Symposium Papers, Atlanta, GA, United states, pp. 51-63.

Gattrell M., Park J., MacDougall B., Apte J., McCarthy S., and Wu C. W. , 2004, "Study of the Mechanism of the Vanadium 4+/5+ Redox Reaction in Acidic Solutions," Journal of The Electrochemical Society, 151(1), p. A123.

Gu Y., and O'Neal D. L., 1995, "Analytical solution to transient heat conduction in a composite region with a cylindrical heat source," Journal of Solar Energy Engineering, 117(3), pp. 242-248. 
Hamada Y., Kubota H., Nakamura M., Kudo K., and Hashimoto Y. , 2010, "Experiments and evaluation of a mobile high-density snow storage system," Energy and Buildings, 42(2), pp. 178-182.

Hawes D. W., Feldman D., and Banu D. , 1993, "Latent heat storage in building materials," Energy and Buildings, 20(1), pp. 77-86.

Heim D. , 2006, "Phase-Change Material Modeling within Whole Building Dynamic Simulation.," ASHRAE Transactions, 112(1), pp. 518-525.

Hellstrom G. , 1989, Duct ground heat storage model., University of Lund, Department of Mathematical Physics, Lund, Sweden.

Henze G. P. , 2003, "An Overview of Optimal Control for Central Cooling Plants with Ice Thermal Energy Storage," Journal of Solar Energy Engineering, 125(3), pp. 302-309.

Henze G. P. , 2003, "Parametric Study of a Simplified Ice Storage Model Operating Under Conventional and Optimal Control Strategies," Journal of Solar Energy Engineering, 125(1), pp. 2-12.

Henze G. P., Le T., Florita A. R., and Felsmann C. , 2007, "Sensitivity Analysis of Optimal," Ashrae Standard, 129(November), pp. 473-485.

Hussain M. A., and Peters D. C. , 1992, "Retrofit integration of fire protection storage as chilled-water storage - a case study," ASHRAE Transactions, Anaheim, CA, USA, pp. 1123-1132.

Ibanez M., Lazaro A., Zalba B., and Cabeza L. F. , 2005, "An approach to the simulation of PCMs in building applications using TRNSYS," Applied Thermal Engineering, 25(11-12), pp. 1796-1807.

Ibrahim H., Ilinca a., and Perron J. , 2008, "Energy storage systems - Characteristics and comparisons," Renewable and Sustainable Energy Reviews, 12(5), pp. 1221-1250.

Ihm P., Krarti M., and Henze G. P., 2004, "Development of a thermal energy storage model for EnergyPlus," Energy and Buildings, 36(8), pp. 807-814.

Institute E. P. , "CEC/DOE Energy Storage Demonstration."

Kavanaugh S. P. , 1998, "Design method for hybrid ground-source heat pumps," ASHRAE Transactions, Toronto, Canada, pp. 691-698.

Kedl R. J. , 1990, "Conventional wallboard with latent heat storage for passive solar applications," Proceedings of the Intersociety Energy Conversion Engineering Conference, Reno, NV, USA, pp. 222-225.

Keeney K. R., and Braun J. E. , 1997, "Application of Building Precooling to Reduce Peak Cooling Requirements," ASHRAE Transactions, 103(1), pp. 463-469.

Kempton W., and Kubo T. , 2000, "Electric-drive vehicles for peak power in Japan," Energy Policy, 28.

Kempton W., and Tomic J. , 2005, "Vehicle-to-grid power implementation: From stabilizing the grid to supporting large-scale renewable energy," Journal of Power Sources, 144(1), pp. 280-294.

Khudhair A. M., and Farid M. M. , 2004, "A review on energy conservation in building applications with thermal storage by latent heat using phase change materials," Energy Conversion and Management, 45(2), pp. 263-275.

Kim J., and Darkwa J. , 2002, "Enhanced performance of laminated PCM wallboard for thermal energy storage in buildings," Proceedings of the Intersociety Energy Conversion Engineering Conference, Washington, DC, United states, pp. 647-651. 
Kintner-Meyer M., and Emery A. F. , 1995, "Optimal control of an HVAC system using cold storage and building thermal capacitance," Energy and Buildings, 23(1), pp. 19-31.

Kroposki, B., Sen P.K., Malmedal K., 2009, Optimum sizing and placement of distributed and renewable energy sources in electric power distribution systems, Conference Record - IAS Annual Meeting (IEEE Industry Applications Society), 2009 IEEE Industry Applications Society Annual Meeting.

Kuznik F., and Virgone J. , 2009, "Experimental assessment of a phase change material for wall building use," Applied Energy, 86(10), pp. 2038-2046.

Lee K., and Braun J. E. , 2006, "An Experimental Evaluation of Demand Limiting Using Building Thermal Mass in a Small Commercial Building," ASHRAE Transactions, 112(1), pp. 559-572.

Liu C., Li F., Lai-Peng M., Cheng H., 2010, Advanced materials for energy storage, Advanced Materials, v 22, n 8, pp. E28-E62.

MacPhee D., and Dincer I. , 2009, "Heat Transfer and Thermodynamic Analyses of Some Typical Encapsulated Ice Geometries During Discharging Process," Journal of Heat Transfer, 131(8), p. 82301.

Marseille T. J., and Wilke D. A. , 1992, "Review of the aquifer seasonal thermal energy storage building HVAC system at the Melville, New York, Mid-Island mail facility," Proceedings of the Intersociety Energy Conversion Engineering Conference, San Diego, CA, USA, pp. 143-148.

Mcdowall J. , 2006, "Integrating energy storage with wind power in weak electricity grids," Journal of Power Sources, 162(2), pp. 959-964.

Midkiff K. C., Song Y. K., and Brett C. E. , 1991, "Thermal performance and challenges for a seasonal chill energy storage based air-conditioning system," American Society of Mechanical Engineers (Paper), Minneapolis, MN, USA, pp. 1-8.

Morris F. B., Braun J. E., and Treado S. J. , 1994, "Experimental and Simulated Performance of Optimal Control of Building Thermal Storage," ASHRAE Transactions, 100(1), pp. 402-414.

Muraya N. K., O'Neal D. L., and Heffington W. M., 1996, "Thermal interference of adjacent legs in a vertical U-tube heat exchanger for a ground-coupled heat pump," ASHRAE Transactions, 102(2), pp. 12-21.

National Energy Technology Laboratory, 2009, Energy Storage-A Key Enabler of the Smart Grid.

Nelson K. P. , 1999, "Dynamics of primary/secondary chilled water systems," ASHRAE Transactions, Seattle, WA, USA, pp. PART 2/ -.

Nelson K. P., 2000, "Dynamic ice - low-cost alternative for new construction," ASHRAE Transactions, 106, pp. PA/ - .

Nourai A., Kogan V., and Schafer C. , 2008, "Load Leveling Reduces T\&D Line Losses," IEEE Transactions on Power Delivery, 23(4), pp. 2168-2173.

Okajima T. , 1987, "OFFICE BUILDING CHILLED WATER STORAGE SYSTEM.," ASHRAE Transactions, New York, NY, USA, pp. 722-727.

Parker C. , 2001, "Lead-acid battery energy-storage systems for electricity supply networks," Journal of Power Sources, 100(1-2), pp. 18-28.

Peippo K., Kauranen P., and Lund P. D. , 1991, "A multicomponent PCM wall optimized for passive solar heating," Energy and Buildings, 17(4), pp. 259-270. 
Piette M. A. , 1990, "Analysis of a commercial ice-storage system: Design principles and measured performance," Energy and Buildings, 14(4), pp. 337-350.

PNNL prepared for BPA, 2008, Wide-Area Energy Storage and Management System to Balance Intermittent Resources in the Bonneville Power Administration and California ISO Control Areas.

Ponce De Leon C., Frias-ferrer A., Gonzalez-garcia J., Szanto D., and Walsh F. , 2006, "Redox flow cells for energy conversion," Journal of Power Sources, 160(1), pp. 716-732.

Prudent Energy, Technical Specifications, Model: Mark III kW-Class VRB-ESS ${ }^{\mathrm{TM}}$

Prudent University. 2010. http://www.pdenergy.com/en/technology/energy_storage_systems/technical_specifications/techni cal_specifications.html

Rabl A., and Norford L. K. , 1991, "Peak Load Reduction by Preconditioning Buildings at Night," International Journal of Energy Research, 15, pp. 781-798.

Razelli E. , 2003, "Prospects for lead-acid batteries in the new millenium," Journal of Power Sources, Rome, Italy, pp. 2-3.

Rosen M. A., Dincer I., and Pedinelli N. , 2000, "Thermodynamic Performance of Ice Thermal Energy Storage Systems," Journal of Energy Resources Technology, 122(4), pp. 205-211.

Rottmayer S. P., Beckman W. A., and Mitchell J. W. , 1997, "Simulation of a single vertical U-tube ground heat exchanger in an infinite medium," ASHRAE Transactions, Boston, MA, pp. 651659.

Ruud M., Mitchell J., and Klein S. , 1990, "Use of building thermal mass to offset cooling loads," ASHRAE Transactions, 96(2), pp. 820-829.

Rydh C. J. , 1999, "Environmental assessment of vanadium redox and lead-acid batteries for stationary energy storage," Energy.

Rydh C., and Sanden B. , 2005, "Energy analysis of batteries in photovoltaic systems. Part I:

Performance and energy requirements," Energy Conversion and Management, 46(11-12), pp. 1957-1979.

Saft M., Chagnon G., Faugeras T., Sarre G., and Morhet P. , 1999, "Saft lithium-ion energy and power storage technology," Journal of Power Sources, 80(1), pp. 180-189.

Salyer I. O., and Sircar A. K. , 1993, "Development of phase change technology for heating and cooling of residential buildings and other applications," Proceedings of the Intersociety Energy Conversion Engineering Conference, Atlanta, GA, USA, pp. 133-142.

Salyer I. O., and Sircar A. K. , 1997, "Review of phase change materials research for thermal energy storage in heating and cooling applications at the University of Dayton from 1982 to 1996," International Journal of Global Energy Issues, 9(3), pp. Costa M., Buddhi D., and Oliva A. , 1998, "Numerical simulation of a latent heat thermal energy storage system with enhanced heat conduction," Energy Conversion and Management, 39(3-4), pp. 319-330.

Scalat S., Banu D., Hawes D., Paris J., Haghighata F., and Feldman D., 1996, "Full scale thermal testing of latent heat storage in wallboard," Solar Energy Materials and Solar Cells, 44(1), pp. 49-61.

Schaber C., Hammerschlag R., and Mazza P. , 2004, "Utility-Scale Storage of Renewable Energy," The Electricity Journal, 17(6). 
Schoenung SM., 2001, Characteristics and technologies for long-vs. short-term energy storage, Sandia National Laboratories; Report No. SAND2001-0765. Available from: nfoserve.sandia.gov/sand_doc/2001/010765.pdf.

Shonder J. A., and Beck J. V., 1999, "Determining effective soil formation thermal properties from field data using a parameter estimation technique," ASHRAE Transactions, Chicago, IL, USA, pp. 458-466.

Simmonds P. , 1994, "Comparison of energy consumption for storage priority and chiller priority for icebased thermal storage systems," ASHRAE Transactions, New Orleans, LA, USA, pp. 1746-1753.

Smith T. R., and Hittle D. C., 1993, "Analysis of an ice storage air-conditioning system with heat recovery," Solar Engineering, Washington, DC, USA, pp. 133-139.

Snyder M. E., and Newell T. A., 1990, "Cooling cost minimization using building mass for thermal storage," ASHRAE Transactions, 96(2), pp. 830-838.

Sohn C. W., Fuchs J., and Gruber M. , 1999, "Chilled water storage cooling system for an army installation," ASHRAE Transactions, Seattle, WA, USA, pp. PART 2/ -.

Sohn C. W., Underwood D. M., and Lin M. C. , 2006, "An Ice-Ball Storage Cooling System for a Laboratory Complex.," ASHRAE Transactions, 112(1), pp. 676-682.

Stewart Jr. W. E. , 2000, "Improved fluids for naturally stratified chilled water storage systems," ASHRAE Transactions, Dallas, TX, USA.

Stewart W. E. , 2001, "Operating characteristics of five stratified chilled water thermal storage tanks," ASHRAE Transactions, Cincinnati, OH, United states, pp. 12-21.

Tamblyn R. T. , 1985, "CONTROL CONCEPTS FOR THERMAL STORAGE.," ASHRAE Transactions, 91(1B), pp. 5-11.

Tamblyn R. T. , 1985, "CONTROL CONCEPTS FOR THERMAL STORAGE.," ASHRAE Transactions, Chicago, IL, USA, pp. 5-11.

Trueman C. S. , 1987, "OPERATING EXPERIENCE WITH A LARGE THERMALLY STRATIFIED CHILLED-WATER STORAGE TANK.," ASHRAE Transactions, New York, NY, USA, pp. 697-707.

Tyagi V., and Buddhi D. , 2007, "PCM thermal storage in buildings: A state of art," Renewable and Sustainable Energy Reviews, 11(6), pp. 1146-1166.

Vandenbossche P., Vergels F., Vanmierlo J., Matheys J., and Vanautenboer W. , 2006, "SUBAT: An assessment of sustainable battery technology," Journal of Power Sources, 162(2), pp. 913-919.

Vanderlinden S. , 2006, "Bulk energy storage potential in the USA, current developments and future prospects," Energy, 31(15), pp. 3446-3457.

Wagner R., and Batterie H. , 1997, "Large lead / acid batteries for frequency regulation, load levelling and solar power applications," Power, 67, pp. 163-172.

Weinstock I. B. , 2002, "Recent advances in the US Department of Energy's energy storage technology research and development programs for hybrid electric and electric vehicles," Journal of Power Sources, 110, pp. 471-474.

Winter M., Brodd R., 2004, What Are Batteries, Fuel Cells, and Supercapacitors? Chemical Reviews 104 (10), pp. 4245-4270. 
Xu X., Zhang Y., Lin K., Di H., and Yang R., 2005, "Modeling and simulation on the thermal performance of shape-stabilized phase change material floor used in passive solar buildings," Energy and Buildings, 37(10), pp. 1084-1091.

Yavuzturk C., Spitler J. D., and Rees S. J., 1999, "Transient two-dimensional finite volume model for the simulation of vertical U-tube ground heat exchangers," ASHRAE Transactions, 105(2), pp. 465474.

Yu F. W., and Chan K. T. , 2007, "Optimum load sharing strategy for multiple-chiller systems serving air-conditioned buildings," Building and Environment, 42(4), pp. 1581-1593.

Zalba B., Cabeza L. F., and Mehling H. , 2003, "Review on thermal energy storage with phase change : materials , heat transfer analysis and applications," Applied Thermal Engineering, 23(3), pp. 251283.

Zeng H., Diao N., and Fang Z. , 2003, "Heat transfer analysis of boreholes in vertical ground heat exchangers," International Journal of Heat and Mass Transfer, 46, pp. 4467-4481.

Zhang Y., Zhou G., Lin K., Zhang Q., and Di H., 2007, "Application of latent heat thermal energy storage in buildings: State-of-the-art and outlook," Building and Environment, 42(6), pp. 21972209.

Zhou G., Krarti M., and Henze G. P., 2005, "Parametric Analysis of Active and Passive Building Thermal Storage Utilization," Journal of Solar Energy Engineering, 127(1), pp. 37-46.

Zhou J., Wei G., Turner W. D., Deng S., Claridge D. E., and Contreras O. , 2005, "Control optimization for chilled water thermal storage system under complicated time-of-use electricity rate schedule," ASHRAE Transactions, Orlando, FL, United states, pp. 184-195.

Zhu Y., and Zhang Y., 2001, "Modeling of thermal processes for internal melt ice-on-coil tank including ice-water density difference," Energy and Buildings, 33(4), pp. 363-370.

\subsection{Stakeholder Engagement: Discussion on the Needs and Role of Energy Storage in High-Performance Buildings}

For better understanding of the issues and interactions between energy storage in commercial buildings and the power grid, the project team sought supplemental external inputs through discussions with a few energy storage stakeholders. Twenty persons representing a broad spectrum of stakeholders were individually contacted over phone and a structured discussion was held. The stakeholders include building owners, operators and occupants, utilities, regulators, equipment manufacturers and vendors, and energy service firms such as designers and installers. The segments of the stakeholders and the number of participants in each segment are described as follows:

- Business (5)

- Research Institution (2)

- Academia (5)

- Finance Institution (3)

- Utilities (2) 
- Utility Association (1)

- Urban Planning Professional Body (1)

- State Electricity Regulatory Authority (1)

This helped the project team to gain deeper insights in the technical status, performance, costs, research needs, and business issues related to implementation of on-site energy storage in commercial buildings.

During the interview process, the project team focused on the following major areas of interest:

- Experience With On-Site Energy Storage

- Business Models

- Regulatory Practices and Policies

- R\&D Needs.

\subsubsection{Experience with On-Site Energy Storage}

Some respondents had no direct personal experience with on-site storage, but were aware of commercial and demonstration installations. Regarding the storage technologies currently being considered or already applied, following were the observations of the respondents:

- The most commonly considered storage option at the building and community levels is thermal energy storage with chilled water or ice.

- Most thermal storage projects are currently at the district heating or cooling level rather than at the building level.

- Sensible heat storage is more energy efficient than ice storage because of higher chiller COP. Sensible heat storage offers nearly $100 \%$ round-trip efficiency.

- Battery storage installations are usually associated with PV demonstration projects where grid connection to the PV installation is not feasible or storage of electrical energy is required in off-grid installations. It may be also required in some cases for mission critical applications.

The research team explored whether, in addition to demand charges or TOU pricing, on site renewable energy generation could be a driver for on-site energy storage. The stakeholder sample observed that there is little motivation for installation of renewable energy generation in commercial buildings except in large government and university facilities. LEED participation may provide incentives to a broader range of business entities.

Other observations from the respondents are:

- Reliable systems are available for thermal storage. Reduced occupant comfort is no longer an issue though integration of thermal storage into buildings could be a challenge, specifically for smaller buildings because of space constraints. 
- High maintenance requirements and costs for battery bank systems are definite drawbacks for electrochemical storage. For thermal storage systems, equipment damage and degradation, corrosion and leakage issues exist but are not as significant.

- The benefits of energy storage are small compared to the same from commonly available energy savings retrofits. Any investment in energy storage should be preceded by investments in energy conservation. Demand response solution, i.e., load shedding, emergency generation, and using building thermal mass are effective alternatives to a TES system.

- Investment in energy storage is justified only when there are cost savings due to utility incentives or there is need for extra capacity in the building or equipment can be downsized by adding energy storage in a new building under construction. However while TOU rates are essential to justify storage in commercial buildings, it may be harder to justify thermal storage without simultaneous demand for increased capacity.

- Though current TOU rates may incentivize energy storage, long term availability of incentives should be guaranteed because payback periods for storage investments may be 5-10 years.

- Real-time optimal response to TOU pricing for some customers will require sophisticated analysis tools based on building energy systems including storage, design and energy use history. Broader distribution of such analysis tools are important for the expanding the use of storage as a TOU price response option.

\subsubsection{Business Models}

Utility regulatory bodies establish rates, or the conditions under which the market determines the rates. Government policies could include mandated emission reduction measures, tax incentives for new technologies, and appliance or equipment efficiency standards. These can either support or discourage energy storage. The representative stakeholders expressed the following on the current regulatory and policy framework.

- TOU pricing is essential to encourage storage and implementation of TOU pricing would result in a quick adoption of energy conservation measures and storage investment. Conversely, a rapid switching to TOU pricing may put a group of building owners at a disadvantage as they may be less able to respond to price signals. Further utility rate structures that ensure recovery of investment by IOUs could be jeopardized by TOU rate implementation. These factors are potential impediments to quick TOU implementation.

- Consistency and stability of financial incentives and regulatory policies are key facilitators. There is a need for simplified utility rate structure calculations that can be used to make control decisions.

- Currently utilities periodically report project benefits of the DSM program to the public utility commissions. In a particular instance, one evaluation criteria has been changed from a rates impact model (which looks at the effects on customer rate only), to a total resource test (which looks at the total cost to all stakeholders). This is biased against increased storage because storage is generally associated with increased energy consumption.

- There are opposing views on the need for federal government support for energy storage demonstration projects. Some expressed that available technologies for thermal storage have been adequately demonstrated, while others expressed a need towards these. 


\subsubsection{Regulatory Practices and Policies}

Utility regulatory bodies establish rates, or the conditions under which the market determines the rates. Government policies could include mandated emission reduction measures, tax incentives for new technologies, and appliance or equipment efficiency standards. These can either support or discourage energy storage. The representative stakeholders expressed the following on the current regulatory and policy framework.

- TOU pricing is essential to encourage storage and implementation of TOU pricing would result in a quick adoption of energy conservation measures and storage investment. Conversely, a rapid switching to TOU pricing may put a group of building owners at a disadvantage as they may be less able to respond to price signals. Further utility rate structures that ensure recovery of investment by IOUs could be jeopardized by TOU rate implementation. These factors are potential impediments to quick TOU implementation.

- Consistency and stability of financial incentives and regulatory policies are key facilitators. There is a need for simplified utility rate structure calculations that can be used to make control decisions.

- Currently utilities periodically report project benefits of the DSM program to the public utility commissions. In a particular instance, one evaluation criteria has been changed from a rates impact model (which looks at the effects on customer rate only), to a total resource test (which looks at the total cost to all stakeholders). This is biased against increased storage because storage is generally associated with increased energy consumption.

- There are opposing views on the need for federal government support for energy storage demonstration projects. Some expressed that available technologies for thermal storage have been adequately demonstrated, while others expressed a need towards these.

\subsubsection{R\&D Needs}

On key technical barriers to be overcome, and supporting tools needed for design and operation, the stakeholder representatives expressed divergent views and these are summarized below:

- Research is required for developing general measurement and verification $(\mathrm{M} \& \mathrm{~V})$ practices and support may be required for developing advanced design guides.

- Neighborhood-level storage has great potential, but development and demonstration of appropriately scaled storage projects are required.

- Additional tools are needed for TES design and performance evaluation. Improved tools should be holistic and should cover GSHPs, seasonal storage, passive solar and building PCMs, taking into account building environment, orientation, and thermal mass of the building and its surroundings.

- Water- and ice-based systems are the dominant near-term technologies.

- Reversible fuel cells that can produce fuel for storage using off-peak electricity and produce electricity using the stored fuel could be quite attractive opportunity when the first costs of the system decline to an acceptable level. 
- PCM has great potential which is yet to be realized. They can be integrated in the building envelope components and may find greater market acceptance. PCM energy storage tanks are not so favored because of issues with leaks, fire hazards, and others.

- Stratified chilled water tank energy storage, especially with temperature stratification additive such as SoCool, which suppress the freezing point/density point, is seen as having great potential

- Seasonal storage may be used to harness the available environmental resources (e.g., wind, solar, ground) to flatten thermal load and future building designs could extend the classic passive solar energy design approach. The objective would be to store heating and 'cooling' both diurnally and seasonally. Optimizing such processes is still the subject of active research.

- GSHP projects have high first costs and this is a major concern that could be addressed through further research. Hybrid GSHPs coupled to solar thermal systems in heating-dominated environments and to cooling towers in cooling-dominated environments have benefits of long term sustained performance due to ground temperature stability.

\subsubsection{Conclusions on Perceived Need and Role of Energy Storage in Commercial Buildings}

The following conclusions were drawn from the phone interviews:

- Stakeholders indicated potential of battery storage for buildings applications, but did not see a nearterm business model to support it.

- Ownership model of batteries is not clear. Should the utility own it; should it be inside the building or outside the buildings?

- Very little experiences with batteries that are utilized often for time-shifting or balancing services. O\&M cost associated with frequent cycling are unknown.

- Thermal energy storage is proven technology and buildings controls strategies exist to integrate use of TES into overall HVAV controls.

- Thermal energy storage is significantly less expensive for time-shifting than are batteries.

\subsection{ANL's Accomplishments: Agent-Based Modeling of Commercial Buildings}

\subsubsection{Problem Definition}

As of 2008, the U.S. commercial building sector was responsible for $18.5 \%$ of primary energy consumption, $36.4 \%$ of electricity use, and $18.1 \%$ of carbon dioxide emissions (EIA 2008). Success in developing more energy-efficient buildings will depend heavily on an improved understanding of the complex interactions between the buildings themselves, the power system, and the electricity market. Buildings vary widely in terms of their attributes (e.g., physical, functional, occupational, ownership, management, decision-making, and market structure aspects). In addition, current and developing energy storage options enhance the feasibility of net-zero-energy buildings by enabling renewable energy applications and by controlling demand profiles. All of these factors will influence the energy use, energy consumption patterns, electricity bills, and (eventually) wholesale electricity prices. At the same time, 
technical, market, and regulatory developments in power systems will affect the retail price of electricity paid by building owners/operators. The resulting price signals emerging from these supply-and-demand interactions will influence the incentives for adopting various energy savings and storage options. As one of the largest consumers of power, the commercial buildings sector may also influence future electricity market outcomes and grid operations.

Advanced modeling techniques with sufficient fidelity and resolution, such as agent-based modeling and simulation (ABMS), are required to analyze these interactions and to obtain deeper insights into the impacts and various feedbacks of building standards, smart grid developments, and storage technologies.

\subsubsection{Project Scope and Tasks}

This research is part of an integrated research project performed by ANL, NREL, and PNNL. The objective of the research is to analyze the energy consumption patterns of commercial buildings with various energy storage options and the buildings' interactions with the electric power grid under a multitude of energy conservation scenarios and demand-side schemes, including load response and price response programs. The research is conducted in a complementary and coordinated manner by making use of the specific strengths of each of the three laboratories in the areas of simulations of buildings, understandings of the grid's market dynamics, and the interactions between the electric grid and end users. ANL will develop agent-based representations for a range of commercial buildings and investigate various operating strategies for energy storage and their impact on the electricity market. This approach attempts to emulate unpredictable, realistic behavior that accounts for uncertainty in real-time electricity price expectations and the variety of energy saving strategies that may be used by different building agents. PNNL will employ an alternate optimization-based approach to investigate storage sizing and control strategies and the cost-effectiveness of energy storage systems for various regions in the United States. These complementary analysis methods will be supported with the EnergyPlus modeling and optimization capability at NREL to characterize building agents and their baseline load profiles; thus, all three collaborators will use a consistent set of building parameters.

More specifically, ANL's research will focus on energy consumption patterns of commercial buildings with various storage options and the interaction with electric power systems under multiple energy conservation scenarios and demand-side schemes, including reliability-based (load response) and market-based (price response) programs. The investigation will span both short-term demand response programs and long-term engagement in energy efficiency measures. The analysis will examine different types of energy storage technologies and how these can contribute to a more flexible, dynamic, and efficient interaction between buildings and the power systems.

Enhanced modeling and simulation are critical to enabling the true energy savings potential in buildings. An agent-based modeling and simulation tool will be developed to address this issue. This tool can be further utilized to study the value proposition of storage in commercial buildings from the building owner and grid perspectives. In this study, the ABMS approach will be used to analyze the interactions between buildings and the power systems. We are currently developing a modeling prototype that can be incorporated into ANL's Electricity Market Complex Adaptive System (EMCAS) model at a later date. During the simulation, while interacting with the power systems and adapting to different market conditions, the building agents will be modifying and adjusting their load profiles through their demand- 
and price-based response mechanisms. This dynamic behavior will, in turn, influence the operation of the supply side of the power systems and also affect the market prices of electricity.

The development of this prototype includes the following tasks:

1. Characterize various types of commercial building agents (in collaboration with NREL).

2. Develop ABMS representations of commercial building agents.

3. Develop decision logic for the control of energy use by commercial building agents.

4. Develop and test a prototype of the building agent framework.

5. Test the decision-making processes of building agents for various cases.

This report describes the development of agent-based representations of commercial building stock and the framework for simulating commercial buildings as consumer agents interacting with the power grid.

\subsubsection{Methodology}

\subsubsection{Agent-Based Modeling and Simulation}

Agent-based modeling and simulation (ABMS) is a new modeling paradigm that is having farreaching effects on the way that researchers in various disciplines use electronic laboratories to conduct their research. By modeling systems from the bottom up, researchers are exploring how system behaviors emerge from the behaviors of large numbers of interacting individuals, or agents.

An agent is an autonomous and self-directed entity (hardware or software), which is characterized by a set of attributes. The behavior of an agent is usually driven by its goals. To achieve the goals, specific rules are determined to guide the agent's performance when interacting with the other agents. An agent can usually evolve by self-learning so that it can adapt its decision-making based on the ambient information. Furthermore, agents are also situated in the system constituted by agents and their environment. The relationship between agents and the environment are illustrated in Figure 3.1. 


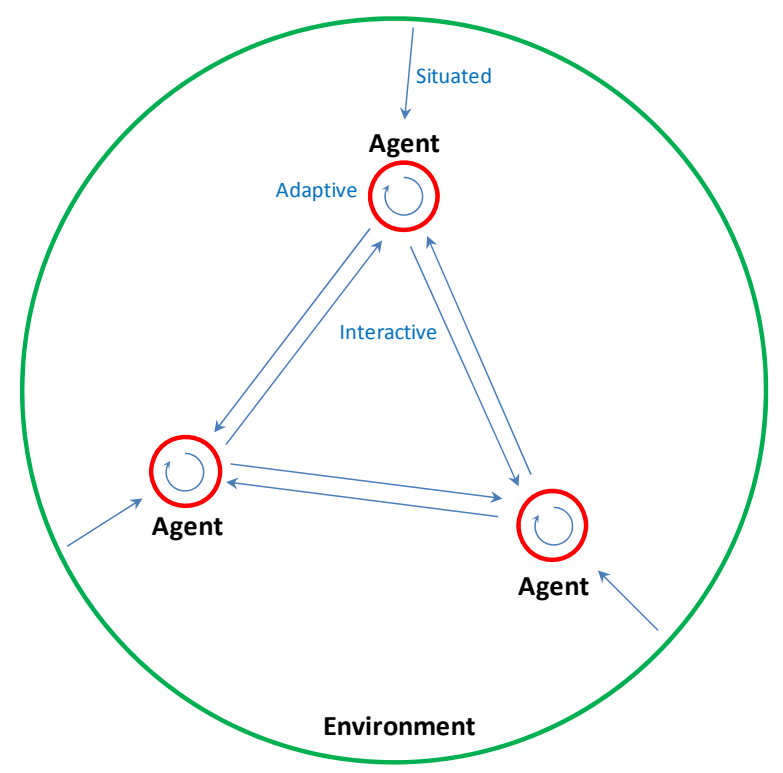

Figure 3.1. Illustration of ABMS Modeling Environment

As described in (Macal and North 2005), from a practical modeling standpoint, agents are considered to have the following characteristics:

- An agent is identifiable, a discrete individual with a set of characteristics and rules governing its behaviors and decision-making capability. Agents are self-contained. The discreteness requirement implies that an agent has a boundary such that users can easily determine whether something is part of an agent, is not part of an agent, or is a shared characteristic.

- An agent is autonomous and self-directed. An agent can function independently in its environment and in its dealings with other agents, at least over a limited range of situations that are of interest.

- An agent is situated, living in an environment with which it interacts with other agents. Agents have protocols for interaction with other agents, such as for communication, and the capability to respond to the environment. Agents have the ability to recognize and distinguish the traits of other agents.

- An agent may be goal directed, having goals to achieve (not necessarily objectives to maximize) with respect to its behaviors. This allows an agent to compare the outcome of its behavior relative to its goals.

- An agent is flexible, having the ability to learn and adapt its behaviors based on experience. This requires some form of memory. An agent may have rules that modify its rules of behavior.

The ABMS approach has the unique capability to represent the decentralized decision-making process that takes place among agents on both the demand and supply sides of the electricity market. This modeling capability, which is not present in traditional power system simulation tools, will be particularly important to understand the complex processes underlying the energy use of commercial buildings (as the consumer agents) and their behaviors and energy conservation strategies in restructured electricity markets. 


\subsubsection{Electricity Market Complex Adaptive System}

Researchers at the Center for Energy, Environmental, and Economic Systems Analysis (CEEESA) at ANL have developed the EMCAS model, which uses an agent-based simulation approach, to simulate restructured electricity markets. While the planning and operation activities of traditional electric utility systems used to be strongly driven by least-cost and reliability concerns, recent trends toward restructuring and unbundling are creating opportunities for new participants with new business models to enter the markets, which, in turn, are creating diverse and dynamic markets. Centralized, monopolistic decision-making organizations are giving way to heterogeneous, decentralized decision structures. The "single" decision-maker is replaced by a host of decision entities, each of which operates with its own unique business strategies, risk preferences, and decision models.

Many of the global optimization and equilibrium-based power systems analysis tools developed over the last two decades implicitly assume a centralized decision-making process, which limits their ability to analyze the forces prevalent in today's emerging markets adequately. This limitation is amplified by recent experiences that have shown the difficulties in understanding the operation of these markets. ANL's EMCAS model provides a new platform for simulating the operation of electricity markets in an agent-based framework.

In EMCAS, diverse participants in the electricity market are represented as agents, which have their own sets of objectives, decision-making rules, and behavioral patterns. Further, agents can draw on an array of historical information (e.g., past power prices) and projected data (e.g., next-day load) to support their unique decision processes.

An EMCAS simulation runs over six decision levels, ranging from the simulation of hourly dispatch to long-term planning. At each decision level, agents make certain decisions, including determining rates of electricity consumption (customer agents), unit commitment (generation company agents), bilateral contracting (generation and demand companies' agents), and unit dispatch (independent system operator [ISO]/regional transmission organization [RTO] agents). Agents then apply their own decision rules and evaluate how well these rules meet their objectives. Rules that fail to meet objectives can be modified in subsequent time steps. In this manner, agents may "learn" from past efforts and gravitate to strategies that improve their respective positions. Agents go through a look-back/look-ahead process. This approach allows for exploration of a wide range of behaviors that cannot be captured by conventional optimization or equilibrium methodologies.

An EMCAS simulation includes both the customers who represent the end users of electricity and the demand companies from whom they purchase electricity. The latter can be conventional distribution companies or brokers. EMCAS also includes the physical generators and the generation companies that own them, as well as the transmission lines and busses and the transmission companies that own them. An ISO or RTO can be included when one exists. The agents interact on several layers, including a physical layer, several business layers, and a regulatory layer.

EMCAS can simulate various market operating rules established by a regulator agent. The rules can range from those applying to a conventional, vertically integrated utility operating under rules established by a local public utility commission to a fully deregulated market that is operating under forward-bidding procedures. A market information system provides data used by all participants. A random event generator allows for simulation of unexpected incidents, such as generator or transmission line outages. 
What sets the EMCAS design apart from most other models is the unique combination of methodologies and modeling approaches. EMCAS combines agent-based modeling and simulation with the following modeling techniques:

- Complex-adaptive systems (CAS) approach to represent agent learning and adaptation,

- Utility function characterization of agent objectives,

- Heuristic optimization for unit commitment,

- Demand response functions to reflect consumer reactions, and

- Transmission load flow analysis.

Unlike conventional electric system models, the ABMS techniques in EMCAS do not postulate a single decision maker with a single objective for the entire system. Rather, agents are allowed to establish their own objectives and apply their own decision rules. The CAS approach empowers many agents to learn from their previous experiences and change their behaviors when future opportunities arise. That is, as the simulation progresses, agents can adapt their strategies based on the success or failure of previous efforts. Genetic algorithms are used to provide a learning capability for certain agents. EMCAS has been applied successfully in a number of relevant areas, including in the design of efficient wholesale electricity markets and the impact of plug-in hybrid electric vehicles on electricity demand and the power systems.

\subsubsection{Normative Building Energy Calculation and ISO 13790 Simple Hourly Method}

Several models and tools have been developed to evaluate energy use and conditions of the indoor environments in commercial buildings. They range from simplified normative procedures that are useful for hand calculations to dynamic simulation models that use detailed numerical calculations of heat, air, and moisture transfer by sophisticated systems that control temperature, daylight, etc. The simplified calculation procedures often use only a few items of input data and a limited set of equations to maintain a high level of transparency, reproducibility, and robustness. Major benefits of using the normative model include (1) reducing input parameters as much as possible; (2) making modifications to the input parameters easy by directly using the building design and operational parameters to be implemented; and (3) maintaining an adequate level of accuracy, especially for air conditioned buildings where the thermal dynamics of the indoor environment has a high impact.

ISO 13790, Energy performance of buildings - Calculation of energy use for space heating and cooling (2008), specifies the normative building energy calculation approach that was originally developed by the European Committee for Standardization (CEN) in its Energy Performance of Buildings Directive (EPBD) program. Besides the monthly method, a simple hourly method is also introduced in ISO 13790. This method is based on an equivalent resistance-capacitance (R-C) network. Heat transfer by ventilation, infiltration, solar radiation, and internal heat gains are considered as flows into different building component nodes, so that a building's hourly indoor air temperature, as well as heating and cooling loads, can be calculated.

In this model, the input parameters include building geometry (e.g., floor area, elevation, and window-wall ratio); materiality (e.g., U-value, light transmission, and absorption factors of enclosure); heating, ventilation, and air conditioning (HVAC) (e.g., schedule, efficiencies, and set-point temperature); 
and lighting and equipment (e.g., intensity and schedule). Typical meteorological year (TMY) hourly weather data are also used. Then, the heating and/or cooling needs are found by calculating, for each hour, the heating or cooling power $\left(\varphi_{H C, n d}\right)$ that needs to be supplied to or extracted from the indoor air node $\left(\theta_{\text {air }}\right)$ to maintain a certain set-point indoor air temperature.

Heat transfer by ventilation $\left(H_{v e}\right)$ is connected with the supply air temperature $\left(\theta_{\text {sup }}\right)$ and the interior temperature $\left(\theta_{\text {int }}\right)$. Heat transfer by transmission is split into the window part $\left(H_{t r, w}\right)$ and non-window part ( $H_{t r, e m}$ and $\left.H_{t r, m s}\right)$; only the non-window part is connected by a single thermal capacity $\left(C_{m}\right)$, representing the building thermal mass. The heat gains from internal and solar sources are split into three parts $\left(\varphi_{\text {air }}, \varphi_{s}\right.$, and $\left.\varphi_{m}\right)$ and applied to the nodes of indoor air $\left(\theta_{\text {air }}\right)$, internal environment $\left(\theta_{s}\right)$, and thermal mass $\left(\theta_{m}\right)$, respectively. Figure 3.2 depicts these elements of the simple hourly method.

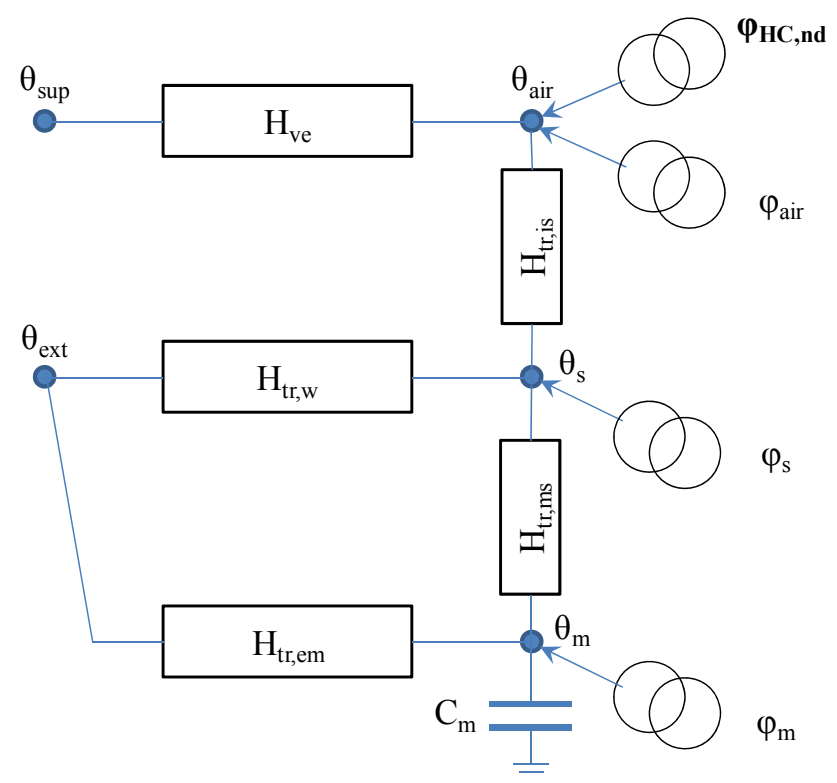

Figure 3.2. Thermal R-C Model of the Simple Hourly Method

The detailed calculation procedure is described in ISO 13790. Validation of the simple hourly method at the thermal needs level was also performed against detailed dynamic simulations (Nielsen 2005; Millet 2007).

On the basis of the calculated thermal needs, we developed modules to estimate the hourly end-use energy for heating, cooling, lighting (interior and exterior), equipment (interior and exterior), refrigeration, fan, and pump according to the building design and operation specifications. These categories were then summed up to get the total end-use consumption of electricity and natural gas.

\subsubsection{Framework Development}

Broadly, there are two fundamental methods for modeling the energy consumption of a certain number of buildings at the city/regional/national level: the top-down approach and bottom-up approach (Swan and Ugursal 2009; Kavgic, Mavrogianni et al. 2010). The physically based bottom-up approach takes into account information on building design and operations. Also called the "white-box" approach, it is thus more flexible in simulating the consequences of changes to building operations than are the 
"black-box" or top-down statistical methods. Typically, the bottom-up energy simulation of building stock consists of the following steps:

1. Categorizing the whole building stock according to energy consumption characteristics;

2. Designing building prototypes, each representing a building stock category that is used as an input dataset for simulation in the first step;

3. Performing simulations by using these prototypical building models to predict the energy consumption per unit floor area or household in each building stock category as an agent; and

4. Aggregating the total energy consumption by summing up the predicted energy consumption of all building stock categories.

We implemented a physically based, simple hourly building energy model to estimate the hourly electricity demand of a single building. This model was tested for 10 types of commercial buildings that were the major electricity consumers in the Commercial Building Energy Consumption Survey of 2003 (CBECS) (EIA 2006).

In this approach, we consider a cluster of buildings of the same type within the same region (i.e., using the same climate data) to be one aggregated agent. The hourly electricity demand of this agent is determined by multiplying the total floor area of this building type in this region to the electricity use intensity (in $\mathrm{MW} / \mathrm{m}^{2}$ ) of its representative design, which is calculated by the simple hourly method. Figure 3.3 illustrates the calculation procedure of this framework. Complete sets of input parameters for each representative building with respect to climate zone and building age are stored in a database. When the total floor area, building age (pre- or post-1980), and primary heating source (electricity or nonelectricity) are specified for each building agent, the software selects the corresponding input files from the representative building parameter database and the right climate data from the climate database. Input data files are then dispatched to the simple hourly model. The calculated hourly electricity demands of building agents are then aggregated to derive the total hourly demand profile of the region. Given the demand profile and a power supply curve, the electricity price can then be determined, which informs building operations as a feedback.

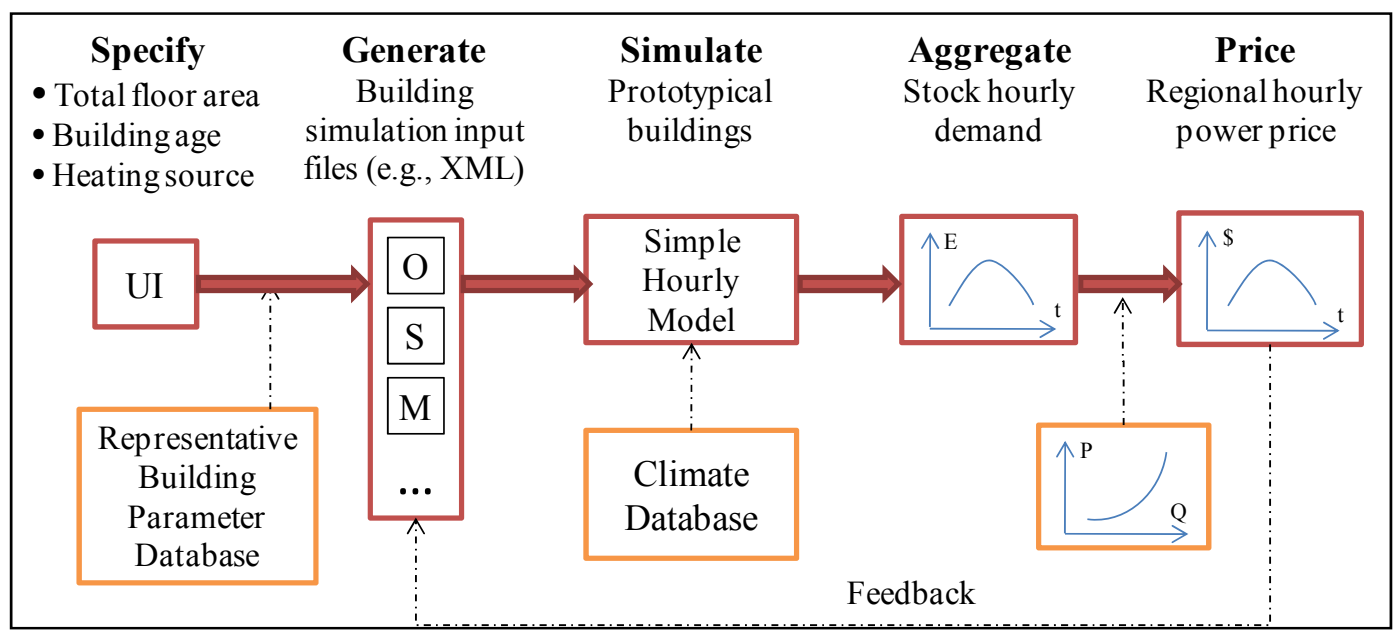

Figure 3.3. Agent-Based Building Stock Energy Simulation Process

(Note: $\mathrm{XML}=$ Extensible Markup Language) 


\subsubsection{Selection of Building Types}

In order to estimate the electricity consumption of the actual commercial building stock, the building energy model should be able to estimate the energy consumption of different building types. The 2003 CBECS provides a list of types of commercial buildings and their surveyed energy consumption data. The 10 types listed in Table 3.3 were selected from the CBECS. The 2003 CBECS indicates that these 10 types cover $83.7 \%$ of the total electricity consumption of commercial buildings in the United States.

Table 3.3. The 10 Building Types Modeled as Agents

\begin{tabular}{|c|c|c|c|}
\hline Abbr. & Building Type & 2003 Electricity Consumption (kWh) & $\%$ of CBECS Total \\
\hline $\mathrm{O}$ & Office & 211 & 20.2 \\
\hline $\begin{array}{l}\mathrm{S} \\
\mathrm{M}\end{array}$ & $\begin{array}{l}\text { Supermarket } \\
\text { Strip Mall }\end{array}$ & $153^{\mathrm{a}}$ & 14.7 \\
\hline $\mathrm{E}$ & Education & 109 & 10.5 \\
\hline $\mathrm{H}$ & Healthcare & 73 & 7.0 \\
\hline W & $\begin{array}{l}\text { Warehouse } \\
\text { and Storage }\end{array}$ & 72 & 6.9 \\
\hline $\mathrm{L}$ & Lodging & 69 & 6.6 \\
\hline FE & Food Service & 63 & 6.0 \\
\hline $\mathrm{R}$ & $\begin{array}{c}\text { Retail } \\
\text { (other than mall) }\end{array}$ & 62 & 5.9 \\
\hline FS & Food Sales & 61 & 5.8 \\
\hline & Total & 873 & 83.7 \\
\hline
\end{tabular}

Source: CBECS (2003) (EIA 2006).

"Classified as "Enclosed and strip mall" in CBECS 2003.

Other building types have different energy consumption patterns and cannot be modeled simply. Because of their small share in the national electricity consumption, they are ignored in this study. Table 3.4 shows the building types that are not modeled in this project.

Table 3.4. Building Types not Modeled

\begin{tabular}{c|c|c|c|c|c|c|}
\hline Building Type & $\begin{array}{c}\text { Public } \\
\text { assembly }\end{array}$ & $\begin{array}{c}\text { Public order } \\
\text { and safety }\end{array}$ & $\begin{array}{c}\text { Religious } \\
\text { worship }\end{array}$ & Vacant & Service & Other \\
\hline 2003 Electricity & 49 & 17 & 18 & 4 & 44 & 39 \\
$\begin{array}{c}\text { Consumption }(\mathrm{kWh}) \\
\text { \% of CBECS Total }\end{array}$ & $5 \%$ & $2 \%$ & $2 \%$ & $0 \%$ & $4 \%$ & $4 \%$ \\
\hline
\end{tabular}

Definitions of the building types from Table 3.3 and Table 3.4are listed in Table 3.5. 
Table 3.5. Building Types Definition ${ }^{1}$

\begin{tabular}{|c|c|c|}
\hline Building Type & Definition & Representative Examples \\
\hline Office & $\begin{array}{l}\text { Buildings used for general office space, } \\
\text { professional office, or administrative offices. } \\
\text { Medical offices are included here if they do } \\
\text { not use any type of diagnostic medical } \\
\text { equipment (if they do, they are categorized as } \\
\text { an outpatient health care building). }\end{array}$ & $\begin{array}{l}\text { Administrative or professional office } \\
\text { Government office } \\
\text { Mixed-use office } \\
\text { Bank or other financial institution } \\
\text { Medical office (see previous column) } \\
\text { Sales office } \\
\text { Contractor's office (e.g., construction, plumbing, } \\
\text { HVAC) } \\
\text { Not-for-profit or social services } \\
\text { Research and development } \\
\text { City hall or city center } \\
\text { Religious office } \\
\text { Call center }\end{array}$ \\
\hline $\begin{array}{l}\text { Enclosed and } \\
\text { Strip Malls }\end{array}$ & $\begin{array}{l}\text { Shopping malls comprised of multiple } \\
\text { connected establishments. }\end{array}$ & $\begin{array}{l}\text { Enclosed mall } \\
\text { Strip shopping center }\end{array}$ \\
\hline $\begin{array}{l}\text { Retail } \\
\text { (Other Than } \\
\text { Mall) }\end{array}$ & $\begin{array}{l}\text { Buildings used for the sale and display of } \\
\text { goods other than food. }\end{array}$ & $\begin{array}{l}\text { Retail store } \\
\text { Beer, wine, or liquor store } \\
\text { Rental center } \\
\text { Dealership or showroom for vehicles or boats } \\
\text { Studio/gallery }\end{array}$ \\
\hline Education & $\begin{array}{l}\text { Buildings used for academic or technical } \\
\text { classroom instruction, such as elementary, } \\
\text { middle, or high schools, and classroom } \\
\text { buildings on college or university campuses. } \\
\text { Buildings on education campuses for which } \\
\text { the main use is not classroom are included in } \\
\text { the category relating to their use. For } \\
\text { example, administration buildings are part of } \\
\text { "Office," dormitories are part of "Lodging," } \\
\text { and libraries are part of "Public Assembly." }\end{array}$ & $\begin{array}{l}\text { Elementary or middle school } \\
\text { High school } \\
\text { College or university } \\
\text { Preschool or daycare } \\
\text { Adult education } \\
\text { Career or vocational training } \\
\text { Religious education }\end{array}$ \\
\hline Lodging & $\begin{array}{l}\text { Buildings used to offer multiple } \\
\text { accommodations for short-term or long-term } \\
\text { residents, including skilled nursing and other } \\
\text { residential care buildings. }\end{array}$ & $\begin{array}{l}\text { Motel or inn } \\
\text { Hotel } \\
\text { Dormitory, fraternity, or sorority } \\
\text { Retirement home } \\
\text { Nursing home, assisted living, or other residential } \\
\text { care } \\
\text { Convent or monastery } \\
\text { Shelter, orphanage, or children's home } \\
\text { Halfway house }\end{array}$ \\
\hline Health Care & $\begin{array}{l}\text { Buildings used as diagnostic and treatment } \\
\text { facilities for inpatient and outpatient care. } \\
\text { Medical offices are included here if they use } \\
\text { any type of diagnostic medical equipment (if } \\
\text { they do not, they are categorized as an office } \\
\text { building). }\end{array}$ & $\begin{array}{l}\text { Hospital } \\
\text { Inpatient rehabilitation } \\
\text { Medical office (see middle column) } \\
\text { Clinic or other outpatient health care } \\
\text { Outpatient rehabilitation } \\
\text { Veterinarian }\end{array}$ \\
\hline $\begin{array}{l}\text { Warehouse } \\
\text { and Storage }\end{array}$ & $\begin{array}{l}\text { Buildings used to store goods, manufactured } \\
\text { products, merchandise, raw materials, or } \\
\text { personal belongings (such as self-storage). }\end{array}$ & $\begin{array}{l}\text { Refrigerated warehouse } \\
\text { Non-refrigerated warehouse } \\
\text { Distribution or shipping center }\end{array}$ \\
\hline Food Service & $\begin{array}{l}\text { Buildings used for preparation and sale of } \\
\text { food and beverages for consumption. }\end{array}$ & $\begin{array}{l}\text { Fast food } \\
\text { Restaurant or cafeteria }\end{array}$ \\
\hline Food Sales & $\begin{array}{l}\text { Buildings used for retail sale or wholesaling } \\
\text { of food. }\end{array}$ & $\begin{array}{l}\text { Grocery store or food market } \\
\text { Gas station with a convenience store } \\
\text { Convenience store }\end{array}$ \\
\hline
\end{tabular}

\footnotetext{
${ }^{1}$ From http://www.eia.doe.gov/emeu/cbecs/building types.html.
} 
The following types are not considered in this project:

\begin{tabular}{|c|c|c|}
\hline \multirow{10}{*}{ Public Assembly } & \multirow{10}{*}{$\begin{array}{l}\text { Buildings in which people gather for social or } \\
\text { recreational activities, whether in private or } \\
\text { non-private meeting halls. }\end{array}$} & $\begin{array}{l}\text { Social or meeting (e.g., community center, lodge, } \\
\text { meeting hall, convention center, senior center) }\end{array}$ \\
\hline & & $\begin{array}{l}\text { Recreation (e.g., gymnasium, health club, bowling } \\
\text { alley, ice rink, field house, indoor racquet sports) }\end{array}$ \\
\hline & & $\begin{array}{l}\text { Entertainment or culture (e.g., museum, theater, } \\
\text { cinema, sports arena, casino, night club) }\end{array}$ \\
\hline & & Library \\
\hline & & Funeral home \\
\hline & & Student activities center \\
\hline & & Armory \\
\hline & & Exhibition hall \\
\hline & & Broadcasting studio \\
\hline & & Transportation terminal \\
\hline \multirow{4}{*}{$\begin{array}{l}\text { Public Order and } \\
\text { Safety }\end{array}$} & \multirow{4}{*}{$\begin{array}{l}\text { Buildings used for the preservation of law and } \\
\text { order or public safety. }\end{array}$} & Police station \\
\hline & & Fire station \\
\hline & & Jail, reformatory, or penitentiary \\
\hline & & Courthouse or probation office \\
\hline \multirow{4}{*}{$\begin{array}{l}\text { Religious } \\
\text { Worship }\end{array}$} & \multirow{4}{*}{$\begin{array}{l}\text { Buildings in which people gather for religious } \\
\text { activities. }\end{array}$} & Churches, chapels \\
\hline & & Synagogues \\
\hline & & Temples \\
\hline & & Mosques \\
\hline \multirow{12}{*}{ Service } & \multirow{12}{*}{$\begin{array}{l}\text { Buildings in which some type of service is } \\
\text { provided, other than food service or retail } \\
\text { sales of goods. }\end{array}$} & Vehicle service or vehicle repair shop \\
\hline & & Vehicle storage/ maintenance (car barn) \\
\hline & & Repair shop \\
\hline & & Dry cleaner or Laundromat \\
\hline & & Post office or postal center \\
\hline & & Car wash \\
\hline & & Gas station \\
\hline & & Photo processing shop \\
\hline & & Beauty parlor or barber shop \\
\hline & & Tanning salon \\
\hline & & Copy center or printing shop \\
\hline & & Kennel \\
\hline \multirow{7}{*}{ Other } & \multirow{7}{*}{$\begin{array}{l}\text { Buildings which are industrial or agricultural } \\
\text { with some retail space; buildings having } \\
\text { several different commercial activities that, } \\
\text { together, comprise } 50 \% \text { or more of the floor } \\
\text { space, but whose largest single activity is } \\
\text { agricultural, industrial/ manufacturing, or } \\
\text { residential; and all other miscellaneous } \\
\text { buildings that do not fit into any other } \\
\text { category. }\end{array}$} & Airplane hangar \\
\hline & & Crematorium \\
\hline & & Laboratory \\
\hline & & Telephone switching \\
\hline & & Agricultural with some retail space \\
\hline & & Manufacturing or industrial with some retail space \\
\hline & & Data center or server farm \\
\hline Vacant & $\begin{array}{l}\text { Buildings in which more floor space was } \\
\text { vacant than was used for any single } \\
\text { commercial activity at the time of interview } \\
\text { for the CBECS } 2003 \text { (EIA 2006). Therefore, } \\
\text { a vacant building may have some occupied } \\
\text { floor space. }\end{array}$ & Vacant space \\
\hline
\end{tabular}




\subsubsection{Agent Descriptions}

\subsubsection{Agent Formation}

To simulate the interplay of different players (regulators, generation companies, transmission companies, distribution companies, and consumers), an agent-based modeling platform has been advocated as both a solution and a framework for analyzing the properties of systems in which multiple self-interested parties interact (Dam, Houwing et al. 2008; Exarchakos, Leach et al. 2009; Vytelingum, Voice et al. 2010). Much research has focused on attempting to simulate the electricity price elasticity and the consequences of implementing demand-response programs in a real-time pricing market. In these studies, electricity consumers (i.e., buildings) are usually modeled as predefined, aggregated, and fixedload profiles on the basis of historic regional electricity consumption data. Such a simplified model focuses on the electricity generation and transmission levels but cannot model the diversity and dynamics of building consumers in terms of design and operation.

In this research, we address this shortcoming and provide an agent-based framework for modeling the dynamic response of the commercial building stock in a real-time pricing market. In this framework, a cluster of buildings of the same type located in the same city/region (and therefore using the same climate data) are considered to be an aggregated agent. A total of 10 commercial building agent types are considered in this study.

Each region/city may have multiple commercial building agents. Different weather profiles apply to agents in different regions.

Figure 3.4 illustrates the relationship between building agents, region/city, and transmission lines. The letters in the circles are abbreviations of building types, as defined in Table 3.3.

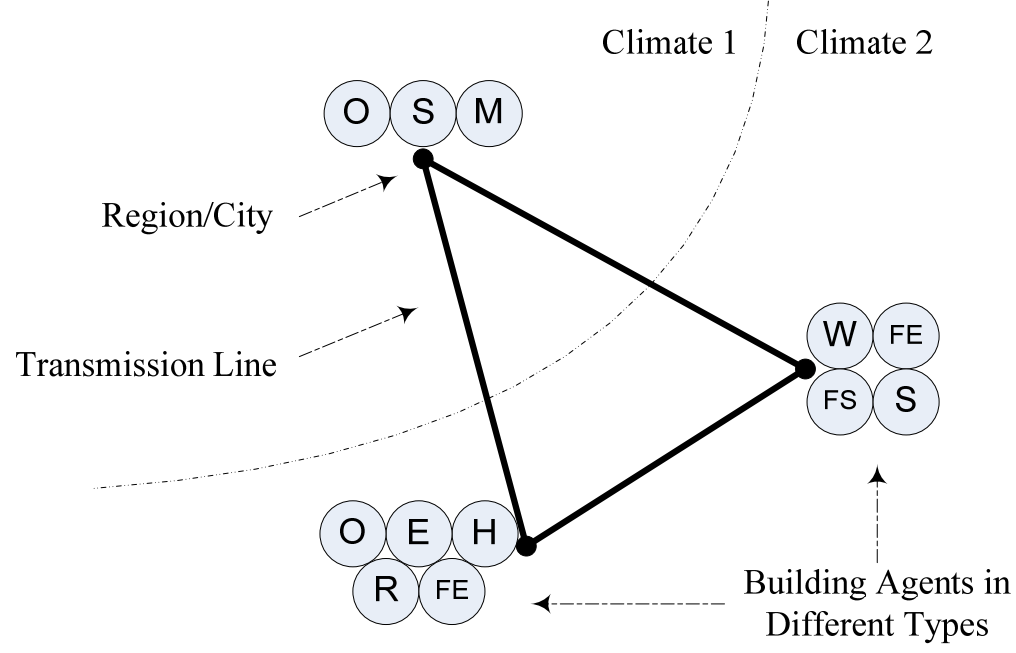

Figure 3.4. Conceptual Relationship between Building Agents, Regions, and Transmission Lines

The hourly electricity demand of an agent is determined by multiplying the total floor area of this building type in this region to the electricity use intensity (in $\mathrm{MW} / \mathrm{m}^{2}$ ) of its representative design, calculated by the simple hourly method. Comparisons between this model and EnergyPlus (DOE 2010) for different commercial building types showed overall compliance. 
Representative designs have the same geometry defined in Energy Efficiency and Renewable Energy's Commercial Building Initiative - Commercial Reference Buildings (DOE 2009). The set of parameters concerning materiality, HVAC, and equipment are classified as Old Vintage (pre-1980) and New Vintage (post-1980), according to when the majority of buildings in the stock were constructed or renovated. The user of the tool is able to select the class that best describes actual conditions, and then the corresponding set of input parameters are applied to the agent.

To create each building agent, a list of input parameters, as shown in Table 3.6, must be specified. These parameters are classified into program, materiality, HVAC, and equipment.

Table 3.6. Required Input Parameters for Each Building Agent

\begin{tabular}{l|l}
\hline \multicolumn{1}{c|}{ Program } & \multicolumn{1}{c}{ Materiality } \\
\hline $\begin{array}{l}\text { Building location } \\
\text { Total conditioned floor area } \\
\text { Building height }\end{array}$ & U-value of envelope \\
$\begin{array}{l}\text { Opaque wall area (all directions) } \\
\text { Window area (all directions) }\end{array}$ & Solar transmittance \\
Occupancy & Rolar Heat Gain Coefficient (SHGC) of glazing \\
\hline \multicolumn{1}{c}{ HVAC } & Solar shading factor of glazing \\
\hline Ventilation needs and schedule & Building thermal inertia \\
Thermostat set-point temperature & \multicolumn{1}{c}{ Equipment } \\
Heating energy source & Interior lighting intensity and schedule \\
$\mathrm{H} / \mathrm{C}$ generation efficiency & Exterior lighting intensity and schedule \\
$\mathrm{H} / \mathrm{C}$ distribution efficiency & Interior equipment intensity and schedule \\
Fan and pump size and schedule & Exterior equipment intensity and schedule \\
\hline${ }^{\mathrm{a}} \mathrm{H} / \mathrm{C}=$ Space Heating and Cooling & Refrigeration capacity and schedule \\
\hline
\end{tabular}

The input parameters of the representative designs are crucial to the simulation results. If local data are available, the accuracy can be improved by dividing the interested area into multiple small regions and specifying local average data for each building agent. However, in most cases, when local building data are not available, regional statistical data are used instead. Griffith et al. (Griffith, Long et al. 2008) studied the ranges of energy modeling input parameters for commercial buildings by building type in different climate zones and checked the simulation results against CBECS 2003.

\subsubsection{Agent Behaviors}

Building agents can have different operation scenarios or mechanisms for performing their demandresponse actions. The "Load Reduction" scenario reduces the intensity of building systems' energy use. The "Load Shifting without Energy Storage" scenario adjusts the building operation schedule. "Load Shifting with Energy Storage" stores energy (thermal or electrochemical) at low cost during the off-peak hours and uses it during the high-cost peak hours.

\subsubsection{Load Reduction}

Three load reduction behaviors can be triggered by utility price signals. Agents can be triggered to: (1) increase/decrease the AC set-point temperature for cooling/heating by a certain number of degrees;

(2) reduce lighting power by a certain percentage or to a certain energy use intensity level (in $\mathrm{W} / \mathrm{m}^{2}$ ); and

(3) reduce internal equipment power by a certain percentage or to a certain energy use intensity level (in 
$\mathrm{W} / \mathrm{m}^{2}$ ). Every building agent, even those connected to the same transmission bus or being of the same building type, may have different thresholds at which load reduction behaviors will be triggered. A generic comparison between scenarios with and without load reduction is illustrated in Figure 3.5, which shows that when the electricity price goes above a certain threshold, some load reduction actions are triggered.

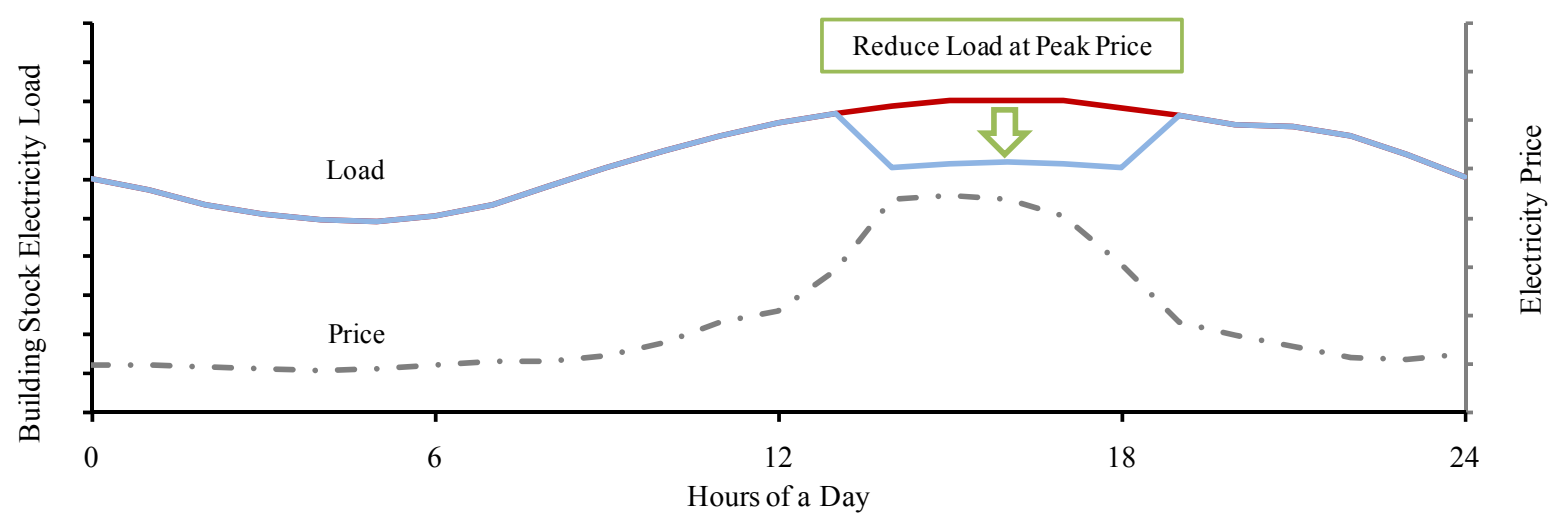

Figure 3.5. Agent Behavior 1: Load Reduction

\subsubsection{Load Shifting without Energy Storage}

By default, each building agent has a set of typical operation schedules for occupancy, lighting, HVAC, and internal/external equipment. In the model, these schedules may be adjusted or modified so that different load-shifting scenarios (i.e., moving energy-intensive activities to off-peak hours) may be simulated. This process is illustrated in Figure 3.6.

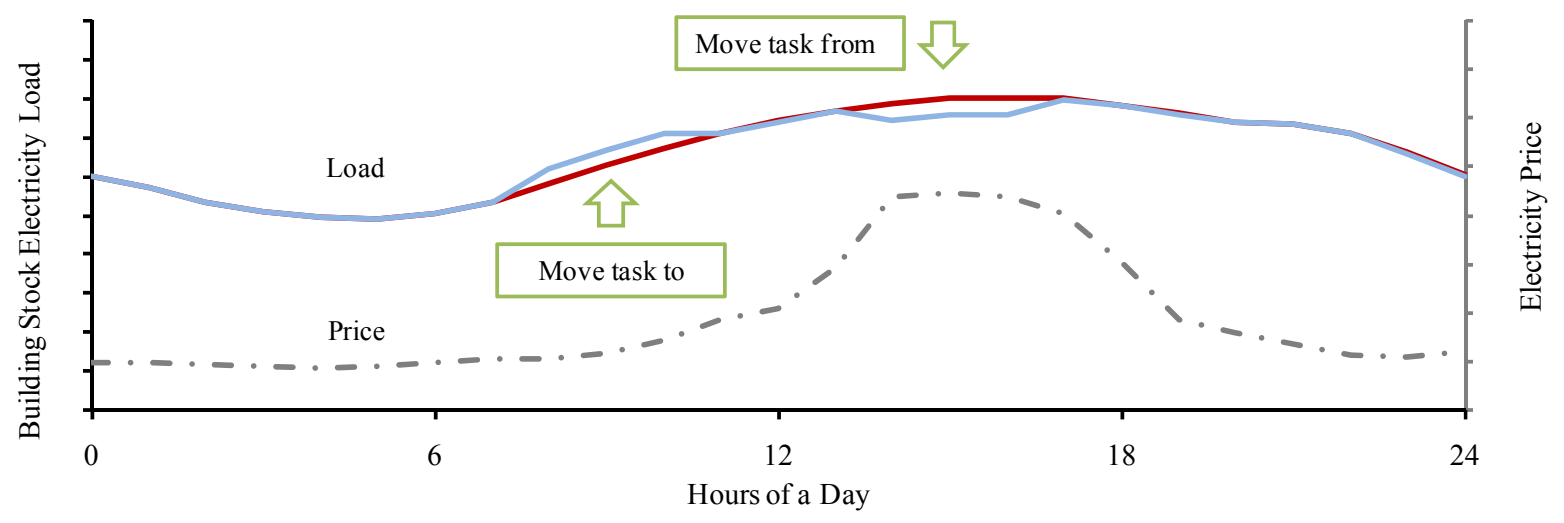

Figure 3.6. Agent Behavior 2: Load Shifting without Energy Storage

\subsubsection{Load Shifting with Energy Storage}

In addition to the above two types of demand response, energy storage for buildings can also be simulated. For electric energy storage, the user needs to specify the parameters - such as battery storage capacity, charge-discharge cycle efficiency, percentage of buildings in the stock using storage, and the schedule to use the stored energy - for each agent. Next, the calculated building electricity load profile will be adjusted accordingly. For thermal storage (and similar to the case with electric storage), users are 
able to specify the properties of the system and make relevant changes to the model. Taking electric energy storage as an example, the battery charging and discharging process for a generic day is illustrated in Figure 3.7.

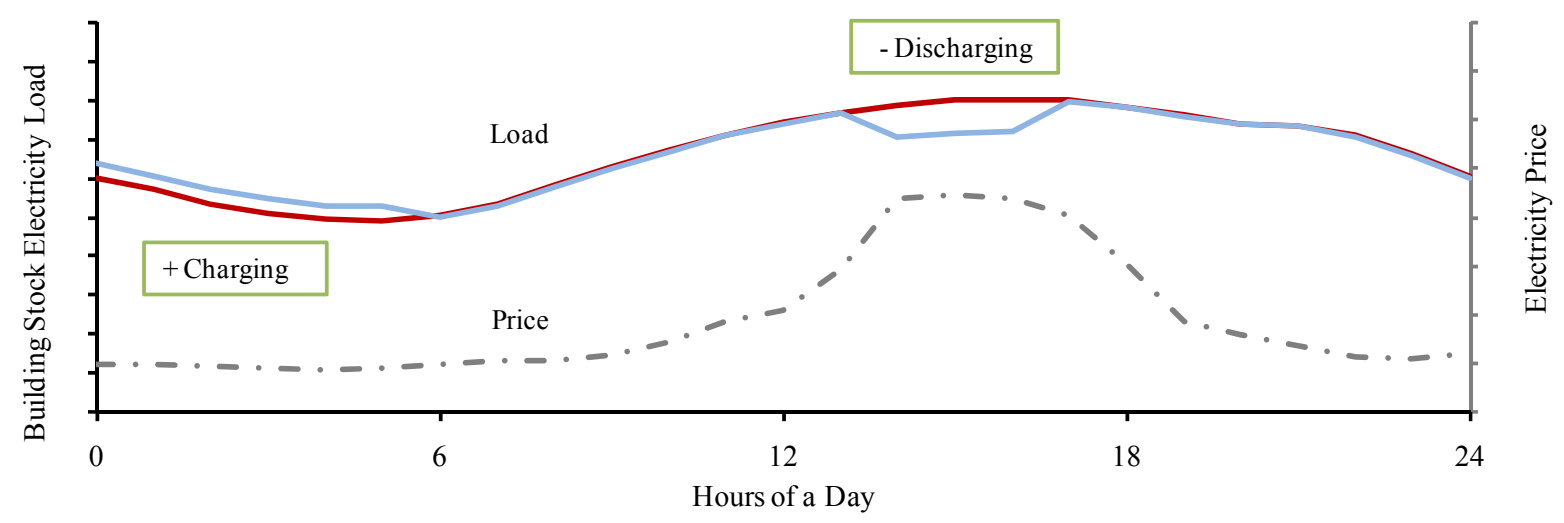

Figure 3.7. Agent Behavior 3: Load Shifting with Energy Storage

\subsubsection{Test Cases and Results}

In this proposed framework, because building agents are based on the bottom-up physical models, building operation behaviors can be connected with the price aspects of the power market.

First, a building agent's input parameters can be dynamically manipulated to reflect the reactions of building operations to the electricity price (e.g., change AC set-point temperature, reduce lighting intensity). This capability quantifies the amount of energy savings to the agents in a typical local climate condition. Second, in an electricity market with real-time pricing, the hourly electricity price can be determined by the building stock load profile and a power supply price curve. This demand-response process is also modeled in the prototype. Third, in an electricity network with energy storage, electricity can be stored at night and discharged to buildings at the peak hours. This section shows three experiments to demonstrate these scenarios.

\subsubsection{Test Case 1: Load Reduction}

A simple building stock consisting of only office buildings is used to demonstrate the demand reduction. Table 3.7 provides characteristics of the building agent in this test case.

Table 3.7. Building Stock Specification for Test Case 1

\begin{tabular}{cccc}
\hline Building Type & $\begin{array}{c}\text { Total Floor Area } \\
\left(\text { million } \mathbf{~ m}^{2}\right)\end{array}$ & Dominant Building Age & Primary Heating Source \\
\hline Office & 1 & Pre-1980 & Natural gas \\
\hline
\end{tabular}

Figure 3.8 illustrates the hourly electricity price profile that was used for the simulation. It is assumed that the electricity demand of this agent has little impact on the electricity price. 


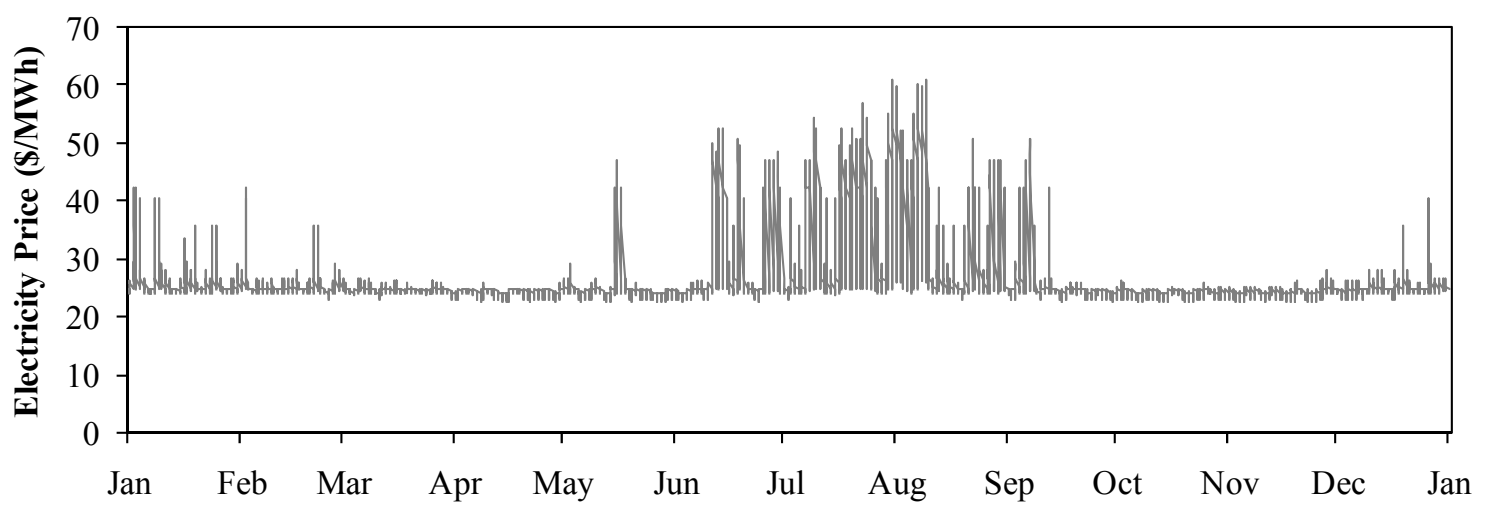

Figure 3.8. Typical Hourly Electricity Price Profile

In this market, given the electricity price in the previous hour, it is assumed that buildings can take three demand-reducing actions (Table 3.8). When the price is above $\$ 45 / \mathrm{MWh}$, the indoor AC set-point increases by $2^{\circ} \mathrm{C}$. When the price is above $\$ 50 / \mathrm{MWh}$ and $\$ 55 / \mathrm{MWh}$, the lighting and internal equipment power, respectively, decrease by $20 \%$.

Table 3.8. Agent Load-Reducing Actions and Electricity Price

\begin{tabular}{ccc}
\hline Demand reduction scenario & $\begin{array}{c}\text { When the power } \\
\text { price is above }\end{array}$ & Action from buildings \\
\hline Cooling set-point & $\$ 45 / \mathrm{MWh}$ & Increase set-point temperature by $2^{\circ} \mathrm{C}$ \\
Lighting & $\$ 50 / \mathrm{MWh}$ & Reduce lighting load by $20 \%$ \\
Internal equipment & $\$ 55 / \mathrm{MWh}$ & Reduce load by $20 \%$ \\
\hline
\end{tabular}

On the basis of TMY climate data and stock specifications, the prototype simulates hourly stock electricity demand and price for a year. Figure 3.9 compares the baseline (no action) and reduced loads simulated for the week of July 22nd. At noon of each business day when the electricity price approaches the daily peak, three load reduction scenarios are activated to reduce the power demand. The corresponding hourly electricity cost is also plotted in Figure 3.10.

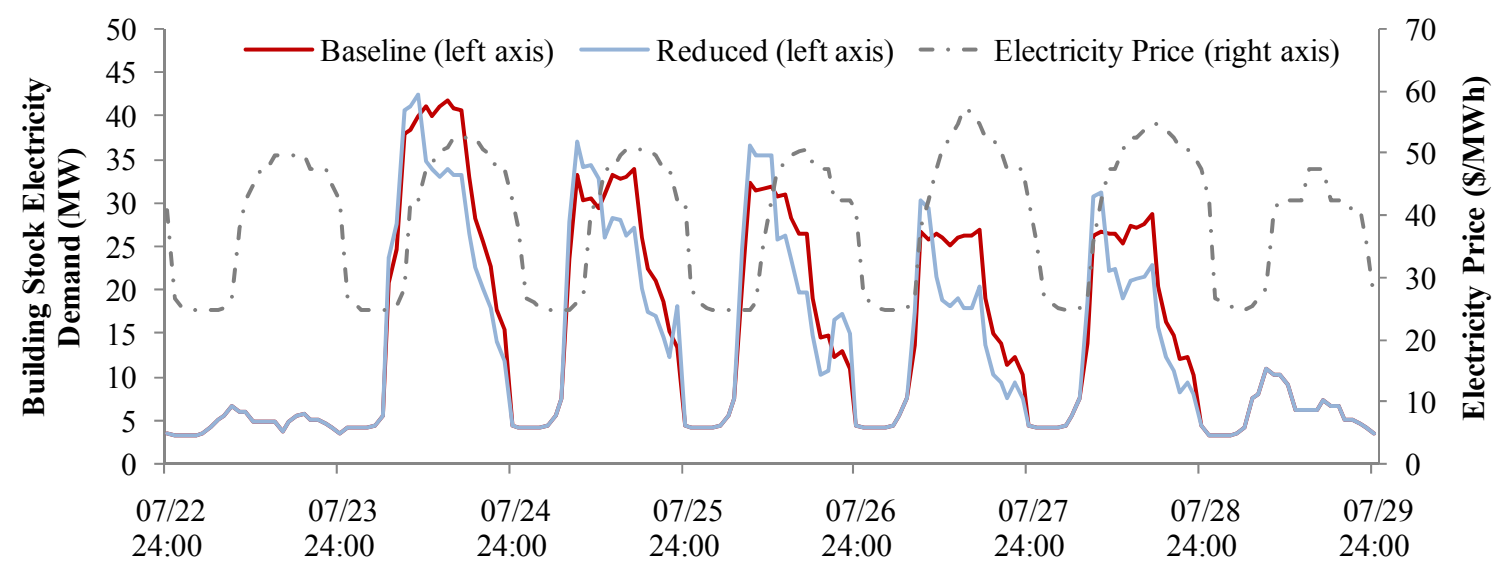

Figure 3.9. Office Agent Electricity Demand Profile Before and After Load Reduction Actions, July 22 through July 29 
It is worth noting that in Figure 3.9 the hourly building stock electricity demand for the "reduced" (blue curve) scenario exceeds the "baseline" (red curve) at the beginning of each occupied period. This is caused by the building thermal mass. In this test case the AC set point temperature of the baseline are 24 and $30^{\circ} \mathrm{C}$ for the occupied and unoccupied period, respectively. If we plot the indoor air temperature (not included in this report) we would notice that for Chicago the indoor air temperature at night never reaches 30 . Therefore, during the unoccupied periods space cooling is not activated and the indoor air temperature "free floats". This free-floating temperature in the "reduced" scenario is higher than in the "baseline", because the building is warmer at the previous day when increasing the AC set point temperature. When a new occupied period starts, it requires more energy to cool the building for the warmer "reduced" scenario. Even though the energy consumption at certain time is increased, it does not bring too much electricity cost increase, because the energy "over shooting" happens at the period when electricity price is low. This can be observed in Figure 3.10.

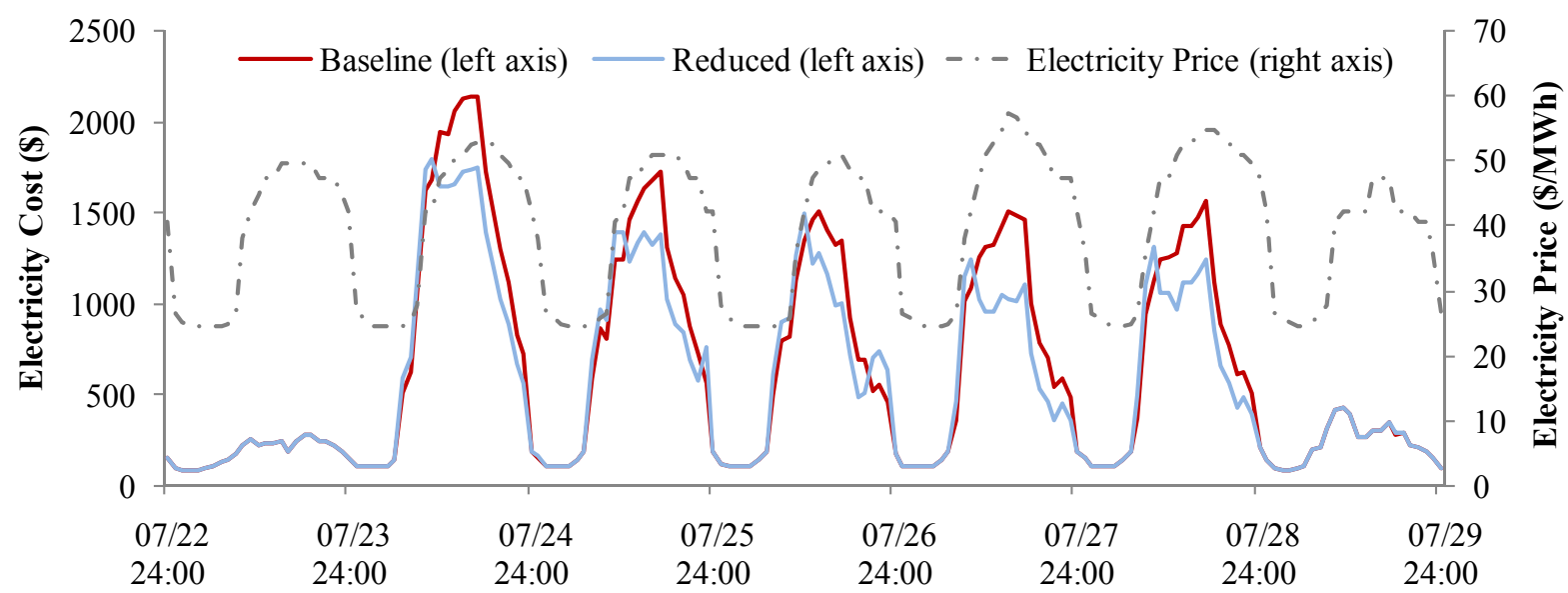

Figure 3.10. Office Agent Hourly Electricity Cost Before and After Load Reduction Actions, July 22 through July 29

To quantify the effectiveness of different load reduction scenarios, the annual electricity conservation and utility savings are aggregated (Table 3.9). In this particular test case, the reductions in lighting and internal equipment power have very little impact on energy and monetary savings because of the higher thresholds and small reduction percentages for these two scenarios. However, increasing the $2^{\circ} \mathrm{C}$ cooling set-point temperature at an electricity price of $\$ 45 / \mathrm{MWh}$ or above does lead to a $2.83 \%$ reduction in annual electricity consumption and $3.41 \%$ increase in monetary savings.

Table 3.9. Utility Savings of the Demand Reduction Actions for the Test Case 1 Building Stock

\begin{tabular}{lrrrr}
\hline \multirow{2}{*}{ Demand Reduction Scenario } & \multicolumn{2}{c}{ Annual Electricity Reduced } & \multicolumn{2}{c}{ Annual Monetary Savings } \\
& In MWh & In \% & \multicolumn{1}{c}{ In MWh } & \multicolumn{1}{c}{ In \% } \\
\hline (a) Cooling set-point temp. & 2,733 & $2.83 \%$ & 93,707 & $3.41 \%$ \\
(b) Lighting & 231 & $0.24 \%$ & 12,163 & $0.44 \%$ \\
(c) Internal equipment & 44 & $0.05 \%$ & 2,549 & $0.09 \%$ \\
(a), (b), and (c) & 3,009 & $3.11 \%$ & 108,418 & $3.95 \%$ \\
\hline
\end{tabular}




\subsubsection{Test Case 2: Grid Reaction}

Test Case 1 showed an example of estimating the energy and monetary savings of load reduction strategies when the electricity price profile is fixed. If we consider a network at the city/state scale in the real-time electricity market, the electricity price can also change when buildings reduce their peak loads. A much larger building stock with a combination of different building types (Table 3.10) is modeled in this test case. The relative proportion of each type is estimated according to the CBECS 2003 building characteristics summary for the U.S. Midwest.

Table 3.10. Building Stock Specifications in Test Case 2

\begin{tabular}{lccc}
\hline \multicolumn{1}{c}{ Building Type } & $\begin{array}{c}\text { Total Floor Area } \\
\left(\text { million } \mathbf{~ m}^{2}\right)\end{array}$ & $\begin{array}{c}\text { Dominant } \\
\text { Building Age }\end{array}$ & Primary Heating Source \\
\hline Office & 108 & Pre-1980 & Natural gas \\
Supermarket & 14 & Post-1980 & Natural gas \\
Strip Mall & 11 & Post-1980 & Electricity \\
Education & 92 & Pre-1980 & Natural gas \\
Healthcare & 29 & Post-1980 & Natural gas \\
Warehouse and Storage & 109 & Post-1980 & Natural gas \\
Lodging & 41 & Pre-1980 & Electricity \\
Food Service & 16 & Post-1980 & Natural gas \\
Retail (other than mall) & 32 & Post-1980 & Natural gas \\
Food Sales & 12 & Post-1980 & Natural gas \\
\hline
\end{tabular}

We consider a macro-model of the electricity market, a "black box" that abstracts the market mechanism and trading, as well as the transmission power flows, involved in an actual electricity market. Given the characteristics of the market, our prototype generates the market prices based on the economics of supply and demand, as shown in Figure 3.11. The supply curve is generated from the capacity of local generation companies. In each hour, the intersection of the supply curve and the total electricity demand determines the electricity price for that hour.

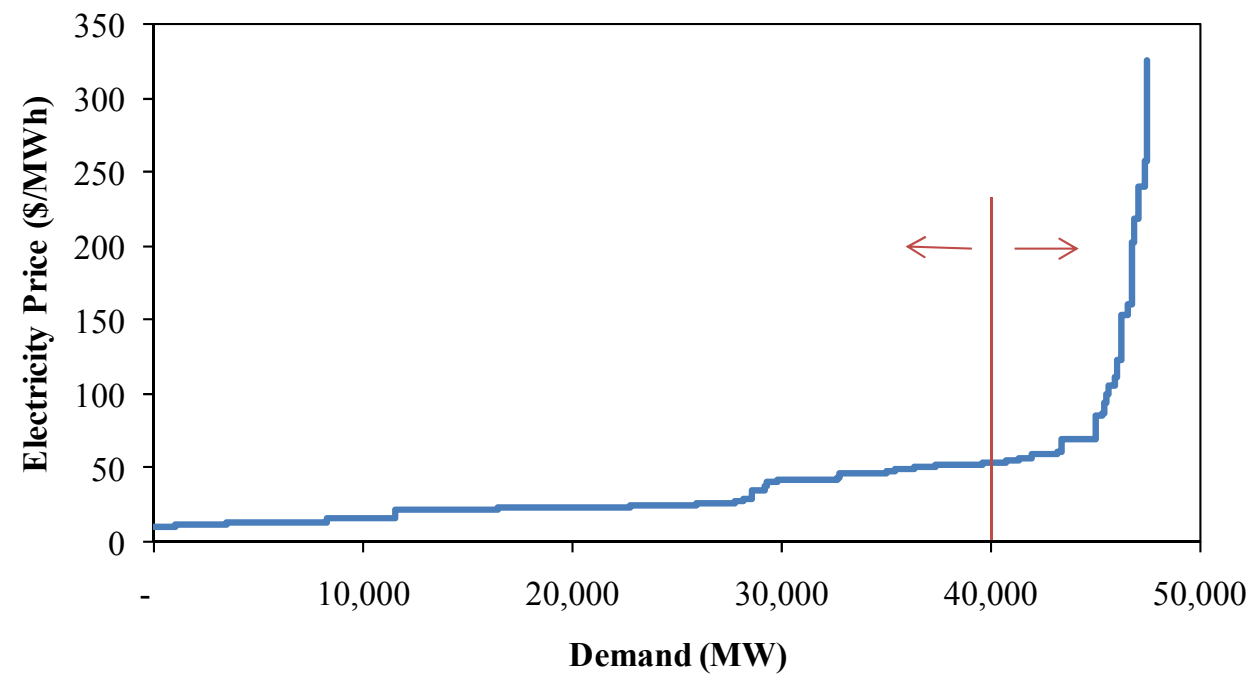

Figure 3.11. Sample Electricity Supply Curve 
Given that the commercial sector is not the only electricity consumer, we assume that the residential, industrial, and transportation sectors in total consume $65 \%$ of the total regional electricity demand (EIA 2009). This portion is modeled as a fixed-base demand curve below the fluctuating demand of commercial buildings. For the baseline case in which no building agent performs any demand reduction actions, the regional electricity demand profile is calculated as shown in Figure 3.12. This hourly regional electricity demand profile together with the electricity supply curve (Figure 3.11) determines the estimated regional electricity price profile. This baseline profile is shown in Figure 3.13.

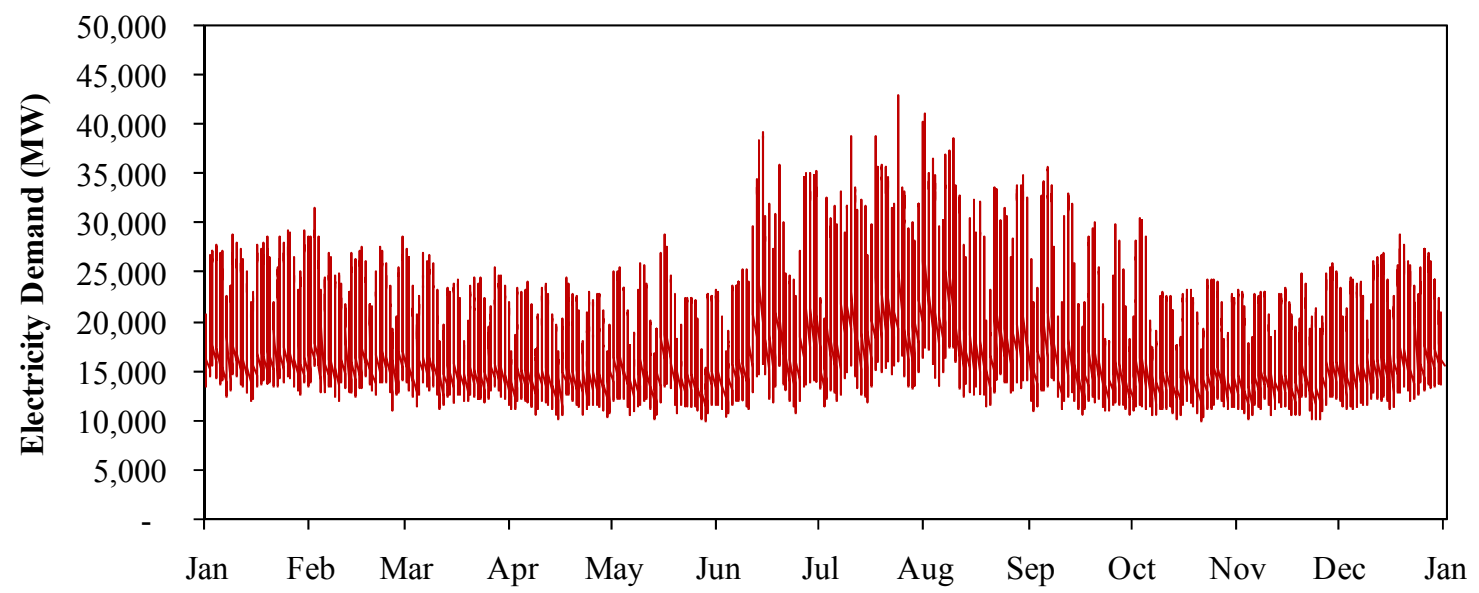

Figure 3.12. Estimated Electricity Load Profile - Baseline

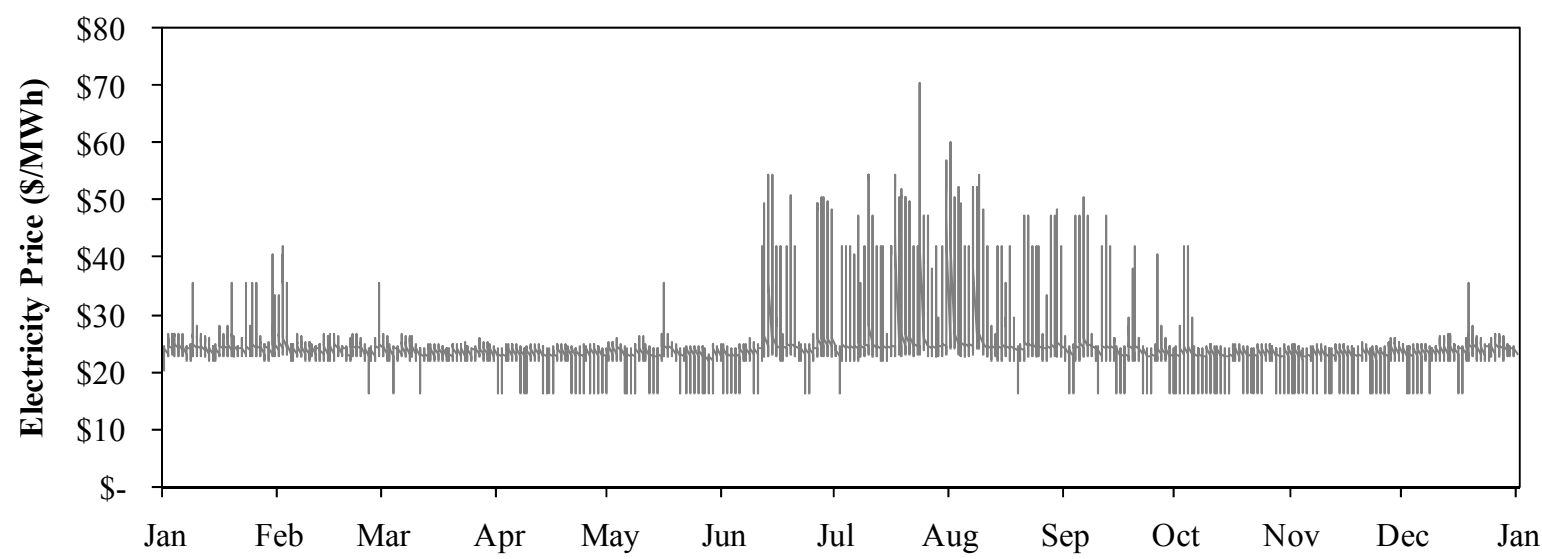

Figure 3.13. Estimated Electricity Price Profile: Baseline

In Test Case 2, the load reduction actions are applied to more building types. The set of assumptions and corresponding building actions is listed in Table 3.11. 
Table 3.11. Agent Load-Reducing Actions and Electricity Price

\begin{tabular}{lccc}
\hline $\begin{array}{l}\text { Demand Reduction } \\
\text { Scenario }\end{array}$ & $\begin{array}{c}\text { Agents Applied } \\
\text { to: }\end{array}$ & $\begin{array}{c}\text { When the Power } \\
\text { Price Is Above: }\end{array}$ & Action from Buildings \\
\hline $\begin{array}{l}\text { (a) Cooling set-point } \\
\text { temperature }\end{array}$ & $\mathrm{O}, \mathrm{H}, \mathrm{R}, \mathrm{FE}$ & $\$ 45 / \mathrm{MWh}$ & Increase set-point temp. by $2^{\circ} \mathrm{C}^{\circ} \mathrm{C}$ \\
$\begin{array}{l}\text { (b) Heating set-point } \\
\text { temperature }\end{array}$ & $\mathrm{O}, \mathrm{H}, \mathrm{R}, \mathrm{FE}$ & $\$ 45 / \mathrm{MWh}$ & Decrease set-point temp. by $2^{\circ} \mathrm{C}^{\circ} \mathrm{C}$ \\
$\begin{array}{l}\text { (c) Lighting } \\
\text { (d) Internal equipment }\end{array}$ & $\mathrm{O}, \mathrm{S}, \mathrm{R}, \mathrm{E}, \mathrm{FE}$ & $\$ 45 / \mathrm{MWh}$ & Reduce lighting load by $30 \%$ \\
${ }^{\mathrm{a}} \mathrm{O}=$ office; $\mathrm{H}=$ helo & $\$ 45 / \mathrm{MWh}$ & Reduce int. equip. load by $30 \%$ \\
\hline
\end{tabular}

${ }^{\mathrm{a}} \mathrm{O}=$ office; $\mathrm{H}=$ healthcare; $\mathrm{R}=$ retail (other than mall); $\mathrm{FE}$ = food service; $\mathrm{S}=$ supermarket; $\mathrm{E}=$ education.

The simulation results are plotted in Figure 3.14, which compares the hourly load profile with and without load-reduction actions. Small reductions in electricity demand appear during the middle of each day, when the electricity price is high. All of the demand reduction actions have led to a decrease in annual regional electricity consumption (including all of the sectors) of about $0.2 \%$.

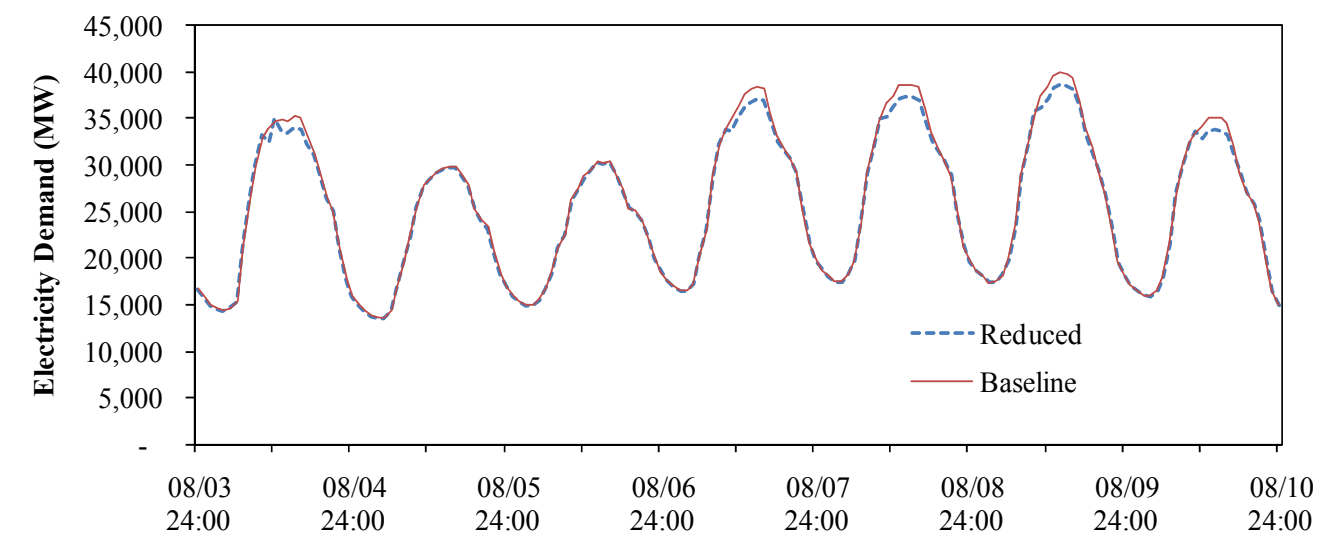

Figure 3.14. Commercial Building Stock Electricity Demand Before and After Reduction Actions, August 4 through August 11

However, on the price side, these actions of building agents have also impacted the market prices of electricity. As a consequence, daily peak electricity prices are reduced by up to $\$ 10 / \mathrm{MWh}$ during the summer (Figure 3.15). Although in this Test Case 2 simulation, only a portion of the building agents took action, the changes in load and price profiles demonstrate the impact of commercial buildings on the power grid.

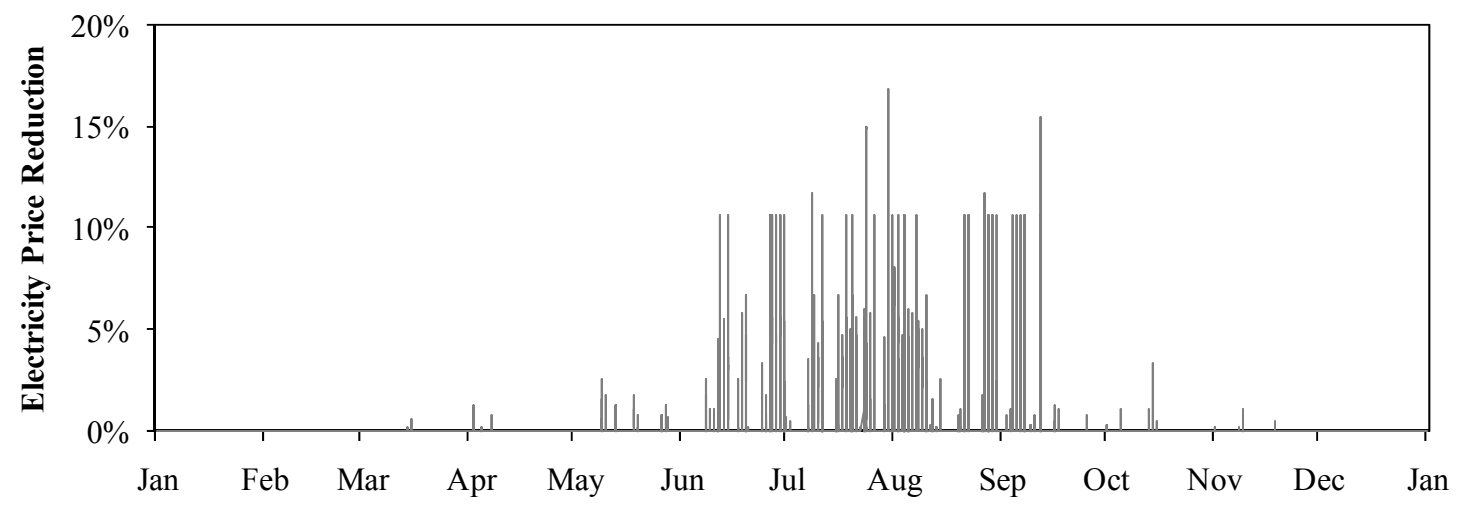

Figure 3.15. Test Case 2: Electricity Price Reduction 
We calculated the electricity price monthly volatility during the summer season (shown in Figure 3.16) to compare the fluctuations of electricity prices before and after demand reduction (DR). Standard deviation is used as volatility in this case. Comparison indicates that load-reduction actions lead to a reduction of up to $5 \%$ in electricity price volatility when compared to the baseline scenario.

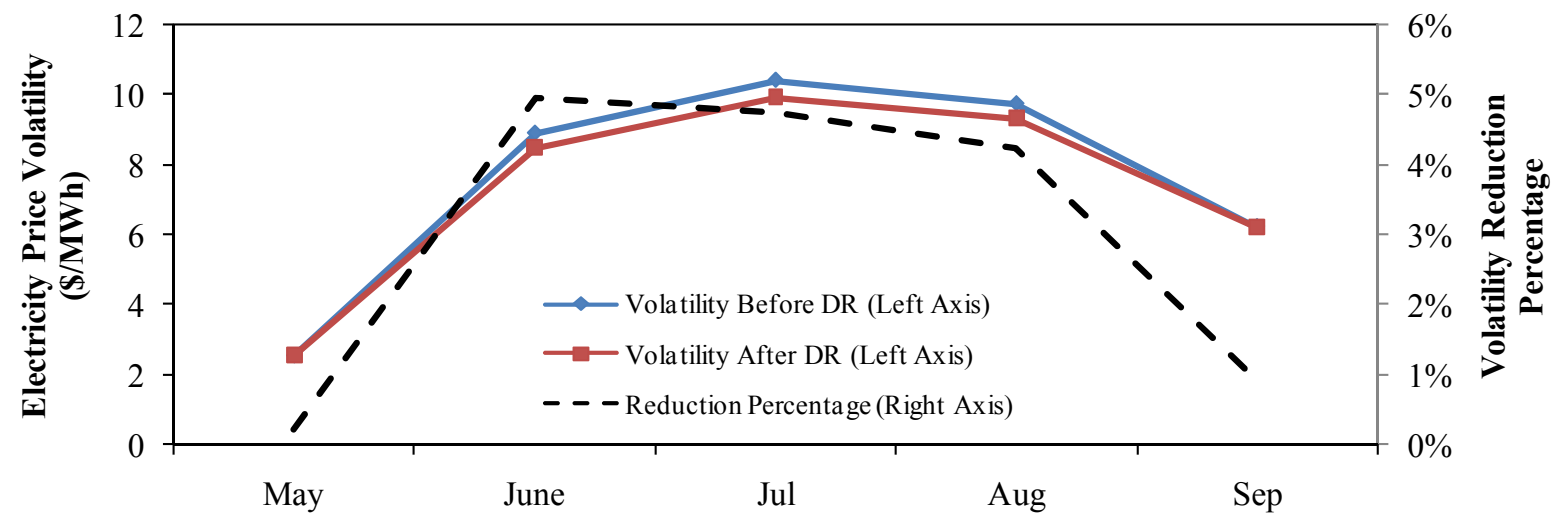

Figure 3.16. Electricity Price Volatility Reduction (Note: DR = Demand Reduction)

\subsubsection{Test Case 3: Electrical Energy Storage}

If the building stock has some energy storage capabilities, electricity can be stored during the offpeak hours and discharged during the on-peak hours. This does not conserve energy - actually consumes more due to the system losses - but leads to noticeable cost savings for building owners and operators.

For this analysis we simplified the specification of electrical energy storage and only required the following input parameters:

- Total energy storage capacity by building agent: $\mathrm{Cp}$

- Storage charge time and discharge time: tcharge and tdischarge

- Energy efficiency for charge and discharge process: $\eta$ charge and $\eta$ discharge

- Minimum daily electricity price spread for the use of energy storage: pspread

These four types of parameters allow building agents to choose the time and duration of peak and offpeak hours according to the day-ahead electricity market price. For example, for a building agent that has the total electricity storage defined with the following parameters: capacity $=8,600 \mathrm{MWh} ; \mathrm{t}_{\text {charge }}=6 \mathrm{~h}$; $\mathrm{t}_{\text {discharge }}=3 \mathrm{~h} ; \eta_{\text {charge }}=95 \% ; \eta_{\text {discharge }}=85 \%$; and $\mathrm{p}_{\text {spread }}=10 \$ / \mathrm{MWh}$; the hourly electricity consumption and battery status for a typical week are shown in Figure 3.17 and Figure 3.18, respectively. 


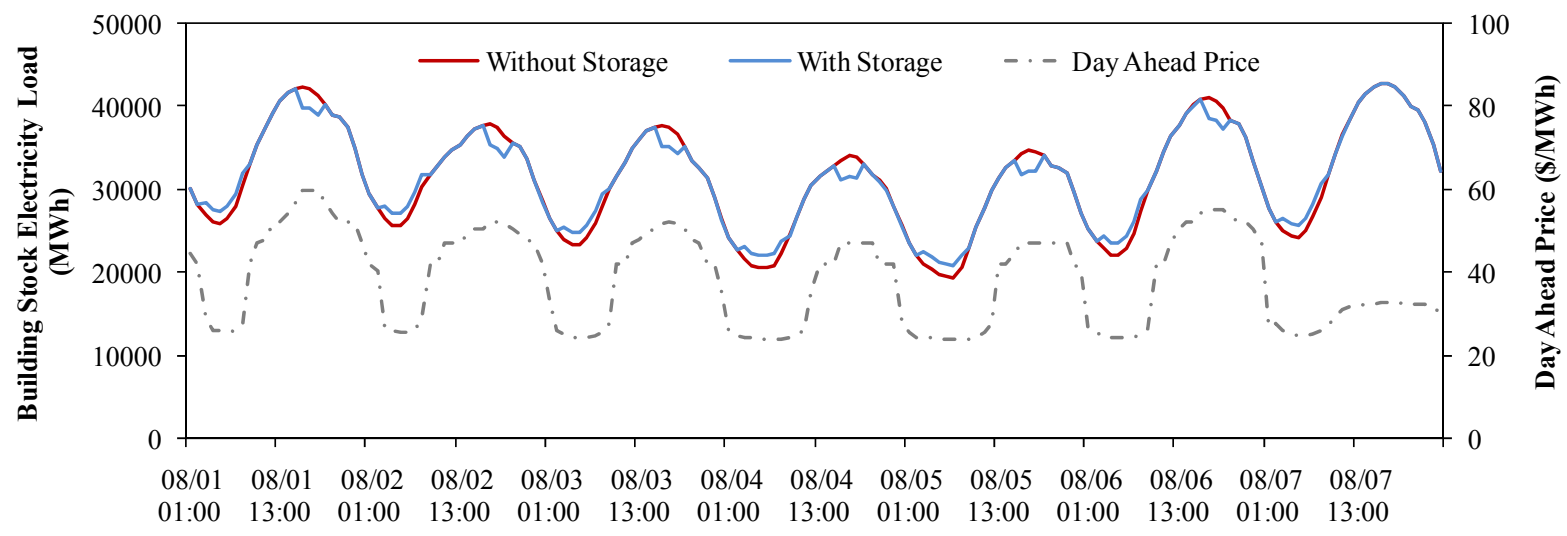

Figure 3.17. Building Stock with and without Electricity Storage

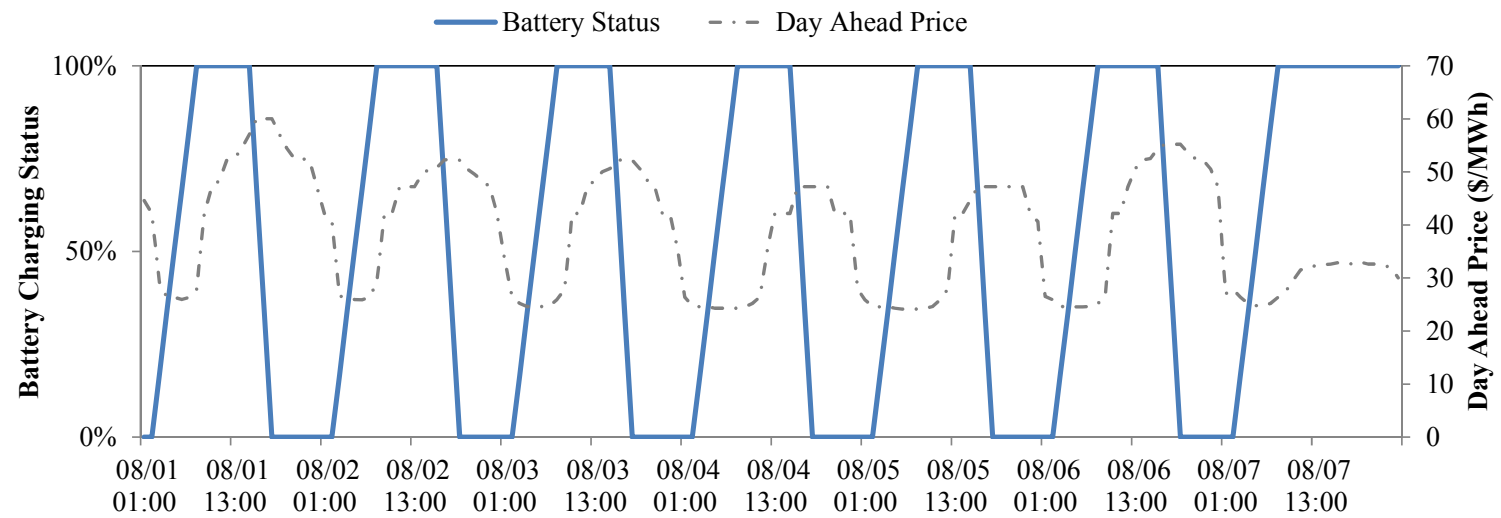

Figure 3.18. Building Stock Battery Storage Hourly Status

As shown in Figure 3.17, the model selected 6 night hours with the lowest electricity price for battery charging, and 3 hours with the highest price (daily peak) to discharge. On the last day of this week, the electricity price is relatively stable, with a daily price spread less than the minimum $20 \$ / \mathrm{MWh}$ required to provide the necessary economic benefit for the use of energy storage. Therefore, the building agent decides not to discharge the battery.

Figure 3.17 also illustrates the amount of peak load reduction that can be achieved in each day by using energy storage. Since the peak load of building stock appears at or is close to the peak electricity price hours, building electricity costs have also been reduced. A comparison of hourly electricity costs of building stocks with and without energy storage is provided in Figure 3.19. 


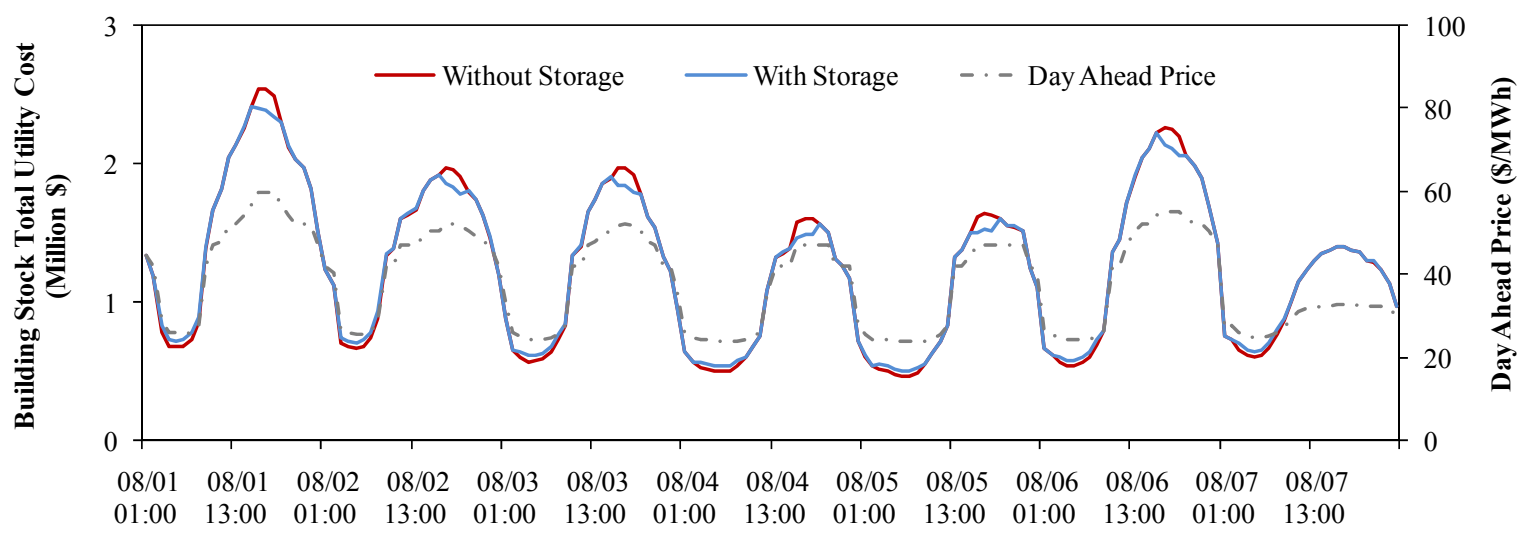

Figure 3.19. Building Stock Total Utility Cost with and without Storage

\subsubsection{Summary}

This report describes a preliminary research performed on simulating commercial buildings as intelligent agents that interact with the power grid. A bottom-up, agent-based prototype model, together with a building stock simulation framework, has been developed in order to analyze several test case studies. By using a macro-model of the electricity supply curve, the dynamic pricing process in the electricity market was also modeled. This simulation is the first attempt to address the role of commercial buildings in a "white-box" hourly simulation approach and how their various demand response mechanisms and energy storage operating strategies may in turn affect the power grid and electricity prices. The monetary savings that can be achieved by the commercial buildings stock are also addressed. These test cases demonstrate the capabilities of the proposed agent-based modeling framework to help with the large-scale simulations of interactions between the commercial buildings and the power grid. With the advance of smart grid technologies and sophisticated energy management systems for buildings, it is expected that commercial building stock will move from its traditional role of relatively passive and inelastic demand to a very active and much more flexible player in the dynamic electricity market. In addition to active management of their electricity loads to minimize energy costs, commercial buildings in the future may also be able to provide certain ancillary services to the power grid and thus obtain additional revenues. Agent-based modeling seems to be an excellent platform for these types of analysis.

\subsection{PNNL's Accomplishments: Development of an Assessment Framework to Analyze Opportunities of Building Thermal Energy Storage to Smooth Wind Power}

Commercial buildings, like any energy-consuming sector, can contribute to low carbon energy infrastructure through two main paths: energy efficiency and integration of renewable generation. The role of storage in general, thermal storage in particular, will be examined in this light.

Electrical storage in the context of (a) mitigating variability of renewable generation, (b) arbitrage by shifting use from system peak periods to off-peak periods, and (c) ancillary electricity grid services has been extensively discussed in the literature. In these applications, the possibility of locating electrical storage in or near commercial buildings is a minor benefit, if at all. In contrast, thermal storage being 
designed to address cooling (and possibly heating) loads in commercial buildings ${ }^{2}$ needs to be located in or near the buildings and becomes an integral part of the building energy infrastructure. Our focus is therefore primarily thermal storage, although the assessment and optimization framework can be applied equally well to electrical storage through a suitable choice of parameters. Thermal storage is not a substitute for electrical storage, if dispatchable electrical power is needed or if fast-responding balancing services are needed. As we discuss below, thermal storage has a significant role in renewable integration and energy efficiency. Thermal storage, being about 10 to 20 times less expensive than electrical storage, is attractive for cases where it is applicable.

At first sight, it would seem that thermal storage, with the ability to only shift the times of energy usage, cannot reduce energy usage and might possibly increase it. However, if the end use of electricity is space-cooling, the round-trip efficiency using thermal storage can be in excess of $80 \%$ whereas typical battery or compressed air round-trip efficiencies are in the $70 \%$ range. When there is overproduction of renewable energy especially wind energy, spilling can be reduced through thermal storage.

Because space-conditioning loads in commercial buildings constitute a significant end use of electricity, thermal storage can be employed to mitigate variability of renewable generation just as well as electrical storage. Optimal sizing and control of storage are very important issues since there are competing needs: reduction of non-wind energy use especially at peak periods, making the profile of net electricity drawn from the grid or fed to the grid more grid-friendly by reducing overall fluctuations as well as ramp rates. In addition, the control strategy should also be chiller-friendly in the way the chiller is cycled.

In the context of planning, renewable generation often gets de-rated for capacity credit because of its intermittency, and electrical storage is deployed to increase capacity credit. Since a significant end use of electricity is for space-conditioning, thermal storage can also provide capacity credit. How this credit is to be determined is an important question.

It is therefore important to develop a framework that addresses the engineering as well as economic issues and determines optimal sizing and control. As a first major step in creating such a comprehensive framework, we have developed a framework primarily intended to address certain technical questions that characterize the role of storage under different control strategies. These characteristics can then be combined with economic considerations. A detailed economic analysis is not part of this initial framework.

\subsubsection{Development of Analysis Framework}

The framework is designed to help answer a number of questions relating to the performance of storage in the context of buildings, renewable generation and the electrical grid.

From an overall business perspective, there are three major objectives:

1. The combination of storage and renewable generation should improve energy efficiency, at least compared to alternative approaches to meeting the system goals $\mathrm{b}$ and $\mathrm{c}$ below. It should help

\footnotetext{
${ }^{2}$ Thermal storage intended for use with concentrating solar power, such as molten salts, phase-change materials, graphite etc are not in the scope of our discussion.
} 
accelerate the penetration of renewable generation thereby contributing to a low carbon infrastructure

2. From an operational perspective, the combination of storage and intermittent generation needs to be grid-friendly. Smaller the fluctuations in the power drawn from the grid or fed into the grid, and, smaller the ramp (up or down) rates the more grid-friendly the combination is. The combination should help reduce peak loads

3. From a utility planning perspective, storage affects the capacity credit assigned by planners to renewable generation. Several approaches to determining capacity credit are reported in the literature. [PJM 2007a; PJM 2007b; Milligan et al., 1997].

The more complex ones require elaborate stochastic reliability evaluations. Simpler approaches providing close approximations can be incorporated in our framework. A comprehensive framework will address these issues combining technology and economics to determine optimal sizing and control of storage. Furthermore, forecast errors in renewable generation and loads should be incorporated into control.

The first major step in developing such a framework has been undertaken in this project. The focal has been to examine technical feasibility and to utilize the framework for answering a limited set of questions. This demonstrates the basic principles as well as the value of the framework.

\subsubsection{Definition of Test Problem}

As a first test, we considered the renewable generation and storage as a system interacting with the grid and the loads. We addressed the question of what are potential control strategies to serve the cooling load in the building and maximizing the smoothing of the wind output. Furthermore, how do the control strategy to serve the building load competes with that serving the grid. We assumed a thermal energy storage application, in which the storage is located in or near buildings. The assumed wind farm may be situated at a considerable distance from the buildings. Any transmission-related issues are assumed to be negligible. The reason for choosing thermal energy storage over electric energy storage was based on the fact that thermal energy technology is mature and already existing. Furthermore, is has significant price advantages, Being 10 to 20 times less expensive than electrical storage.

- The optimization problem is to control storage to meet competing objectives. Given a certain amount of storage and the time series of cooling load profile and wind generation profile, the competing objectives are:Reduce the amount of non-wind electricity used to meet the cooling load.

- Reduce the total electricity used to meet the cooling load

- Reduce electricity used during grid peak hours

- Reduce the fluctuations in the power drawn from and fed into the grid

- Reduce the ramping (up or down) rates.

The optimizer should include the charging and discharging characteristics, cooling system (chillers, storage, pumps and fans) characteristics. The optimization variables are the charging and discharging rate. Many of the constraints are naturally formulated in terms of additional variables. The net result is 
that the optimizer needs to handle something like four or five variables for each time interval. The number of variables can easily run into thousands. There are some nonlinearities in these processes. A nonlinear optimization involving a large number of variables has many pitfalls. For the purposes of this framework, good linear approximations are possible and are used. Also, for the purposes of the initial study, the time interval used is one hour.

The mathematical details of the framework are given in a separate report.

\subsubsection{Results and Discussion on the Potential Contribution by Buildings}

In this section, an optimization problem is studied using the framework developed under this project. The problem is, given wind generation and cooling load profiles, and a certain storage, how to optimally charge and discharge storage to meet the cooling load through a combination of direct cooling and storage discharge while best meeting competing objectives mentioned before - to reduce energy use especially during peak periods, increase energy fed into the grid especially during peak hours, while being gridfriendly - reducing amplitudes and ramp rates of power fed into or drawn from the grid.

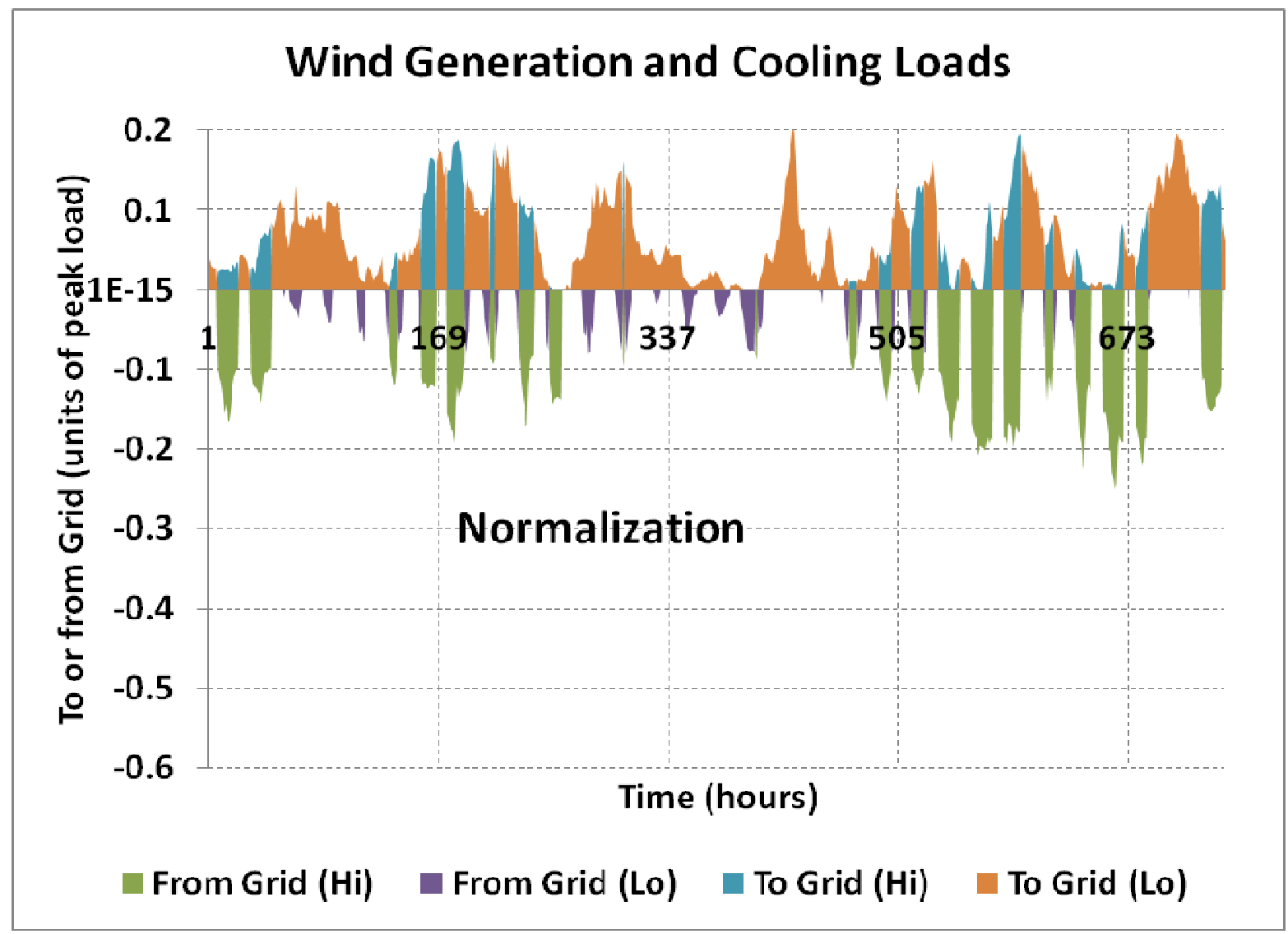

Figure 3.20. A Plot of Wind Generation and Cooling Profiles for the Period of Analysis ( 1 month $=744$ hours) (The scales are chosen for visual consistency with graphs to follow)

First consider the wind generation and cooling load profiles. This graph shows typical wind generation and cooling load profiles for a one-month ( 744 hours) period; each major grid represents a week. The Hi and Lo refer to hours that have been designated peak and off-peak hours. Although normal 
utility pricing practice is to use time-of-day for such designation, it is more common in utility planning to designate a certain percentage (30\% is typical and used in this study) of the highest load periods as peak periods. This designation is an input to the framework and can be modified easily by changing the input.

It is important to normalize loads as well as wind generation. The cooling load is normalized such that the load is measured in units of peak load. It is furthermore necessary to convert thermal loads to electrical loads to address questions such as how big a wind farm is needed to meet the cooling loads (from a set of buildings). A detailed and complex answer incorporating the cooling system characteristics is possible. For the purposes of this study, a constant coefficient of performance is assumed. The wind generation time series are normalized such that the total wind generation for the entire interval is a given multiple of the total electricity needed to meet the cooling loads. This parameter is an input to the framework. Storage and retrieval incurs energy penalty compared to direct cooling and so, with storage, total wind generation to just meet the cooling has to be a factor greater than one; this factor is sensitive to the characteristics of direct cooling as well as of charging and discharging. (Note that even when adequate charge is available for meeting the cooling needs, a certain amount of electricity is needed to run pumps and fans.) Larger factor results in net power flow into the grid, and a smaller factor results in net draw from the grid. A factor of 1.4 was used in generating the results presented.

\subsubsection{Case 1: Absence of storage and direct cooling using wind generation}

In the absence of storage, the cooling load requires a certain amount of electricity. This is subtracted from wind generation, and if the net is positive, the excess generation is fed into the grid; if it is negative, the deficit is made up by drawing power from the grid. The net power flow is shown in the following figure. Peak and off-peak hours are shown in different colors. As can be seen from the plot, there are significant periods, especially peak periods, when the wind generation is not enough to meet the cooling loads, and a small number of peak hours when wind generation exceeds the cooling needs. 


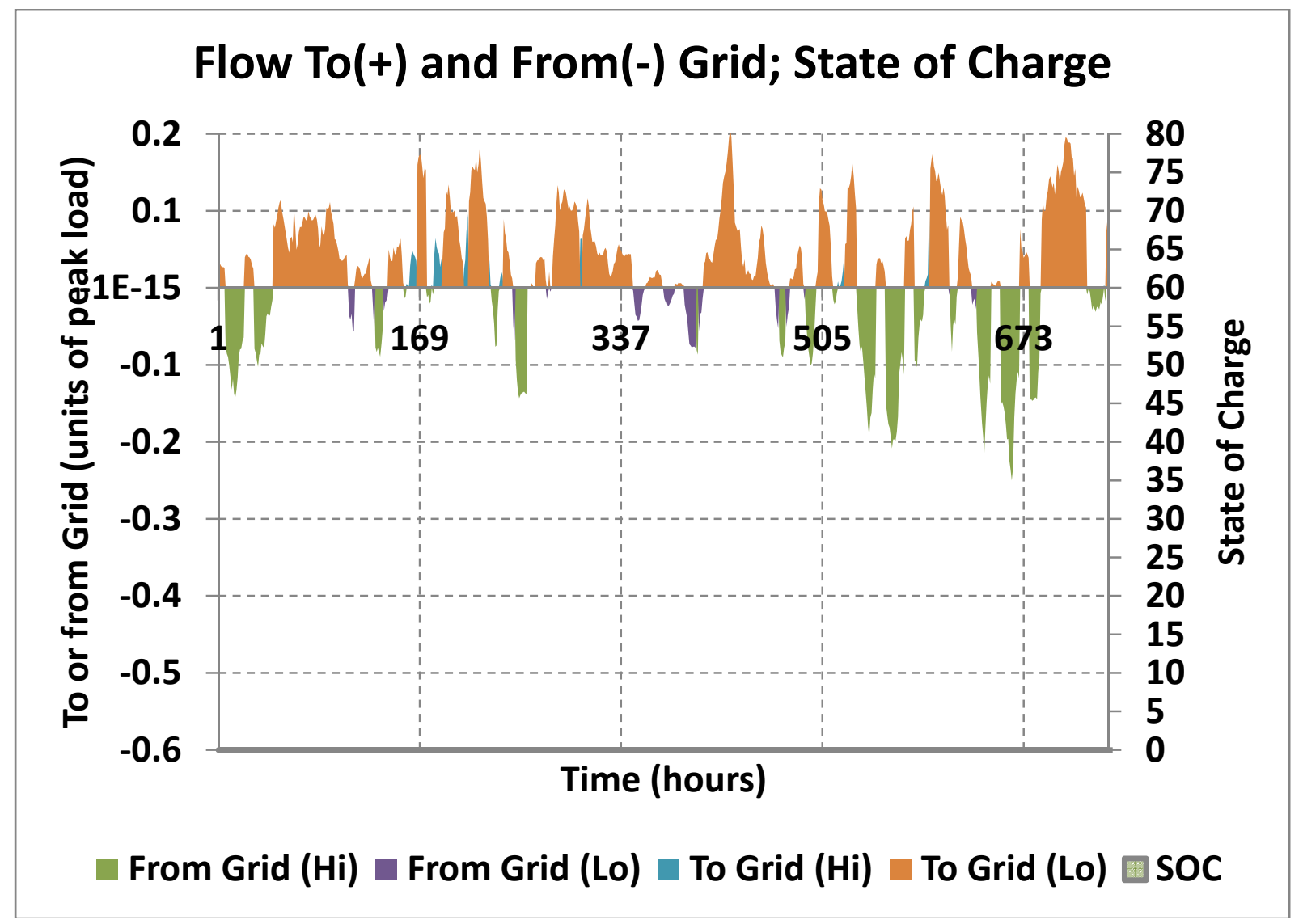

Figure 3.21. A Plot of Net Electricity Flows to (positive) or from (negative) the Grid with No Storage. Peak and off-peak hours are distinguished by the colors. The state of charge is included for visual comparison with plots with storage.

When storage enters the picture, there are many different ways of control (i.e., charging and discharging subject to the constraints) depending on the objective. In what follows, we will examine the results of controlling to meet different objectives, or in some instances multiple objectives. The objectives can be broadly classified as (a) energy-related - reducing power draw from the grid possibly with emphasis on peak hours, increasing power feed into the grid possibly with emphasis on peak hours, and (b) grid-related - increasing grid-friendliness by decreasing swings in power flow as well as ramps. As is commonly the case, multiple objectives cannot all be met without compromise. Even within a single class of objectives, for example the energy-related objectives - whether or not a distinction is made between peak and off-peak hours - requires compromises. The purpose of the framework is to provide capability to address these issues. Additional issues such as capital costs of storage, wind generation, capacity credit require further refinements. 


\subsubsection{Case 2: optimal storage control minimizing electricity from grid and maximizing electricity to the grid}

The following graph shows the optimum charging and discharging under the conditions of minimizing the total electricity drawn from the grid and maximizing total electricity fed into the grid. No distinction is made between peak and off-peak hours. It must be noted in all the graphs that even if the cooling load can be met by discharging storage for a particular hour, electricity is still needed to run pumps and fans as determined by the parameters entered into the model. The state of charge i.e., the amount of charge in storage is also shown. Note that on a few occasions, the storage is fully charged. The storage was constrained to start and end in a fully discharged state. This results in some initialization and finalization dependence; for long enough analysis periods, such as one month we are using, this dependence is not large. A daily or even weekly analysis would show large effect.

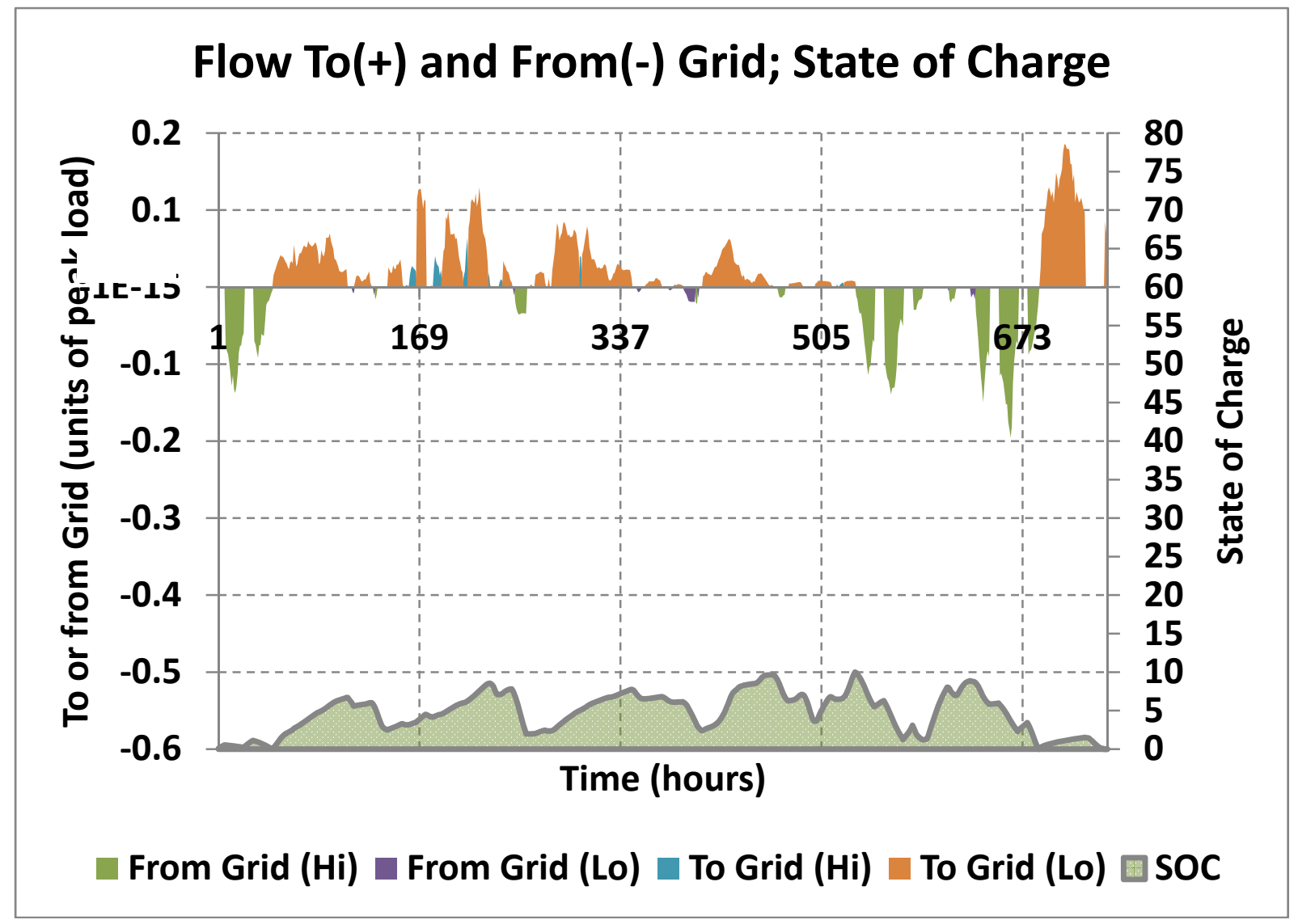

Figure 3.22. A Plot of Net Electricity Flow to (positive) or from (negative) the Grid with a Storage of 10 (in units of peak-load hours), Controlled to Minimize the Power Draw from the Grid (area above the zero line). No distinction is made between peak and off-peak hours, even though they are plotted with distinguishing colors. 


\subsubsection{Case 3: optimal storage control minimizing electricity from grid and maximizing electricity to the grid with peak generation priority}

The following graph shows the optimum charging and discharging under the conditions of minimizing the total electricity drawn from the grid and maximizing total electricity fed into the grid. Peak hour draw is weighted more heavily and peak hour feed into the grid also is weighted more heavily. This accounts for the large difference between this and the previous graph. Large off-peak draws are permitted thereby resulting in a grid-unfriendly profile.

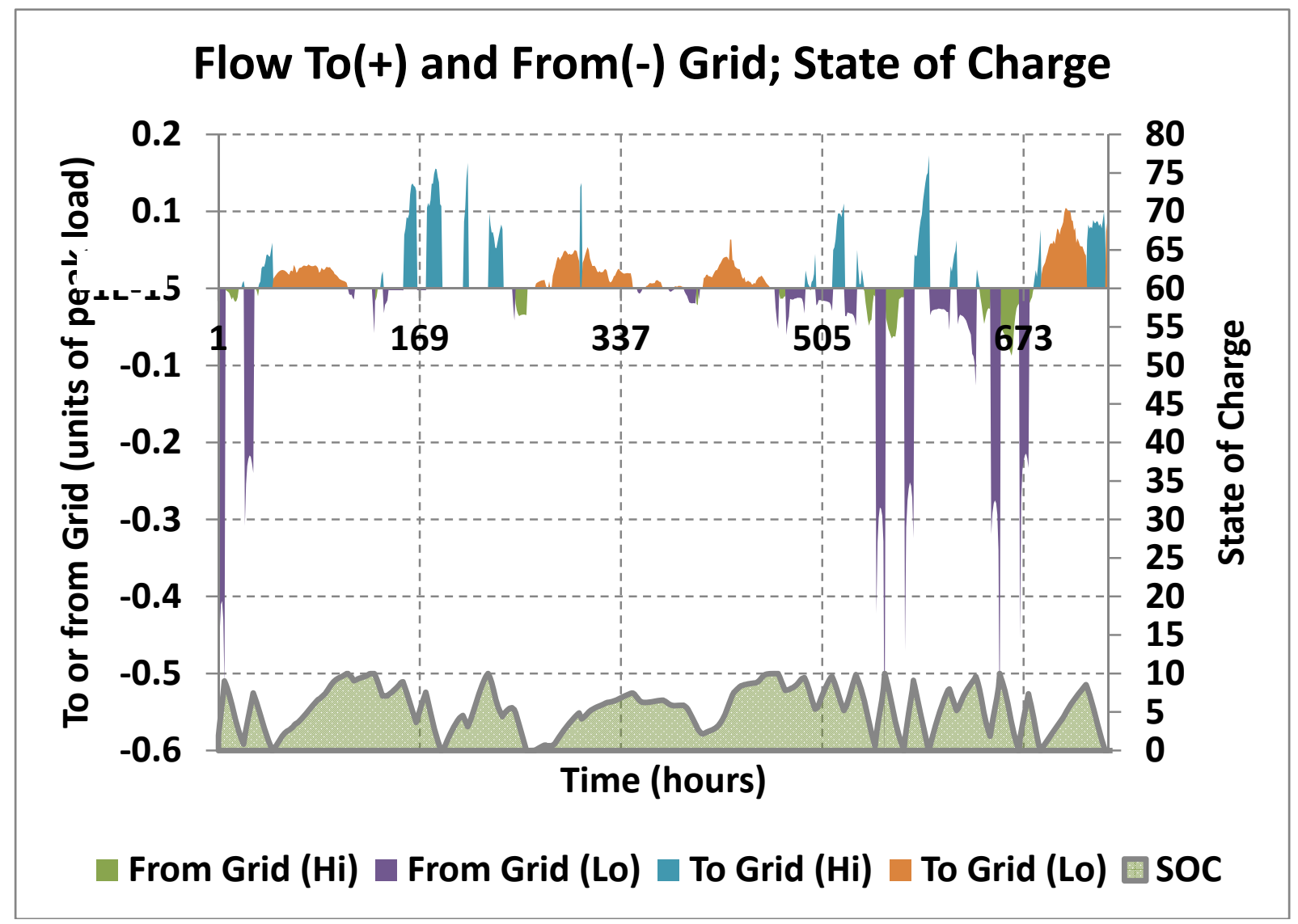

Figure 3.23. A Plot of Net Electricity Flow to or from the Grid with Storage of 10, Controlled to Minimize the Power Draw from the Grid and Maximize Power Feed into the Grid; Peak Hours are more Heavily Weighted than Off-peak Hours. 


\subsubsection{Case 4: optimal storage control with demand and generation limits}

To make the storage more grid-friendly, we will limit the maximum draw from the grid or feed into the grid. The resulting optimal solution is shown below. This still discourages draw from grid during peak hours and encourages feed into the grid during peak hours. The difference between this and the previous graph is limiting the draw from or feed into the grid.

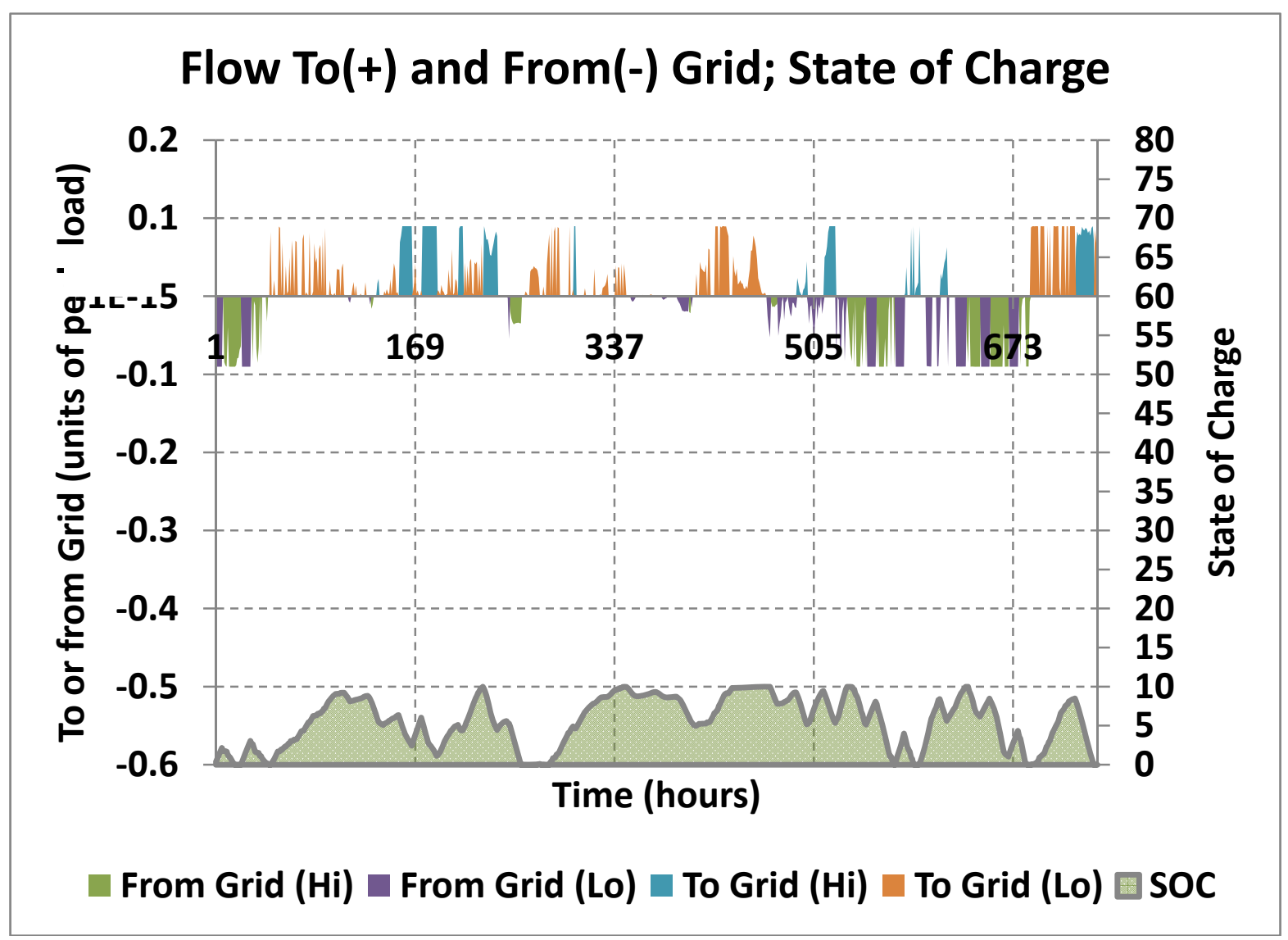

Figure 3.24. A Plot of Net Electricity Flow to or from the Grid, Controlled to Minimize the Power Draw from the Grid and Maximize Power Feed into the Grid while Constraining the Maximum Flow; Peak Hours are more Heavily Weighted than Off-peak Hours. 


\subsubsection{Case 5: optimal storage control with demand, generation, and ramp rate limits with peak priority}

In Figure 3.24 although we see the maximum flow in constrained, there are still changes in the flow resulting in significant ramps. If in addition we discourage ramps, we get the optimum solution depicted below. This results in a more grid-friendly profile.

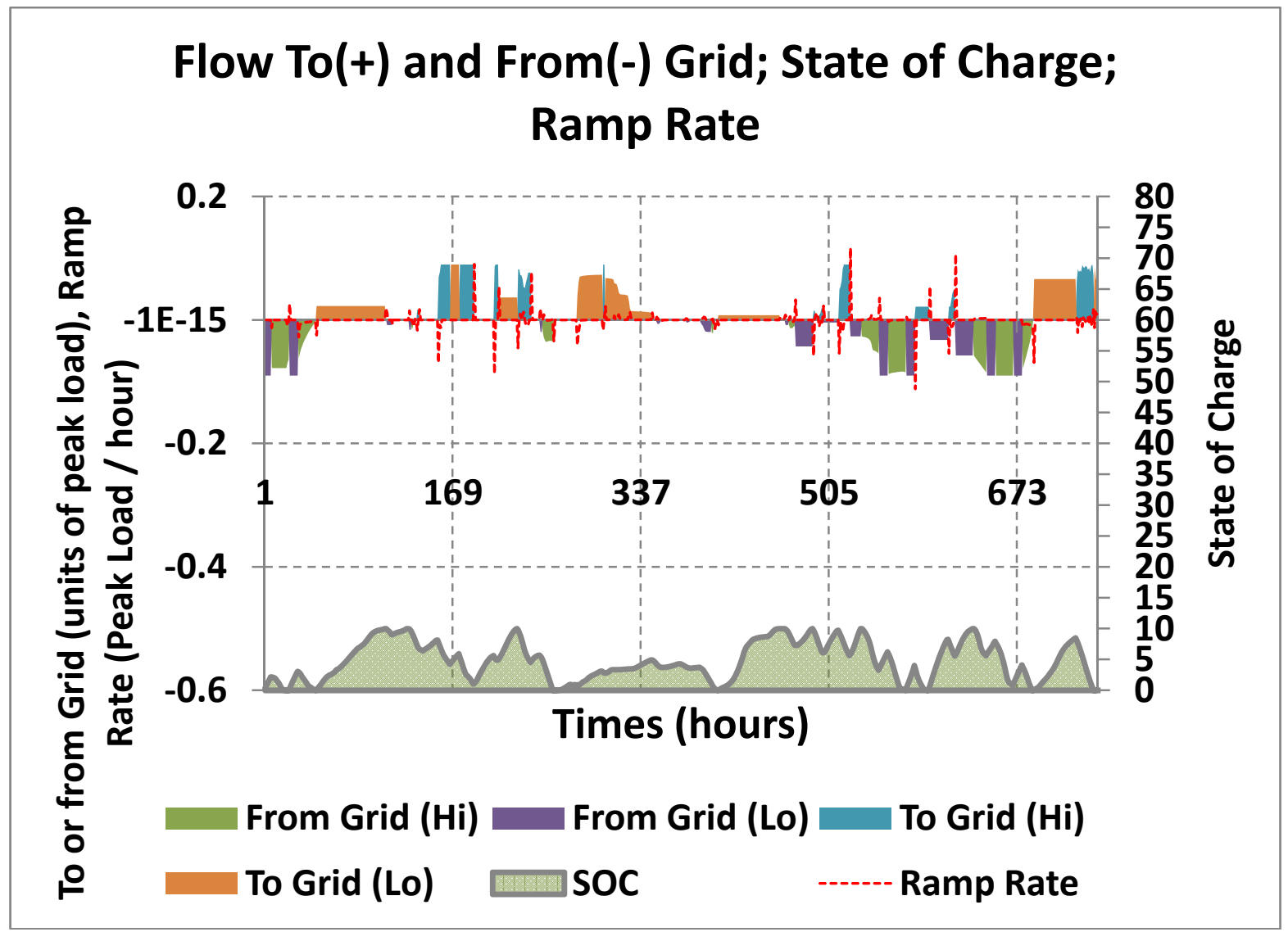

Figure 3.25. A Plot of Net Electricity Flow to or from the Grid, Controlled to Minimize the Power Draw from the Grid and Maximize Power Feed into the Grid as well as Minimizing Ramps While Constraining the Maximum Flow; Peak Hours are more Heavily Weighted than Off-peak Hours. 


\subsubsection{Case 6: optimal storage control with demand, generation, and ramp rate limits without peak priority}

In Figure 3.25, because we weigh peak hours more heavily, during the transition from off-peak to peak (or peak to off-peak) larger ramps can be compensated by energy considerations. Discouraging electricity use during certain hours automatically encourages higher use in between peak hours thereby adversely affecting the ramp rates. When we do not make the distinction between peak and off-peak, ramps can be further reduced as seen in Figure 3.26.

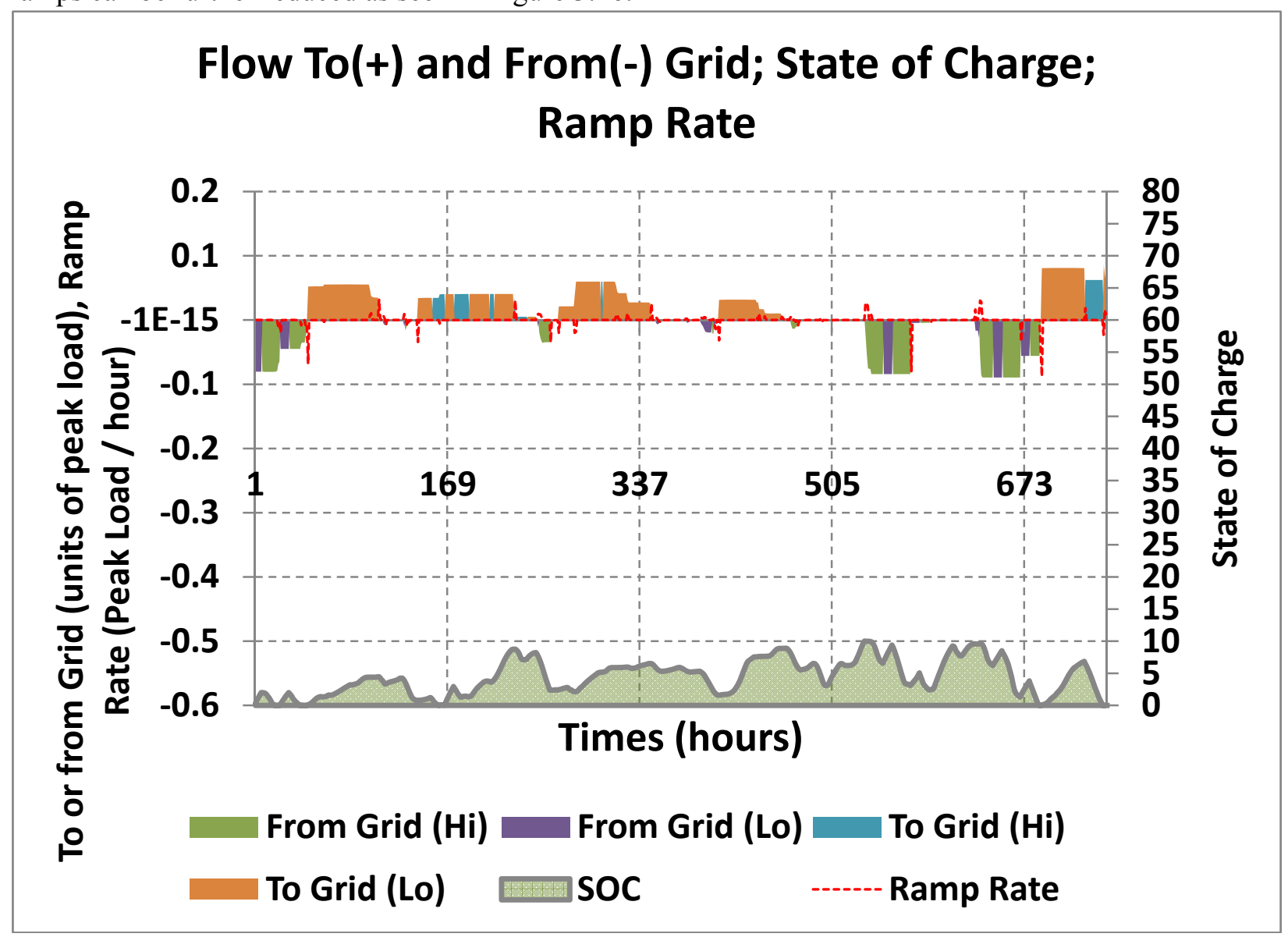

Figure 3.26. A Plot of Net Electricity Flow to or from the Grid, Controlled to Minimize the Power Draw from the Grid and Maximize Power Feed into the Grid as well as Minimizing Ramps While Constraining the Maximum Flow; No Distinction is made Between Peak and Off-peak Hours.

Let us recall three situations, consolidated from Figure 3.21, Figure 3.23 and Figure 3.25, as plotted in Figure 3.27: Net of wind generation and cooling loads seen by the grid with no storage (top plot), with storage controlled for "Energy" - to minimize energy use during peak periods (middle plot), and with storage controlled for a combination of "Energy" and "Grid". Although the bottom graph shows a much more grid-friendly profile, this is accomplished at the cost of increased energy use during peak hours. The precise details depend on how the objective functions are defined and the relative weights given to energy and grid considerations, but the general trends can be seen from the plots. 


\section{No Storage(Top), Storage controlled for Peaks (Middle), for Peaks and Grid-friendliness (Bottom)}

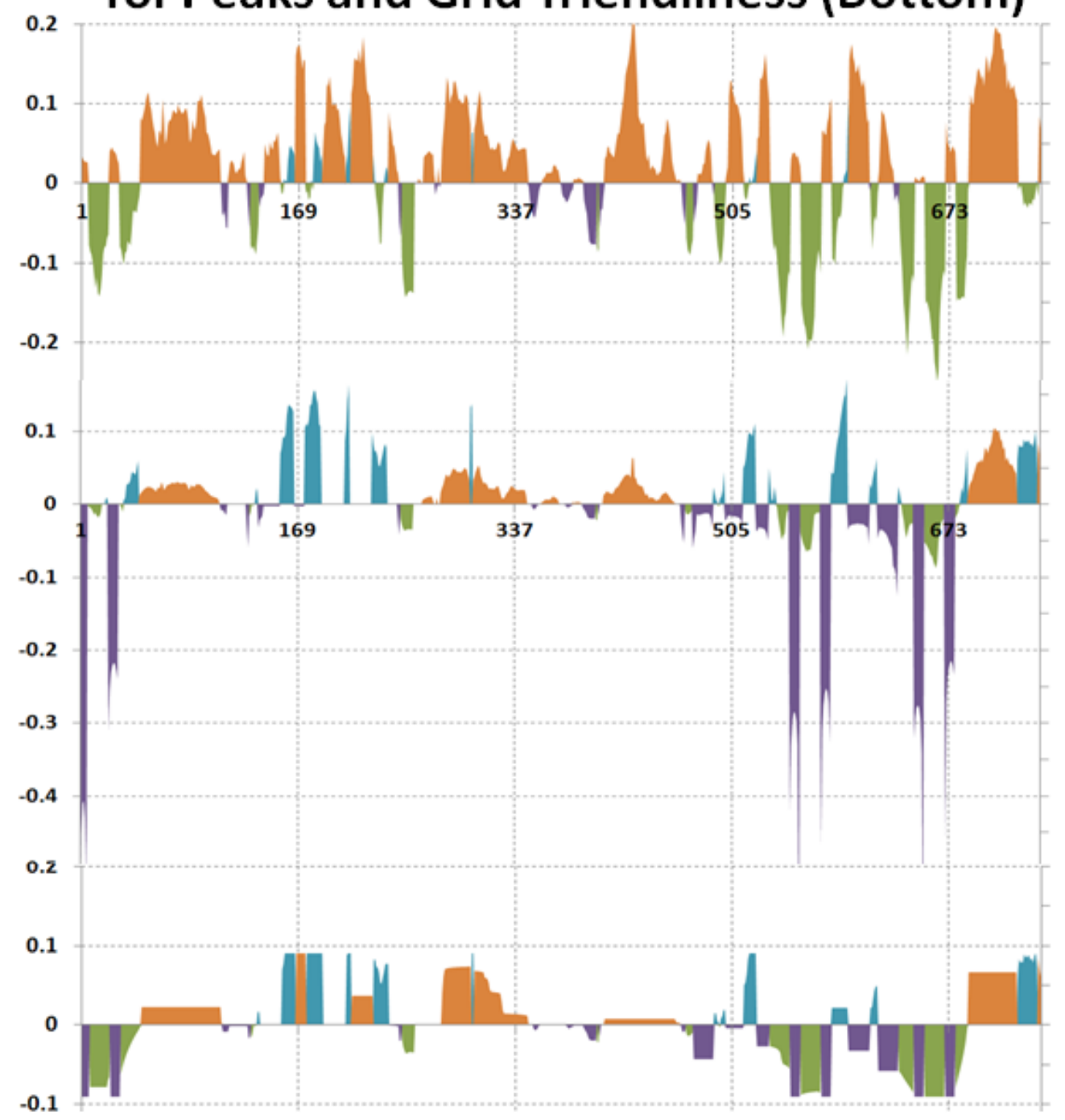

Figure 3.27. A Plot of Net Electricity Flow to or from the Grid. Top: no storage, middle: storage controlled for "energy", bottom: storage controlled for "energy" and "grid".

\subsubsection{Case 7: optimal storage control with large storage}

Increasing the storage addresses the problem of increased peak energy usage. In Figure 3.28, the effect of increasing the storage from 10 to 20 peak-load-hours is shown. The control strategy is the same but there is more storage available to accomplish the dual objectives relating to energy and grid. A gridfriendly profile can be maintained without exacerbating energy usage during peak hours (some initialization effects occur during the first few hours that are not of real concern). Also shown in Figure 3.28 are the ramps. Whenever there is a transition between peak and off-peak ramps tend to increase. 


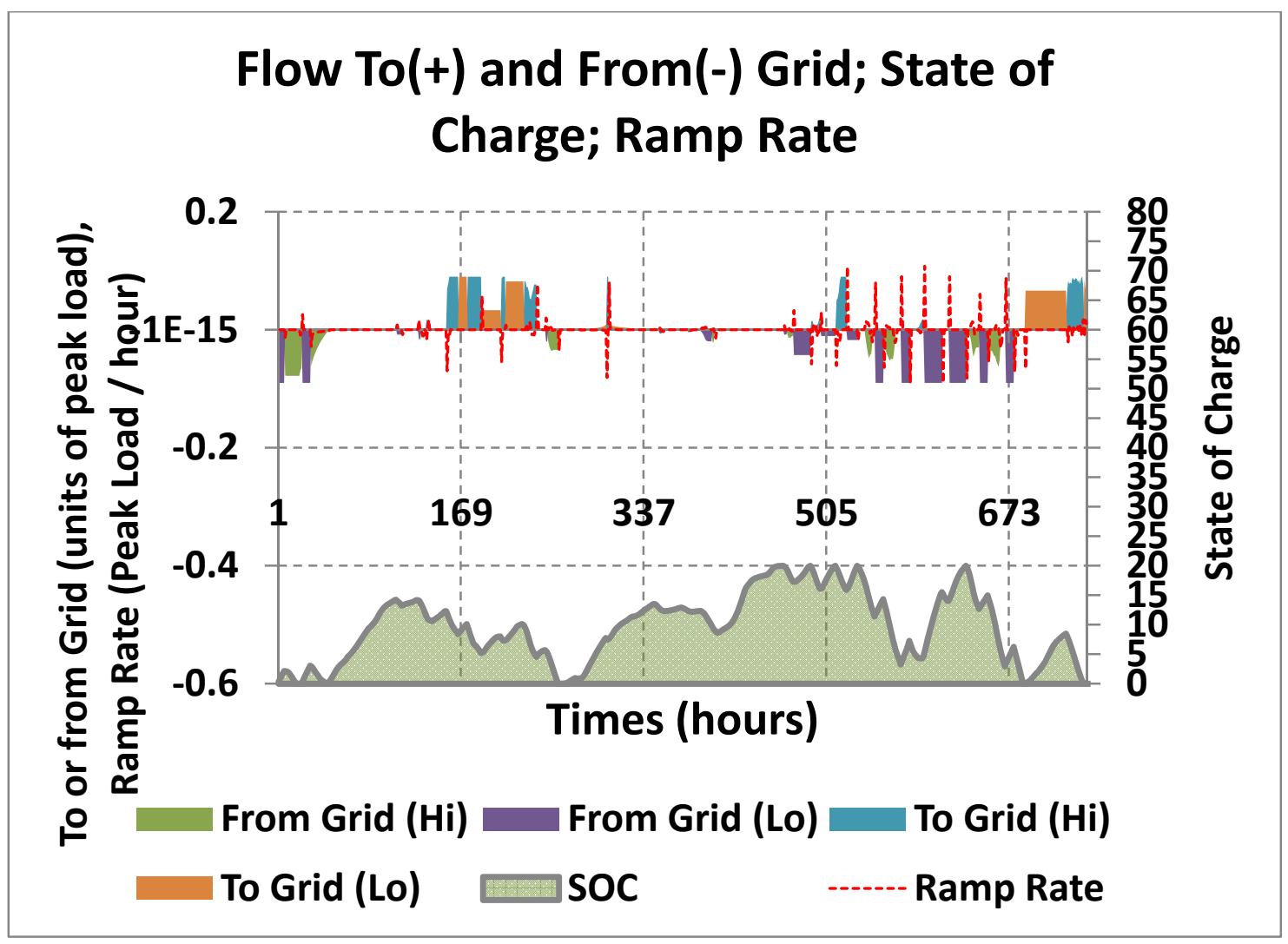

Figure 3.28. A Plot of Net Electricity Flow to or from the Grid. The control strategy is the same as in Figure 3.25. The only difference is that the storage has been increased from 10 to 20 units.

We will look at the 4 cases - the three cases from Figure 3.27, and the one case from Figure 3.28 from a perspective of smoothing capabilities:

A histogram of the power flow from and to the grid is shown in the Figure 3.29. It is important to remember that large bars imply large number of hours for the bin; it should not be confused with the magnitude of the flow (which is given by the vertical axis). The more the distribution peaks tightly around zero, the better for the grid. The benefits of storage are apparent from this figure - renewable generation can be integrated in a much more grid-friendly manner with storage. 


\section{Histogram of Power Extracted from or Fed into the Grid}

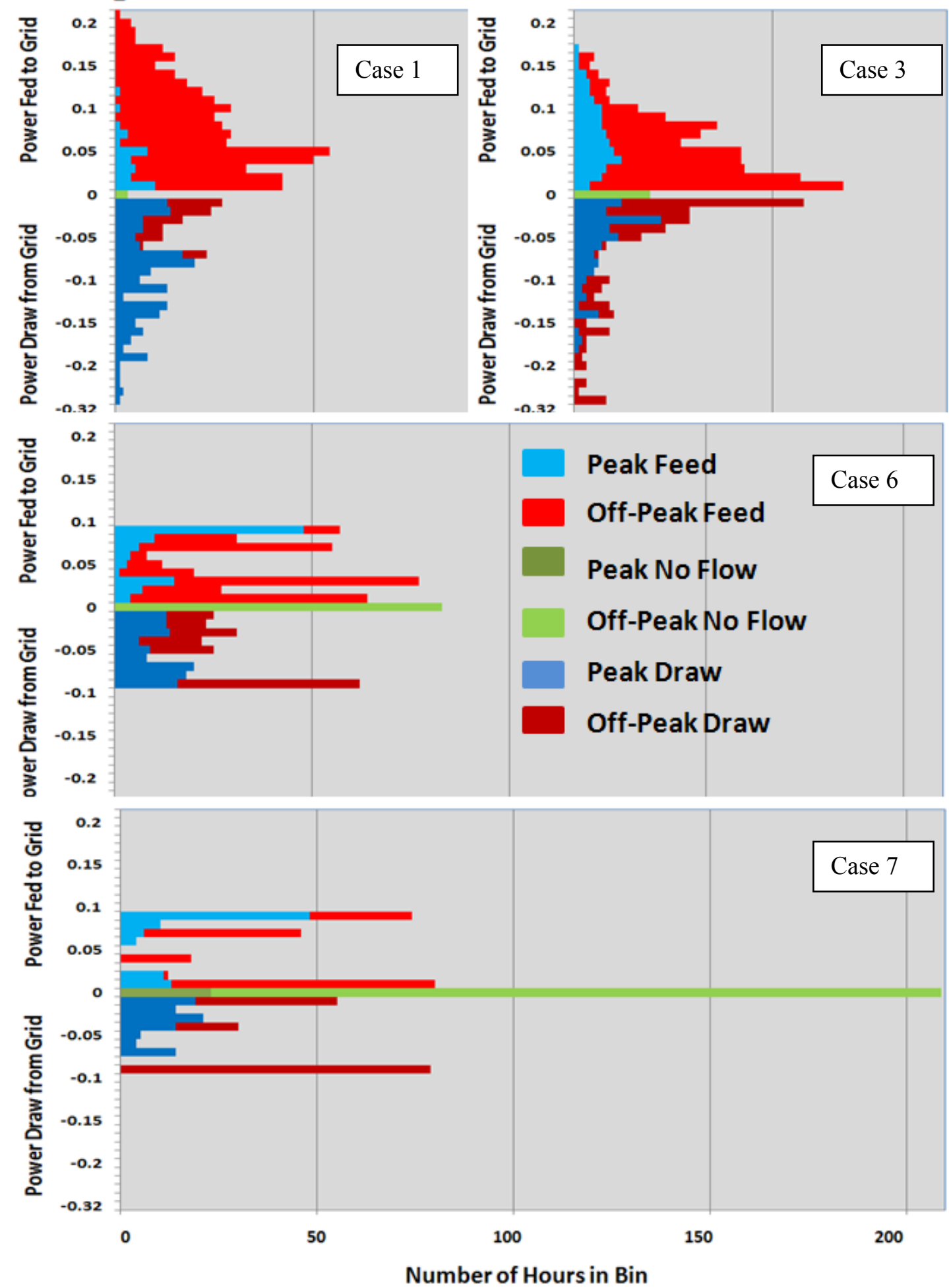

Figure 3.29. Histograms of the Number of Hours in the Month that the Grid Experiences the Power Flow for the Bin. The four plots refer to the four cases explained in the text. 
A histogram of the ramp rates is shown in the Figure 3.30. (The x-axis is plotted on a logarithmic scale.) There is no significant improvement, if any, from case 6 to case 7 . This is a reflection of the relative weights given to peak-load-friendly profile versus grid-friendly profile. Furthermore is indicates the diminishing benefits of upsizing the size of the energy storage.

Histogram of Ramp Rates

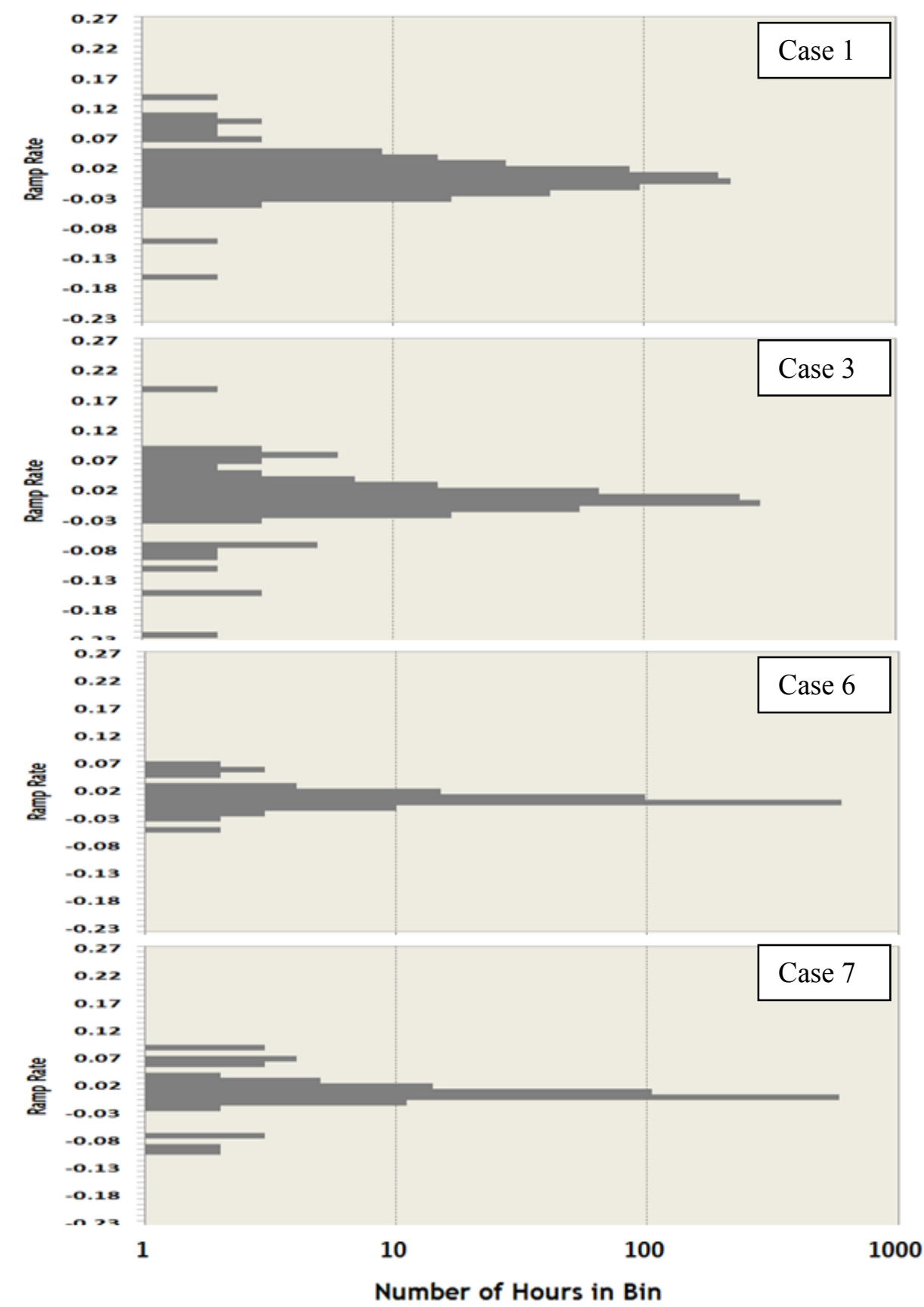

Figure 3.30. Histograms of the Number of Hours in the Month that the Grid Experiences the Ramp Rate for the Bin. The four plots refer to the four cases explained in the text. Note the logarithmic scale of the horizontal axis. 
The total energy flow to and from the grid aggregated separately over all of 223 peak hours and 521 off-peak hours of the month are shown in Figure 3.31. As mentioned before, the control penalized on-peak draw from the grid and rewards on-peak feed into the grid. The effectiveness of storage in accomplishing this is apparent.

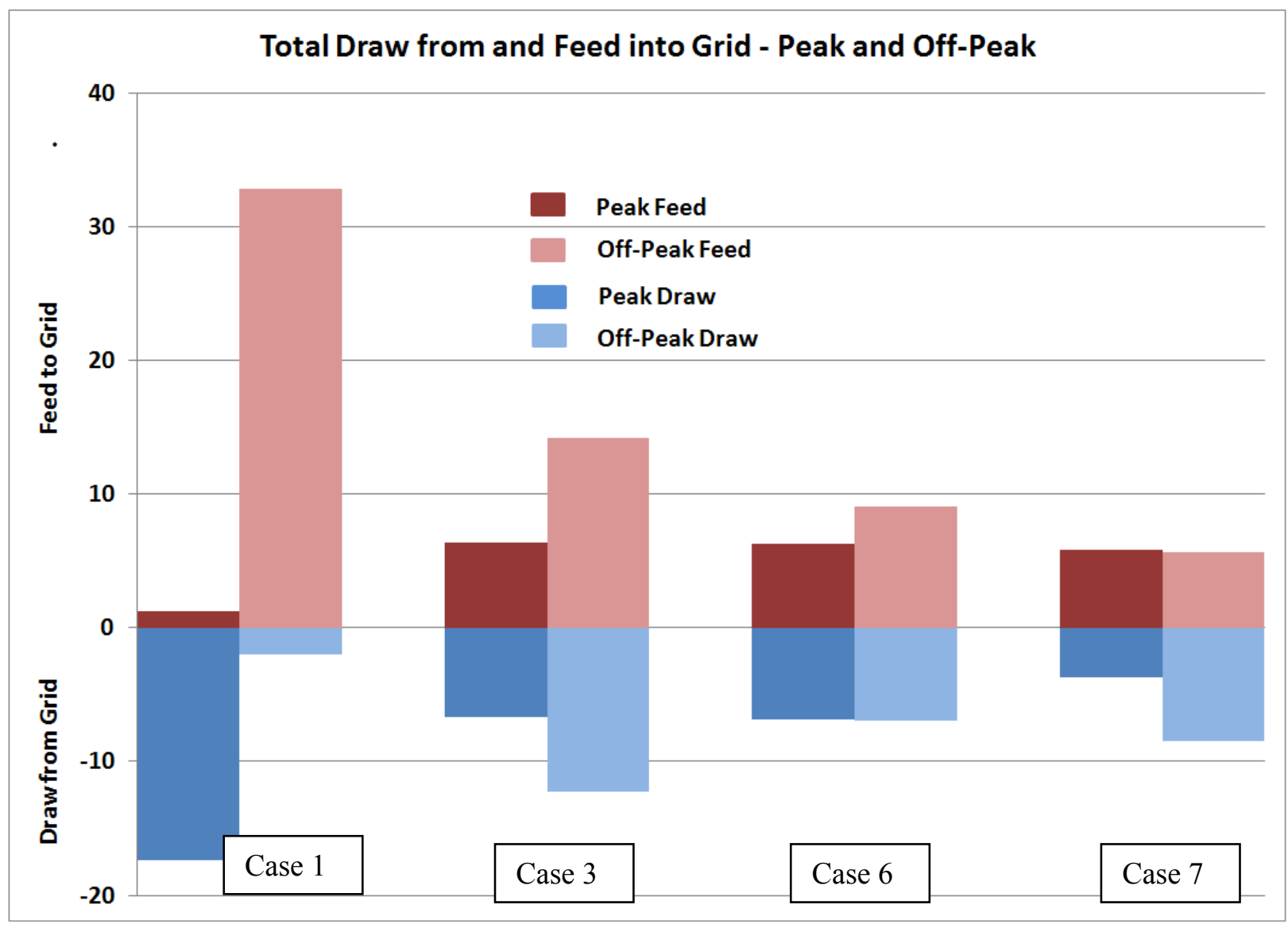

Figure 3.31. Total Energy Flow to and from the Grid Separately Aggregated over all Peak and Off-peak Hours. The four plots refer to the four cases explained in the text.

We have seen how we need to deal with multiple objectives. In the Introduction these were broadly classified as energy-related and grid-related; within each class we can have multiple objectives. When multiple competing objectives need to be addressed, one can assign relative importance for these objectives, and minimize the resulting single objective function, as we have done so far. A more detailed analysis can be performed to explicitly help understand these multiple objectives. A common method is to examine the efficient frontiers sometimes referred to as Pareto frontiers. Figure 3.32 shows the Pareto frontiers for the dual objectives of maximizing energy and grid benefits, for various storage values. 


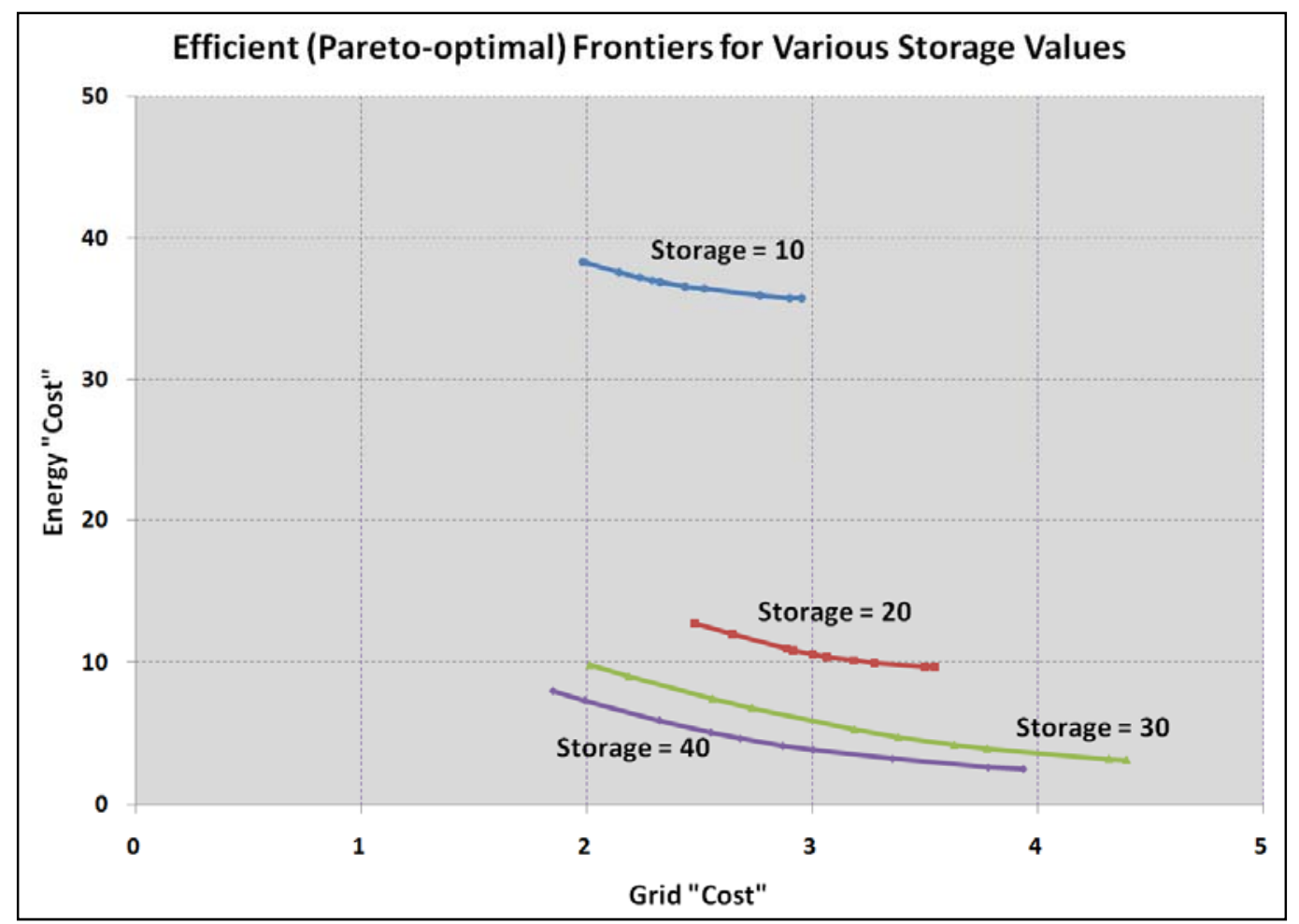

Figure 3.32. Pareto Frontiers for the Dual Objectives of Maximizing Energy and Grid Benefits, for Various Storage Values

To further study optimal sizing and control of storage, it is necessary to address the question of valuation of a more grid-friendly profile, the cost of storage, characteristics of charging and discharging equipment, and the impact of modulating such equipment on the life expectancy and maintenance costs. The valuation of the grid-friendly profile can be done by considering capacity credit for planning purposes as well as the operational benefits. If low-cost thermal storage can significantly enhance capacity credit, it will have a favorable impact on more widespread adaptation of renewable generation. A thorough study of operational benefits requires a study with smaller (than one hour) time steps.

The framework was used to study cooling load from one representative location and wind generation from one representative wind farm. It is essential to study longer term such as annual performance under different load and wind generation scenarios. Also, only cooling season was considered in employing thermal storage. The role of storage in different seasons as well as the possibility of using seasonal storage through such mechanism as ground needs to be studied.

The framework developed so far along with the enhancements discussed above can be used to study national impact with statistically motivated renewable generation and load profiles. A distinction needs to be made between space-conditioning loads which can be addressed by thermal storage and the rest of the system loads. Thermal storage cannot address the problem of meeting generation requirements during periods of very low wind generation. A possible approach is to combine wind generation, thermal storage and existing distributed generation. 


\subsubsection{Conclusions}

Storage is well-recognized as important in addressing renewable integration with the grid. Thermal storage also is recognized as important in shifting peak electrical loads in buildings. In this report we have developed a framework to address the following three questions:

- What is the role of thermal storage in or near buildings, with its potential for higher round trip efficiency than electrical or compressed air storage.

- How can building thermal storage contribute to a low-carbon energy infrastructure by increasing the capacity credit for renewable generation thereby making it more attractive in the generation mix for the utilities.

- How can building thermal storage make renewable generation more grid-friendly by mitigating the problem of intermittency of renewable generation.

The framework was employed in a limited study to demonstrate the potential for storage as well as the capabilities of the framework. Additional studies and enhancements needed to determine optimum sizing and control have been pointed out.

\subsection{NREL's Accomplishments: Support of Building Simulations and Case Study with John Deere}

With the uncertainty in securing the raw energy resources needed to maintain "business as usual," and emissions from energy conversion processes leading to harmful environmental impacts, there is a great need for energy efficiency and optimization from a whole-system perspective. For example, when considering a given commercial building, which likely sources a large portion of its energy needs from the electric power grid, one must trace not only building-specific inefficiencies but also those in the distribution, transmission, and finally in the source generation to determine the building's source energy consumption and overall environmental impact. Such analysis becomes more complex by the fact that the electric grid is supplying power to other commercial buildings, residential neighborhoods, and industrial processes in parallel and the given commercial building cannot be examined in isolation to gauge its overall impact; ascertaining relative impacts can also be a cumbersome analysis. However, focusing on understanding how whole-system operation can be made more efficient is crucial, and can proceed through coupled analyses, identification of shared goals, and implementation of technologies enabling more efficient and cleaner operation.

There has been much progress in industry awareness and implementation of renewable energy systems, moving the US towards a sustainable and clean energy future. However, there has been an insufficient amount of research directed at uncovering the interactions among the various energy supply and demand systems - thus fully taking the intermittent nature of renewable system performance into consideration. Energy storage has been identified as a vital, yet largely neglected facet of this sustainable and clean energy future because it is a bridge toward a smart grid where many engineered systems are orchestrated to allow multi-objective goals to be optimized. Understanding whole-system interactions and how they can be enhanced through energy storage will allow superior dispatch of generation equipment such that energy efficiency is maximized and negative environmental impacts are minimized. With the increased adoption of on-site renewable generation equipment in commercial buildings - such as photovoltaic panels or wind turbines - this need is further emphasized because the building acts as both 
a generator and consumer of electricity. With higher levels of renewable penetration the intermittent generation makes the whole-system less stable and results in increased losses because supply is not wellmatched to demand. Both problems can be resolved with energy storage, as well as many others where benefits are derived from decreased uncertainty in generator availability and increased part-load performance.

This research takes a top-down approach in analyzing energy interactions and accessing how various energy storage technologies enhance operation and performance. An initial literature review showed the wide range of successful energy storage technologies, applications, and projects, which hinted at potential progress. A second study gathered the insights and opinions of experts in the energy storage domain, and identified shared goals for energy storage in both commercial buildings and the electric power grid; lessons learned from many practical and research projects were established. The following sections document the progress that has been made thus far with respect to commercial buildings and on-site energy storage technologies. Section 3.5.1 demonstrates the value of energy storage in the general case for commercial building with increasing levels of renewable penetration, which motivates further applications of energy storage for smart grid concerns. Section 0 documents the strategy for classifying electrical load profiles of the United States' commercial building stock, which allows both temporal and spatial aspects of energy storage needs to be identified and technologies to be recommended. Section 3.5.3 outlines a case study where the building owner seeks to retain otherwise wasted generation by storing thermal energy to offset the next day's HVAC requirements and avoid selling electricity back to the utility at a small fraction of its purchase price. The results herein present the case for energy storage for whole-system energy efficiency and reduced emissions.

\subsubsection{The Value of Energy Storage in Commercial Buildings}

As briefly mentioned, determining a given commercial building's source energy consumption and overall environmental impact is difficult because of the building's many interdependencies which do not allow the analysis to take place in isolation. Nonetheless, it is of interest to examine how storage is valuable to an individual commercial building - especially considering the addition of renewable energy sources, which have become so attractive to building owners in recent years. Toward this goal a prototypical/reference medium office building, representative of the United States building stock as obtained through 2003 CBECS data [EIA, 2006] and modeled in EnergyPlus 5.0 (DOE, 2010), was used in hundreds of simulations to access the impact of electrical energy storage when a building uses increasing levels of photovoltaic panels and electrical storage capacities. The following subsections give a cursory overview of the background, modeling assumptions, and supervisory control tactics to arrive at the final result. It should be noted that this preliminary study is meant to unravel how energy storage can influence source energy consumption from purely a physical perspective, i.e., life cycle cost analysis and/or other payback analyses are not considered at this point. An overview of the study is given below.

Medium Office Building: The prototypical/reference medium office building is assumed to be in Phoenix, Arizona and has three floors with a total floor area of 4,982 $\mathrm{m}^{2}\left(16,345 \mathrm{ft}^{2}\right)$. The building has an aspect ratio of 1.5 and a window-to-wall ratio of 0.33 . The steel frame construction building has a built-up flat roof, insulated entirely above deck, and is assumed to have a core zone and four perimeter zones on each floor. The HVAC system type is a multi-zone variable air volume system. The heating is provided by a gas furnace. Cooling is provided with packaged air conditioning units. 
Generation: To mimic the electric power grid, and the site energy that would be required to operate the building, six microturbines were implemented and staged to meet the building's power demand at any given moment; the prescribed cumulative power of the staged microturbines was oversized by $15 \%$ (as compared to the yearly peak electrical power demand) to ensure the electrical loads were always met. Mimicking the site electricity of the building allows one to ascertain the amount of electricity that would have to be supplied by the utility, which can later by multiplied by hourly measured source-to-site factors to obtain a good approximation of the source energy required to meet this given commercial building's electrical demands. Furthermore, the extent to which a given commercial building utilizes source energy will correlate well with the emissions.

Site-to-Source Factors: Hourly source-to-site factors have been obtained for the Arizona and New Mexico area, thereby being applicable to this investigation located in Phoenix. The hourly values include losses from generation, transmission, and distribution. Thus they represent the actual primary energy consumed during building operation. The use of photovoltaic panels coupled to energy storage will tend to decrease primary consumption, and therefore also emissions, to the extent the photovoltaic panels and energy storage combination can be harnessed. It should be noted that the source-to-site factors are from completely nonrenewable sources, i.e., coal-fired power plants, gas turbines, and nuclear plants that serve the Arizona and New Mexico area where the data was measured.

Photovoltaic panels: The detailed photovoltaic panel, as modeled in EnergyPlus software, has been utilized in this analysis. The amount of photovoltaic panels used in the investigation was assumed to be a fraction of the total roof area from 0 to $100 \%$ in 5\% intervals. Furthermore, for a good annual utilization the tilt angle of the panels are assumed to face due south with a tilt angle of 40 degrees.

Energy Storage: A simple energy storage model from the EnergyPlus software has been used to approximate battery storage. The charging/discharging efficiencies are assumed to be $90 \%$ each way. The charging /discharging rates and capacities are assumed to perform approximately as lead-acid batteries. For sizing the capacity of the energy storage, the worst-case scenario was assumed to be a weekend when the building electrical load is approximately zero and the maximum PV panel size is generating electricity during sunny days. That is, the worst-case storage needs occur with a total roof area of PV and an entire weekend-worth of generation needs to be stored. This equates to approximately $5,000 \mathrm{kWh}$, which is the battery capacity of around 100 Tesla Roadster cars.

Supervisory Control: The energy management system techniques to control the storage of generation are: 1) if the PV generation is larger than the whole-building electrical demand at any given moment then store it by charging the battery, 2) if the PV generation is less than the whole-building electrical demand then use the battery to meet the remaining load, until discharge rate or remaining charge constrain the load matching, and meet the remaining demand with the microturbine generation, and, 3) if PV generation is equal to building demand then do nothing.

Results: The results from the investigation seeking to explore the value of energy storage in commercial buildings utilizing renewable generation are illustrated in Figure 3.33. The figure is presented from a physical perspective and no cost information is contained within. The reasoning for disregarding cost information is to show the synergistic impact on source energy consumption from using both renewable generation and energy storage, where it is noted that there are hundreds of different energy storage technologies and control strategies that would lead to comparable results. Furthermore, there are dozens of renewable technologies that could also displace the source energy required to operate 
the building. The main point to be taken from Figure 3.33 is that renewable generation without some form of energy storage leads to wasted energy because the supply exceeds the demand for larger values of renewable penetration. A secondary point is that there are diminishing returns with storage capacity because the ability to store more energy than is required does not have an effect on source energy consumption, and losses from larger capacity energy storages could further diminishes returns.

Figure 3.33 shows an extreme example - when the roof area is completely covered with PV panels and there is no storage (abscissa equals zero) compared to sufficient storage (abscissa equals 50\%, about 1 day or $250 \mathrm{kWh}$ of storage), leading to approximately $30 \%$ more source energy consumed. It appears that storage does not become important until PV roof area is around $30 \%$ or $40 \%$. This can be explained by reasoning that the generation is always less than the building power demand for the overwhelming majority of time periods. However, as the fraction of energy supplied by renewables increases it is not true that the building power demand always exceeds the PV generation - and this is when storage becomes crucial. One could argue that any excess generation could be put back into the grid and utilized by another building, but this leads to many losses. Furthermore, Figure 3.33 likely underestimates the impact of energy storage on source energy consumption, and thus emissions, because the figure is based on the assumption that the building is being supplied electricity by a microturbine genset which can rapidly modulate electrical output. In the case of realistic whole-system operation, the power plants cannot respond so quickly and source energy consumption would actually be larger and further emphasize the curves presented in the figure.

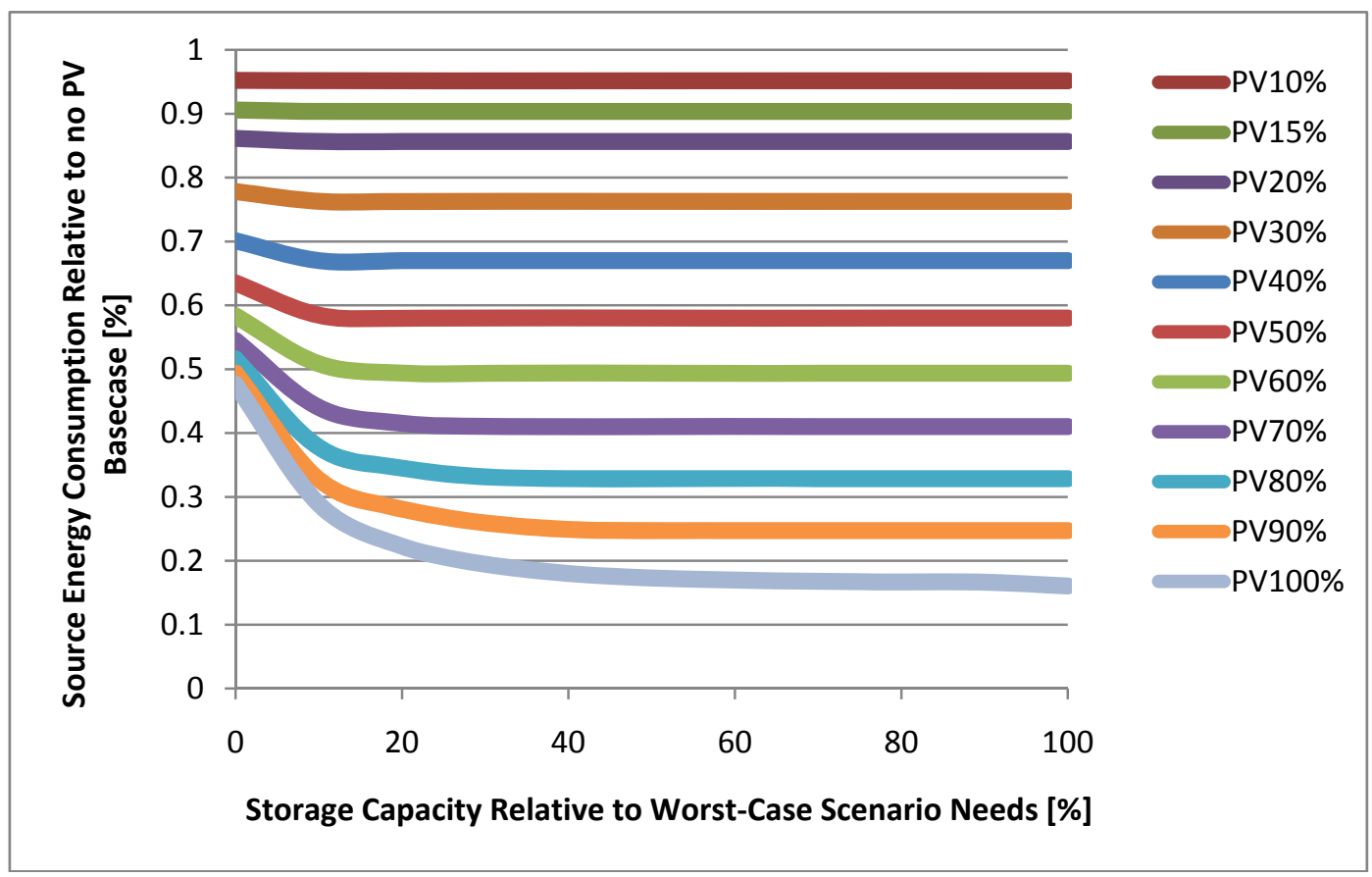

Figure 3.33. The Value of Energy Storage in Commercial Buildings, from a Purely Physical Perspective, Utilizing Renewable Generation

Although the applicability of Figure 3.33 is limited based on the assumptions and simplifications made, the simple analysis motivates further study. As the United States moves away from fossil fuel power generation there are many practical interests concerning energy storage research: threshold level of renewables where storage becomes crucial for energy efficiency; the optimal level of storage capacity; 
and auxiliary commercial building applications where storage can reduce source energy consumption and emissions. Although not an exhaustive list, some commercial building applications where energy storage could be helpful to whole-system efficiency are listed below:

- With the cooling of commercial buildings known to have a large impact on daily peak demand on the grid, a time when whole-system efficiency is low because of peaking plant operation, it is of great importance to couple/mix electrical and thermal storage to lessen the negative impact on the whole-system efficiency.

- Some portion of smart grid operation will rely on placing the true value of unit energy production on unit pricing, and thus must communicate pricing signals (like real-time pricing), and building operators can harness energy storage to meet their requirements at reduced cost because they responded to the signaling.

- Considering future endeavors involving the smart grid, electric cars, and the high levels of renewable penetration it is evident that energy storage is necessary for not only the intermittent nature of physical supply but the intermittent nature of human demands.

\subsubsection{Load Profiles for Prototypical Buildings}

Before applying and exploring the wide-range of energy storage technologies in the previous section for on-site commercial buildings applications, while incorporating the lessons learned from the expert discussions, it was imperative to narrow the scope of work. This would reduce possible redundancies in the investigation, and allow guidelines and recommendations derived from the research to be as targeted as possible. That is, by considering the entire United States commercial building stock and the range of energy storage technologies (numbering in the hundreds) the number of possible on-site energy storage studies for commercial building applications was intractable. The desire to narrow the scope of the investigation started with the goal of categorizing similar commercial building in terms of electrical demand profiles. This ensures that only a subset of the buildings would need to be included in the full investigation, and the parametric space of the project was reduced; one commercial building can be representative of a given category, and the energy storage technologies deemed applicable to the representative building would be analyzed in simulation.

This research builds on the work of Griffith et al. (2008) where EnergyPlus models for each building in the 2003 CBECS were produced in a bottom-up fashion to represent the entire United States commercial buildings sector. In total there are 4,820 building models that are shown to have good agreement with the survey data. Since weighting factors allow one to describe the number and proportion of the total 4,820 buildings that is used to represent a given region, or the entire building stock, it makes sense to use these building models as a starting point for representing the complete variability of electrical demand profiles witnessed in the United States. The simulations were run for each of the 4,820 buildings and the time series of hourly electrical demand were generated; an example of two profiles is shown in Figure 3.34. In the figure it is evident that buildings \#1 and \#103 have significantly different electrical demand profiles. The next step was to develop a systematic methodology for categorizing electrical demand profiles - clustering similar profiles and separating dissimilar profiles. Once a category has been defined, a representative from each category is subject to further investigation for a range of energy storage technologies deemed cost-feasible and applicable to the aforementioned building.. 

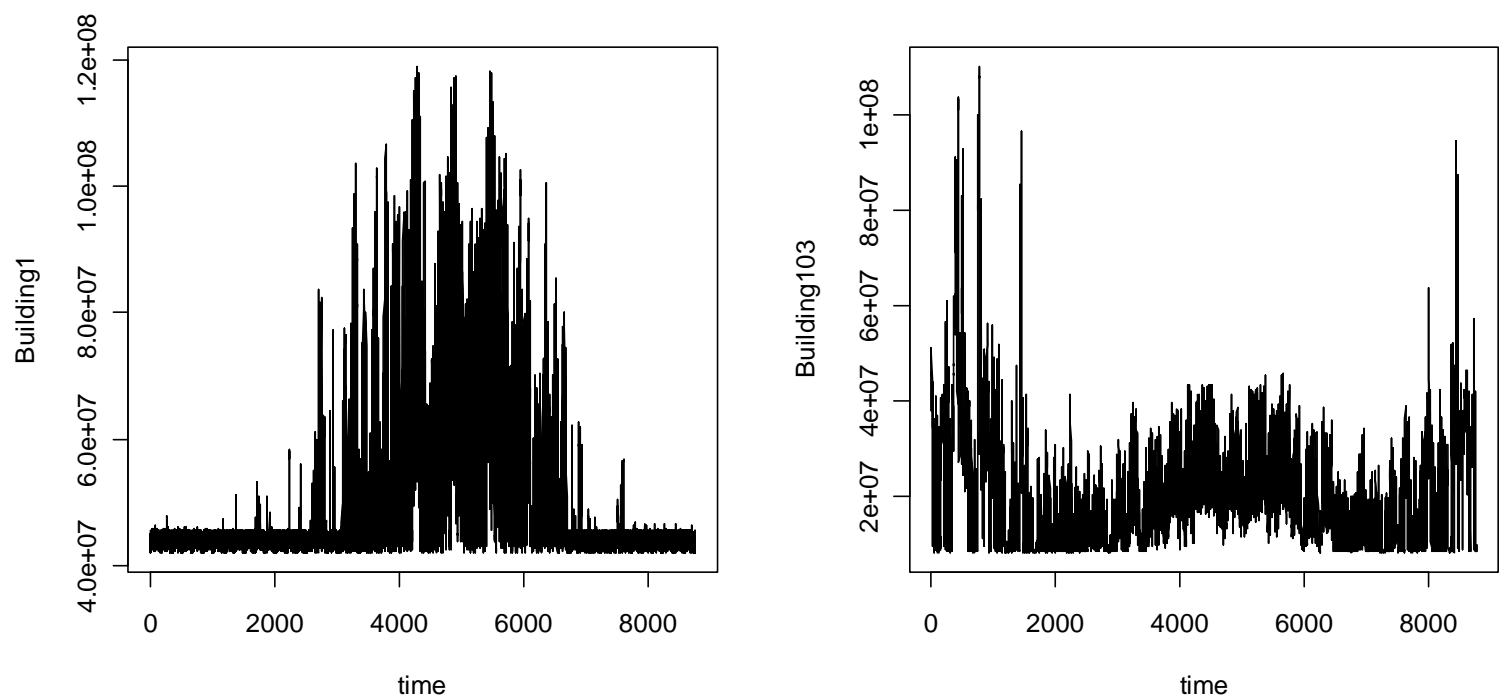

Figure 3.34. Comparison of Two Electrcal Load Profiles from the 4,820 Varieties

\subsubsection{Initial Investigation of Classifying Building Electrical Demand Profiles}

A training data set for classifying electrical demand profiles is not known to exist. Therefore an unsupervised hierarchical clustering routine was employed, and produces classes of buildings that contain similar data features. Since hourly electrical demand were considered (leading to 8760 data points) with a total of 4,820 building in the hierarchical clustering routine, there was a large data set to consider for classifying the buildings. The traditional approach for clustering routines is to calculate some form of distance metric between each point for each building, e.g., Euclidean distance, Manhattan distance, Mahalanobis distance, etc. The total distance metric, i.e., the sum of the absolute value of hourly differences, leads to a measure of how distinct one building is from another. Buildings compared to one another and resulting in a small total distance metric should cluster together. The bottom-up algorithm considered merged pairs with relatively close distance metrics and continues in this manner until a hierarchy (also tree or dendrogram) of clustered buildings exists; an example is shown in Figure 3.35.

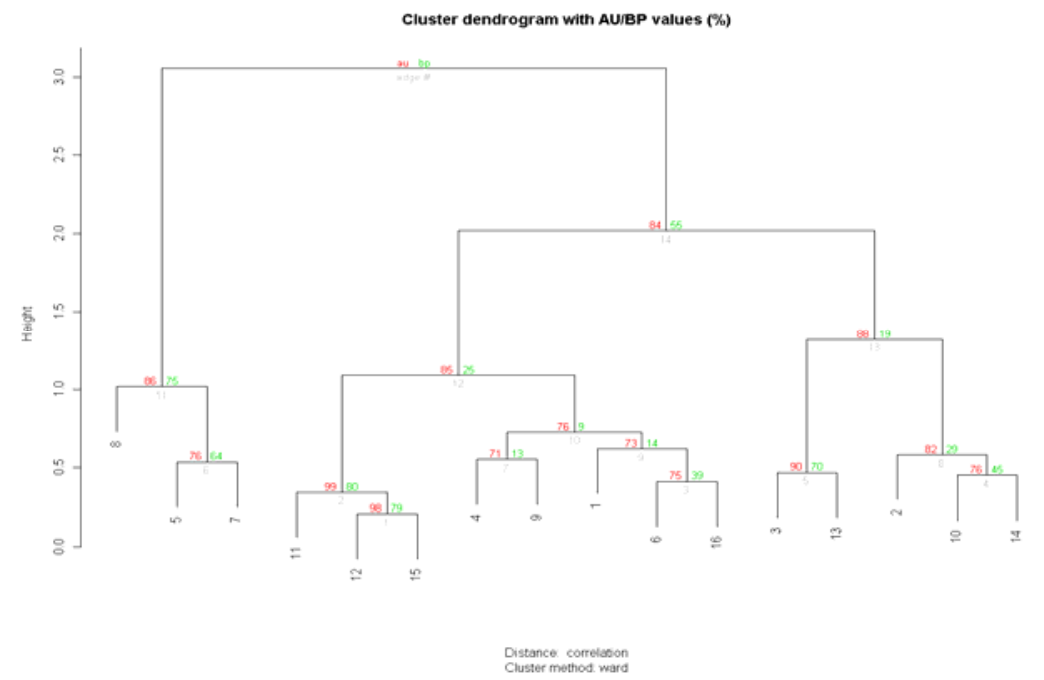

Figure 3.35. An Example Cluster Dendrogram Showing how Similar Buildings are Classified 
It was determined that the unsupervised hierarchical clustering approach for classifying building electrical demand profiles does not work satisfactorily for the considered distance metrics. The reasoning is attributed to two difficulties: 1) the curse of dimensionality, which has the effect on distance functions of reducing the ability to discern differences as dimensionality increases, and 2) the temporal changes in operation (seasonal) are not fully contained in the total distance metric because only relative distances are considered. In simple terms, the difficulties arose because too much information was contained in one simple metric and important frequency and temporal changes were not sufficiently explained with this one simple metric. This does not disregard the unsupervised hierarchical clustering routine, but required that a more intelligent transformation was chosen and crucial features containing temporal and frequency were extracted from the raw data of the electrical demand profiles.

The primary strategy was to classify the known non-stationary time series of each building's electrical demand according to frequency and temporal patterns. That is, all of the buildings have a natural diurnal swing due to daily cycles, however, the higher frequency (hour-to-hour) and lower frequency (seasonal) power demands are also of interest because so much can be inferred from this information, e.g., lower electrical power demands during the heating season indicate some form of gas heating. Although Fourier transformation was considered, as well as other variations of this concept, it was found that its stationary assumptions did not allow crucial information about the raw electrical demand profile to be extracted. This can be easily confirmed by considering Figure 3.34, where seasonal electrical demands are significantly varied and simple Fourier transformation cannot deal with such concerns. It is possible to consider a windowed Fourier transformation. This can be completed by a priori splitting the complete time series into seasons and performing the Fourier transformation individually and separately. Then the researcher must ask when the original time series should be split it will be different for each building due to their varied geographical locations and equipment operations. The answer to all of these questions is to use the discrete wavelet transformation (DWT), which is the soundest theoretical approach to the described problem because both the time and frequency domain are considered simultaneously - at all levels of frequency, for all time periods.

\subsubsection{Wavelet Transformation of the Electrical Demand Profiles}

The discrete wavelet transformation is, the discrete version of the continuous wavelet transform; it is used here because the simulated data is sampled hourly in producing the electric demand profile of each building. The discrete wavelet transformation is a time-scale representation of a digital signal and is obtained using digital filtering techniques. This section gives a brief overview of the discrete wavelet transformation approach to illustrate how it is performed before the details of clustering and classification are presented. Digital filters of different cutoff frequencies are used to analyze different scales of the signal, where the scale is defined as the inverse of the frequency. High scale corresponds to a global view of the problem (e.g., the general pattern of the 8760 hours) and the low scale corresponds to highly detailed information (e.g., hour-to-hour electric demand changes due to equipment scheduling). A measure of the amount of detailed information in the signal, called the resolution of the signal, is changed by the filtering operations. The scale is changed by downsampling and upsampling operations. Downsampling corresponds to reducing the sampling rate (sampling from the original, raw data signal) and thus removing samples, i.e., downsampling by a factor $n$ reduces the number of samples of the original signal by $n$ times. Upsampling is the exact opposite and corresponds to increasing the sampling rate by adding samples to the signal. 
The discrete wavelet transformation begins by passing the original signal $x(n)$ through a half-band digital low-pass filter with impulse response $h(n)$. This corresponds mathematically to the convolution of signal with the filter impulse response, and is defined as:

$$
\mathrm{x}(\mathrm{n}) * h(n)=\sum_{k=-\infty}^{\infty} \mathrm{x}(\mathrm{k}) \cdot h(n-k) .
$$

And the half-band digital low-pass filter removes all frequencies that are larger than half of the highest frequency in the signal.

After the signal has been passed through the half-band digital low-pass filter, half of the samples can be discarded according to the Nyquist criterion because they are redundant due to the filtering operation. This is accomplished simply by downsampling the signal by two (removing every other datum), leaving half the number of points of the original signal and double the scale. That is, the low-pass filter operation removes the high frequency information and the downsampling changes the scale. Furthermore, the resolution of the signal is halved during the half-band digital low-pass filtering because it is related to the amount of information in the signal, and because half the frequencies have been removed it can be interpreted as losing half the information. The procedure is expressed mathematically as:

$$
\mathrm{y}(n)=\sum_{k=-\infty}^{\infty} h(\mathrm{k}) \cdot x(2 n-k) .
$$

The discrete wavelet transformation thus analyzes the signal at different frequency bands, with different resolutions, by transforming the signal into a coarse approximation and detail information; the coarse approximation is further transformed using the same wavelet transformation step. This is accomplished by using two functions, called the scaling function and the wavelet function, which are respectively associated with the low-pass and high-pass filters. Transforming the signal into different frequency bands is obtained by passing the original signal through a series of high-pass and low-pass filters. The original signal $x(n)$ is first passed through a half-band low-pass filter $h(n)$ and high-pass filter $g(n)$. The outcome of the filtering, after half of the samples are discarded according to the Nyquist criterion, constitutes the first level of transformation and is mathematically expressed as:

$$
\begin{gathered}
\mathrm{y}_{\text {high }}(k)=\sum_{n} x(n) \cdot g(2 k-n), \text { and } \\
\mathrm{y}_{\text {low }}(k)=\sum_{n} x(n) \cdot h(2 k-n),
\end{gathered}
$$

where $\mathrm{y}_{\text {high }}(k)$ and $\mathrm{y}_{\text {low }}(k)$ are high-pass and low-pass filter outputs, respectively; down sampling has also occurred by a factor of two.

The discrete wavelet transformation reduces the time resolution by half, since the result is half the number of samples of the original signal. The operation doubles the frequency resolution since the frequency band of the signal is now half of the previous frequency band; this reduces the uncertainty in the frequency by half. The procedure is repeated until no more data points remain, as illustrated in Figure 3.36, where an iteration of the process is called a level. For every level, the number of samples is halved (half the time resolution) and half the frequency band (double the frequency resolution). As shown in the figure, the original signal $x(n)$ is transformed by low-pass $h(n)$ and high-pass $g(n)$ filters. The bandwidth $F$ is labeled at each level and shows how the reduction of time resolution and increased in frequency resolution at different levels. 


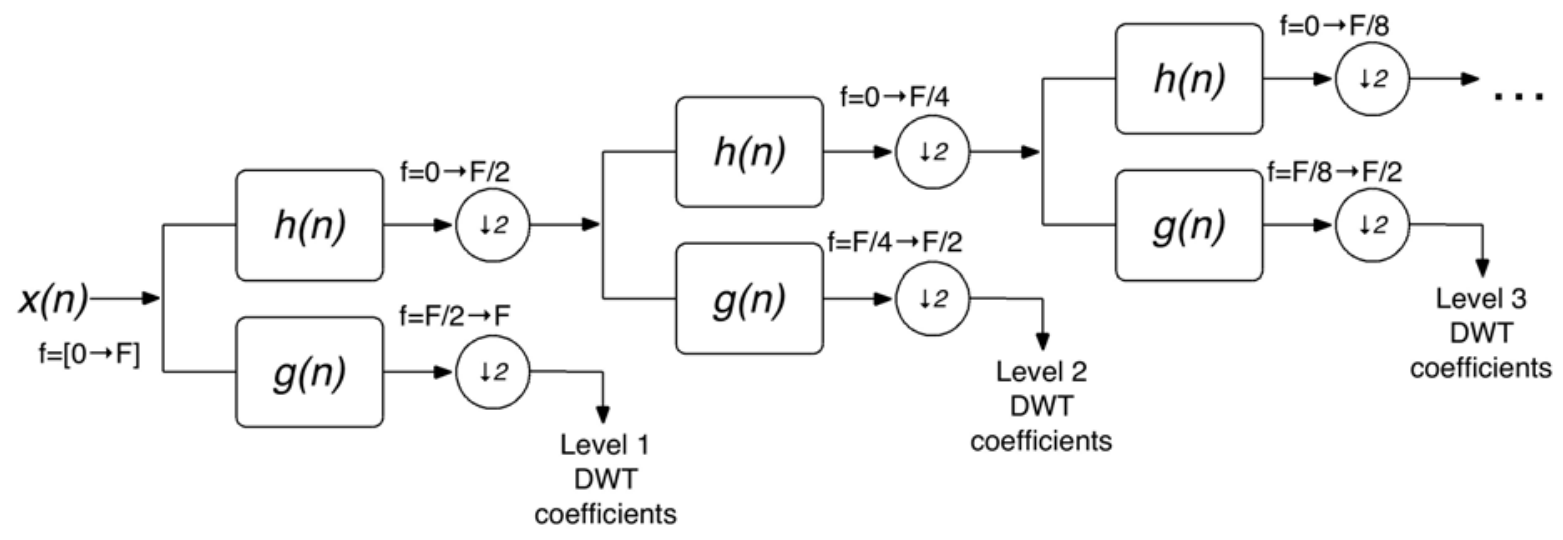

Figure 3.36. The Discrete Wavelet Transformation Process

The most notable frequencies of the original signal $x(n)$ will appear as high amplitudes in the region of the DWT signal that has those frequencies. This is the advantage of DWT over the Fourier transform; the time localization of the frequencies will not be lost, but the time resolution is dependent on the level. Furthermore, more information in the signal resides at higher frequencies. This is where time localization is more precise because there are more samples, and at low frequencies the frequency resolution is good but has low time resolution because of the limited number of samples. The frequency bands of little importance will have low amplitudes, and in many cases can be discarded for data reduction and with little loss of information. This is another advantage of using the DWT for analyzing and classifying commercial building electrical demand profiles; only the most important features can be extracted to explain the signal and they can be classified accordingly using hierarchical clustering without the fear of the curse of dimensionality.

An example of the discrete wavelet transformation is presented in Figure 3.37 and Figure 3.38 for the same two buildings whose electrical demand profiles are contrasted in Figure 3.34. It is interesting to note the distribution of signal power for the various levels, where the DWT contains 13 levels due to the number of points being equal to 8760 . Of particular interest is level 4 , which roughly corresponds to diurnal electrical demands. It is shown in Building \#1 of Figure 3.37 that the level 4 amplitudes only seem to be important during the summer and slightly in the swing seasons, with winter periods have little impact. On the other hand, in Building \#103 of Figure 3.38. Building \#103 Discrete Wavelet Transformation. The level 4 amplitudes are important throughout the year and even have higher amplitudes for some winter days. These differences could be due to simple differences in the primary equipment (e.g., gas or electrical heating) or, depending of the level considered, due to building characteristics, operation, or climactic considerations. The primary goal is to categorize similar building electrical demand profiles, and then to 1) infer on the parameters/features that drive the electrical demand profiles, 2) recognize critical amplitudes and their effect on whole-system efficiency, and 3) investigate energy storage technologies to help damp critical amplitudes and access storage performance. 


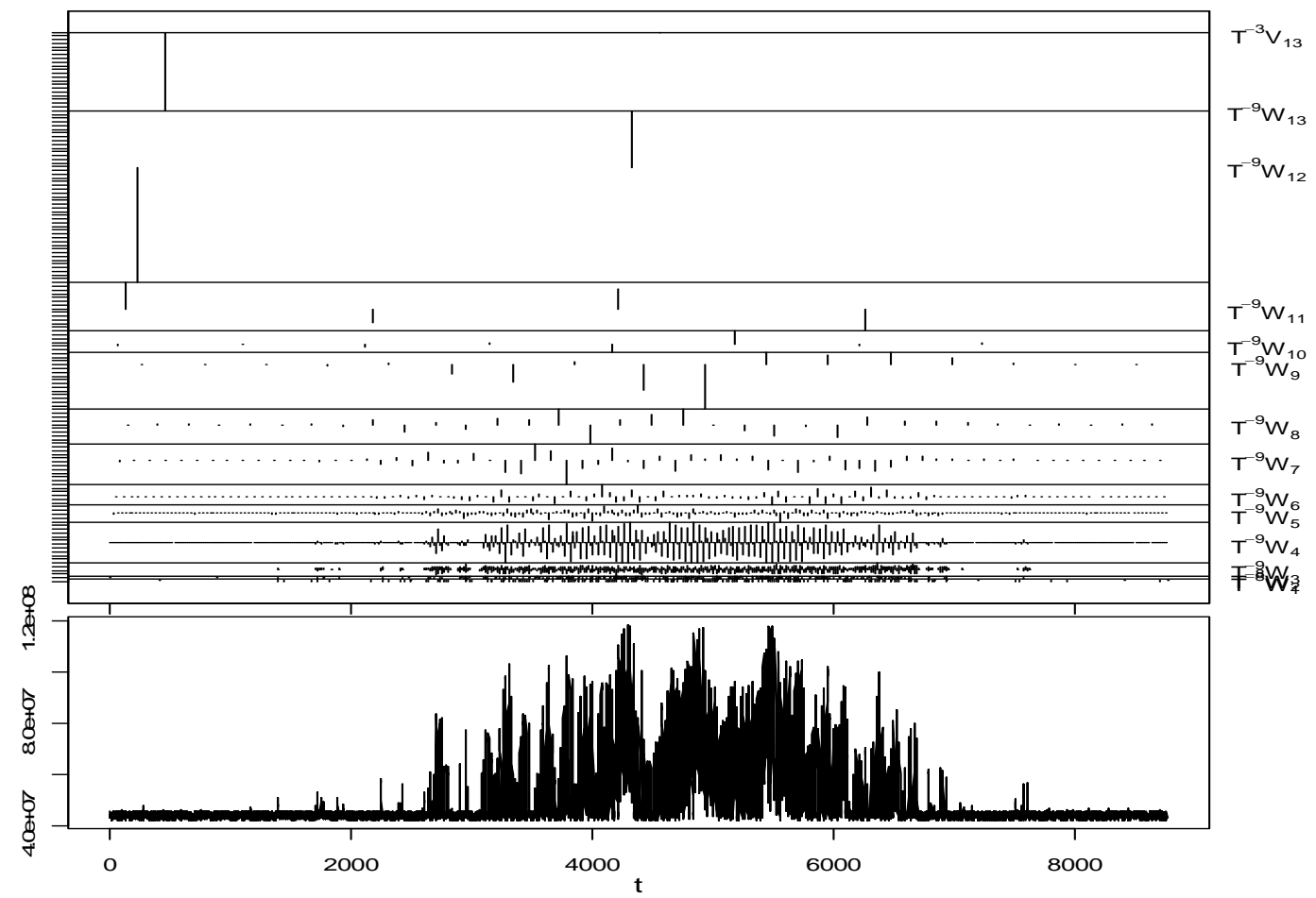

Figure 3.37. Building \#1 Discrete Wavelet Transformation

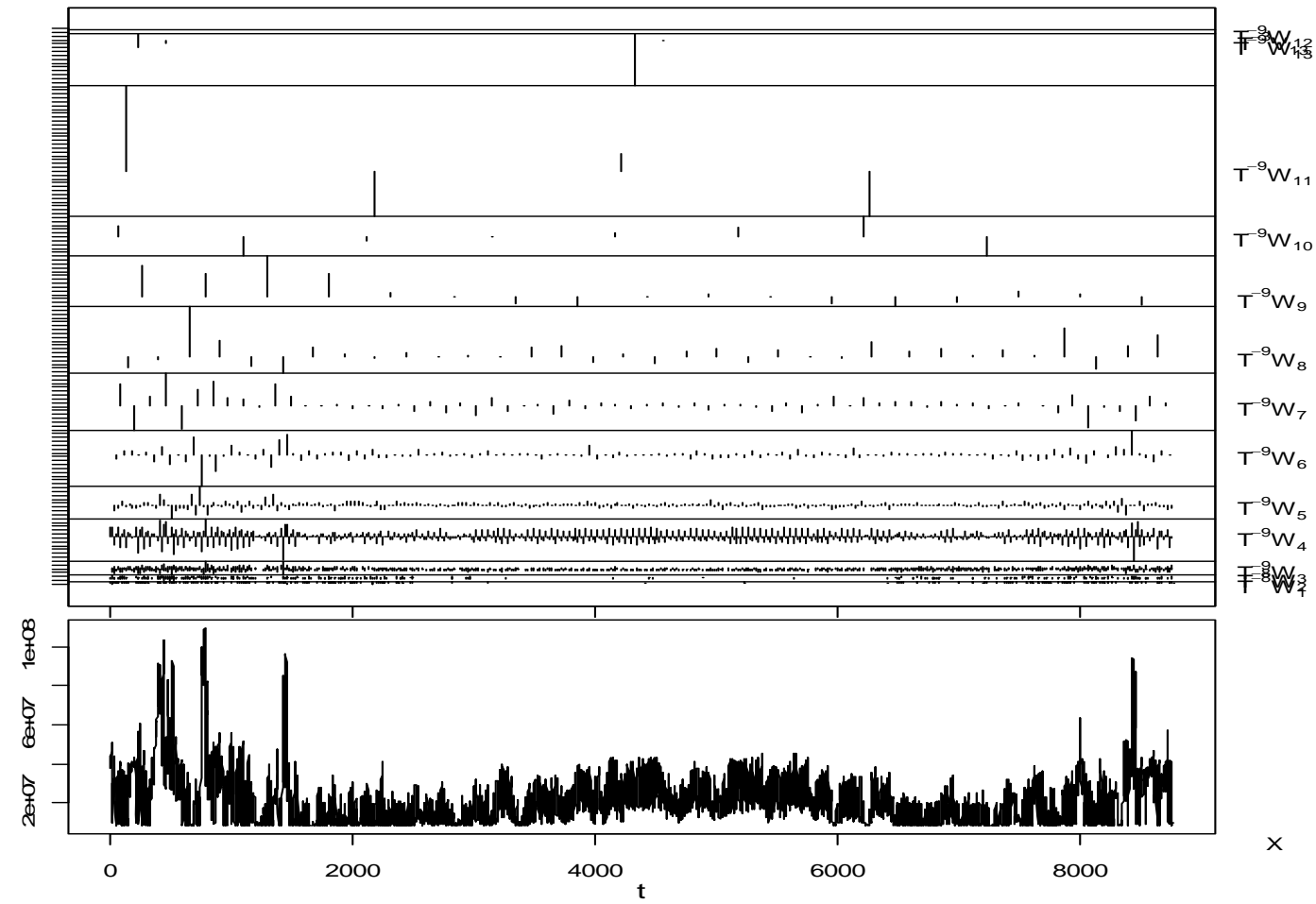

Figure 3.38. Building \#103 Discrete Wavelet Transformation 


\subsubsection{Feature Extraction from the Wavelet Decomposition Analysis}

With the DWT complete for each building's electrical demand profile, there was a need to extract only the most crucial information so that the hierarchical clustering could commence. In fact, due to the production of wavelet coefficient at different levels, i.e., time and frequency resolutions, there was more data available than in the original time series. The crucial point it that the information now available in the form of coefficients at different levels corresponds to unique time and frequency resolutions, for every building's demand profile, and absolute and relative features within each level will allow a given building to be classified.

The measure of the classification method's success will largely depend on the expressivity and the independence of the features that are extracted from the wavelet coefficients at different levels. The wavelet coefficients at each level provide a compact representation giving the energy distribution of the signal in time and frequency. To reduce the dimensionality of the wavelet coefficients at each level, and thus extract so-called feature and store them for the classification routine, statistics over the set of wavelet coefficients at each level where used. In this fashion, the statistical characteristics represent the information contained within the wavelet level and convey the distribution of energy in time and frequency but still allow a reasonably low-dimensional representation of this information. The following features were considered for inclusion in the feature vector considered in the hierarchical clustering:

- Mean measures - including the simple mean, absolute mean, positive-coefficients mean, and negative-coefficients mean, which provide information about the frequency distribution of the signal in each subband.

- Variance measures - including the simple variance, standard deviation, positive-coefficients standard deviation, negative-coefficients standard deviation

- Relative measures - including correlations, autocorrelations, forward differences (in terms of level above), backward differences (in terms of level below), forward ratio (level below), and back ratio (level below), which provide information about the relative frequency distribution between sequential subbands.

The features that are included in the feature vector, because they expressivity and independence, allow similar buildings to be classified because they are close to being indistinguishable and dissimilar buildings to not be considered as the same class of buildings because they are easily distinguishable. Of course, there is some grey area where it is questionable whether a given building should be classified as part of some class, and therefore a Bayesian probabilistic approach has been utilized for the hierarchical clustering as discussed in the next section. Furthermore, the approach utilizes hypothesis testing to decide whether a given feature in the feature vector is advantageous for clustering or if it provides little value and thus can be disregarded.

\subsubsection{Bayesian Probabilistic Hierarchical Clustering}

Traditionally, hierarchical clustering of data is a bottom-up agglomerative algorithm, and one of the most frequently used methods for unsupervised learning. Each data point is initially in its own cluster, and the two closest clusters are iteratively merged until all data points are in the same cluster. The user chooses the distance metric used to access relative "closeness" and the threshold measure to stop the clustering process and yield the optimal number of clusters. These are limitations that make the 
classification very difficult. Fortunately, there have been recent advances in hierarchical clustering [refref4] which employ the powerful Bayesian perspective for producing probabilistic clustering of data. The advantages of this approach are summarized the four points below:

- A probabilistic model is defined through the data and is used for computing a predictive distribution of test points and inquiring whether it belongs to any existing cluster in the tree.

- A model-based criterion is used to access whether or not to merge clusters instead of ad-hoc distance measures.

- Bayesian hypothesis testing is used in decision-making: whether to merge clusters and the depth of the tree.

- The algorithm is fast and been proven to work with real-world data.

The Bayesian hierarchical clustering algorithm makes use of marginal likelihoods in deciding which clusters to merge and also to avoid overfitting the problem. It determines the probability that the data in a potential merge were generated from the same mixture component and compares this to many hypotheses at lower tree levels. For instance, if two leaves in the tree are to be considered for merging then two hypotheses are compared: 1) the data was generated from the same probabilistic model, $\mathrm{p}(\mathrm{x} \mid \Theta)$ with unknown $\Theta$, or 2) the data comes from different probabilistic models. To access the first hypothesis a prior must be specified over the parameters of the model $p(\Theta \mid \beta)$ and the probability of the data can be computed as follows:

$$
p\left(D_{k} \mid H_{1}\right)=\int p\left(D_{k} \mid \theta\right) p(\theta \mid \beta) d \theta
$$

which is the probability that all the data were generated from the same parameter values assumed in the model. The alternative hypothesis is that the data has two or more clusters in it, which is a product over the subtrees and it can be shown that the marginal probability of the data in a tree $\mathrm{T}_{\mathrm{k}}$ is:

$$
p\left(D_{k} \mid T_{k}\right)=\pi_{k} p\left(D_{k} \mid H_{1}\right)+\left(1-\pi_{k}\right) p\left(D_{i} \mid T_{i}\right) p\left(D_{j} \mid T_{j}\right)
$$

The first term is the hypothesis that there is a single cluster $\mathrm{D}_{\mathrm{k}}$, and the second terms sums over all other clusters of data. Bayes rule can be used to determine the posterior probability of the merged hypothesis:

$$
r=\frac{\pi_{k} p\left(D_{k} \mid H_{1}\right)}{\pi_{k} p\left(D_{k} \mid H_{1}\right)+\left(1-\pi_{k}\right) p\left(D_{i} \mid T_{i}\right) p\left(D_{j} \mid T_{j}\right)}
$$

and the quantity is used to decide which two trees to merge. The general algorithm in pseudo code is shown below in Figure 3.39. Bayesian Hierarchical Clustering (Heller and Ghahramani, 2005. 


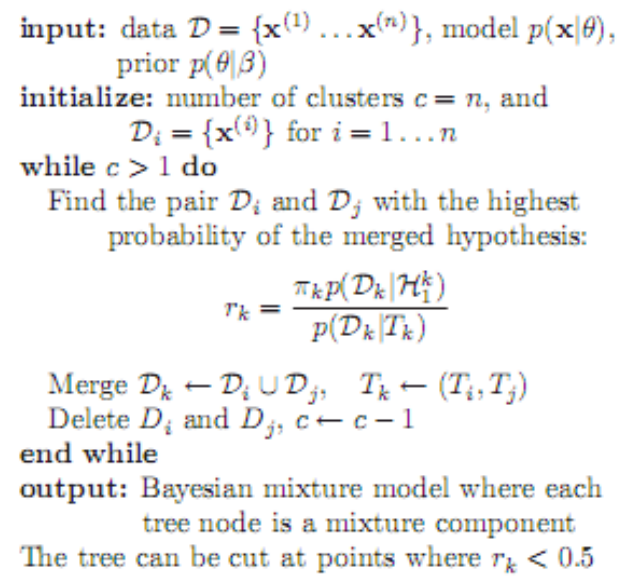

Figure 3.39. Bayesian Hierarchical Clustering (Heller and Ghahramani, 2005)

\subsubsection{Summary and Future Work}

The complete approach of classifying commercial buildings' electrical demand profiles can be summarized in four steps: 1) simulate the 4,820 commercial buildings representative of the United States building stock, 2) perform a discrete wavelet decomposition to obtain temporal and frequency characteristics of the power demand, 3) extract the crucial features defining the DWT, 4) use Bayesian hierarchical clustering for unsupervised classification of the buildings. One the classification of the buildings electrical demand is possible a representative case will be used to apply energy storage technologies that are complementary (in terms of power spectrum and temporal needs) for leveling or otherwise shaping power demand. At this point in time, the majority of the framework for extracting building power demand characteristics and classifying types of buildings has been completed. The next steps and future work will focus on applying appropriate energy storage technologies to the subset of buildings representing the various classes.

\subsubsection{Case Study: Role of Energy Storage as Part of a Renewables Energy Portfolio}

A medium-sized John Deere commercial building in Des Moines, Iowa is currently under construction and integrates renewable energy technology to reduce carbon emissions and increase its energy efficiency. The building will incorporate an on-site wind turbine to produce electricity for partially powering the nearly $12,000 \mathrm{sf}$ building. Furthermore, the HVAC system utilizes a ground heat exchanger, which can be used to store ground thermal energy for later use when excess electricity from the wind turbine is available during the nighttime.

Since renewable energy sources are intermittently active, this complication for building energy needs. During peak times throughout the day there is not enough energy to meet the demand. Likewise, when the renewable energy is most prevalent (night) it often exceeds the load. It would be most efficient, in terms of the customer's utility costs, to conserve this excess energy and use it at the peak time of day. Wind turbines have a maximum energy production does not coincide with the peak energy demand periods of the day, requiring either energy storage or for the producer to sell electricity back to the grid. Different storage methods have been proposed such as high capacity batteries, flywheels, pumped hydro, 
and thermal storage mechanisms such as ice, chilled water, phase change materials, or inherent thermal mass within the building or the Earth. The decision to incorporate storage methods versus exporting electricity to the grid is highly dependent on the cost of the storage technique, how it is integrated to the building, as well as the cost of buying and selling electricity. One possible approach for storing excess energy is utilizing the ground to capture thermal energy using a ground source heat pump system as part of the heating ventilation and air conditioning (HVAC) system. The stored energy can be used at a later time to alter the building load profile through load shifting, thus saving the customer utility charges because a smaller quantity is purchased at higher utility charges and almost no energy is sold back to the grid at a relatively cheap profit.

Ground source heat pumps use the Earth's relatively constant deep ground temperature as an exchange medium instead of ambient air. In the winter when the ground is warmer than the air, heat is drawn from the ground and displaced into the building. In the summer when the ground is cooler than the air, heat is extracted from the building and displaced into the ground. Typically water or antifreeze is used as the working fluid circulating between the ground and the heat pump. An additional electrical source, in this case a wind turbine, will power heaters or cooling coils to create a larger temperature difference between the fluid and the air, which increases the ground's capacity to store or displace heat.

An optimization analysis is beneficial when implementing these technologies to maximize their costeffectiveness and value. The building parameters that can be changed to achieve a target percent energy savings are endless making this a complex optimization. A subspace of these parameters include the number of bore holes in the bore field, the depth of these holes, the capacity of any supplemental boiler and/or chiller, the size of the wind turbine, the number of heat pumps, the zones in which the heat pumps are installed, coefficient of performance (COP) of each heat pump, the size of the pump, and the schedule of operation for both storing and extracting heat from the ground, specifically the charge time and the temperature delta between the set points.

These parameters form the basis for the optimization to achieve the greatest energy reduction at while minimizing the cost. This study presented herein is a preliminary design for the commercial building harnessing a wind turbine and ground source heat pump, and will include and compare the cost of various control strategies on the basis of the percent energy and cost savings they provide.

\subsubsection{Modeling Efforts}

EnergyPlus 5.0 was used for all energy analyses of the medium-sized commercial building. The simulations were managed with the NREL analysis platform, Opt-E-Plus, which transforms userspecified, high-level building parameters (building area, internal gains per zone, HVAC system configuration, etc.) stored in XML files into an input file for EnergyPlus. Opt-E-Plus can automatically generate the XML files, or it can manage XML files that have been assembled or modified elsewhere. Working with the XML files is much faster than modifying EnergyPlus input files directly, because a single XML parameter usually maps to multiple EnergyPlus inputs. EnergyPlus was selected because it is a detailed simulation tool that computes building energy use based on the interactions between climate, building form and fabric, internal gains, HVAC systems, and renewable energy systems. The simulations were run with EnergyPlus 5.0 compiled on local personal computers, and model of the proposed mediumsized office building is shown in Figure 3.40. 


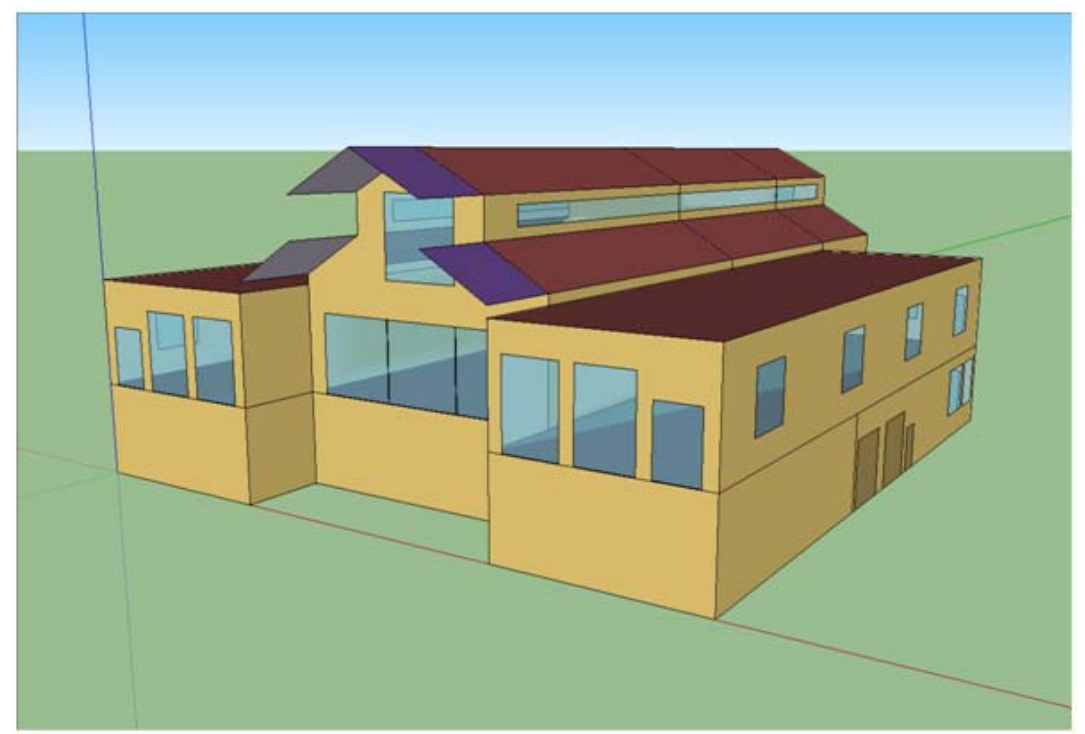

Figure 3.40. The EnergyPlus Model of the Preliminary Designed Medium-Sized Office Building

A vertical ground heat exchanger is included on the supply side of the condenser loop. The loop also contains an electric boiler and a fluid cooler. An electric boiler was chosen for the preliminary study, as opposed to a more conventional natural gas boiler, because the excess electricity generated by the wind turbine could be directly used. Water-to-air heat pumps were added to each zone on the demand side of the plant loop. This component combines a fan, water-to-air cooling/heating coils, and a supplemental heating coil into a single element. A $100 \mathrm{~kW}$ was chosen in the building plans for this project, according to the wishes of the owner, and specified for use in modeling efforts by EnergyPlus. The buying and selling utility rates for electricity were obtained from MidAmerican Energy data and implemented into the model to project how much the electrical load would cost for the entire year. This required adding a twoseason schedule and detailing the charges and tariffs.

This study targets the operation of the boiler and chiller when excess wind energy was generated. The charge time (the time the boiler or chiller set point is deliberately set to a predetermined value to heat or cool the ground) and the change in set point temperatures during operation and charging, are the two specific parameters studied in this preliminary analysis.

A dynamic, predictive setpoint was used within the EnergyPlus Energy Management System (EMS), and was used to calculate the set point based on how much surplus was available using the following equation and solving for $\mathrm{T}_{2}$ :

$$
\mathrm{W}=\dot{\mathrm{m}} \mathrm{C}_{\mathrm{p}}\left(\mathrm{T}_{2}-\mathrm{T}_{1}\right) \quad \Rightarrow \quad \mathrm{T}_{2}=\left[\frac{\mathrm{W}}{\dot{\mathrm{m}} \mathrm{C}_{\mathrm{p}}}\right]+\mathrm{T}_{1}
$$

where, $\mathrm{W}=$ surplus wind turbine power $[\mathrm{kW}]$

$\dot{\mathrm{m}}=$ mass flowrate of the fluid $\left[\frac{\mathrm{kg}}{\mathrm{s}}\right]$

$\mathrm{C}_{\mathrm{p}}=$ specific heat capacity $\left[\frac{\mathrm{J}}{\mathrm{kg} * \mathrm{~K}}\right]$

$\mathrm{T}_{1}=$ inlet temperature $[\mathrm{K}]$

$\mathrm{T}_{2}=$ outlet temperature (set point) $[\mathrm{K}]$ 
This control scheme makes use of the instantaneous and excess power from the wind turbine and transfers it to the ground by either heating or cooling the ground-loop water. Thus, the energy stored in the ground can be used to offset the thermal loads of the next day and the strategy does this by exploiting the relatively low thermal diffusivity of the ground. The control scheme has not been perfected at this time and there is research in progress concerning the swing-season (heating and/or cooling) and the dynamic prediction of future needs for storing the intermittent wind energy supply. In this preliminary design a simpler set point schedule was devised as a proof-of-concept, and further work will look at predictive control schemes. A single set point was chosen for each season to trigger the boiler and chiller. Although this method will not follow the surplus electricity generated as closely as a dynamic control scheme, it should theoretically even out if an appropriate, average value is chosen for the set point. If the proper set point was selected and the buying/selling rates were identical, this method would work as well as a dynamic set point. However, since most utility companies have different rates for buying and selling energy, some imprecision must be accepted in this method. The proof-of-concept results are presented in the following section.

\subsubsection{Preliminary Results}

Figure 3.41 shows a typical night where surplus wind energy is being generated. Without any control scheme or set point override, this surplus energy is wasted or sold back to the grid at an unfavorable rate. When a set point schedule is applied the model, the boiler or chiller is activated and utilizes the surplus energy to pump heat into the ground. In this figure, the total building energy demand is reduced as a result for two hours from 6:00 a.m. to 8:00 a.m. It should be noted that the area between the two cases, without control and with control, represents the amount of thermal load that can be shifted and its effect on electrical demand - about $10 \%$ of the daily $\mathrm{kWh}$ in this case - but in this preliminary, proof-of-concept work there was no active attempt to control when the thermal storage is released; releasing the storage later in the day can allow electrical demand limiting and be more valuable to whole-system efficiency.

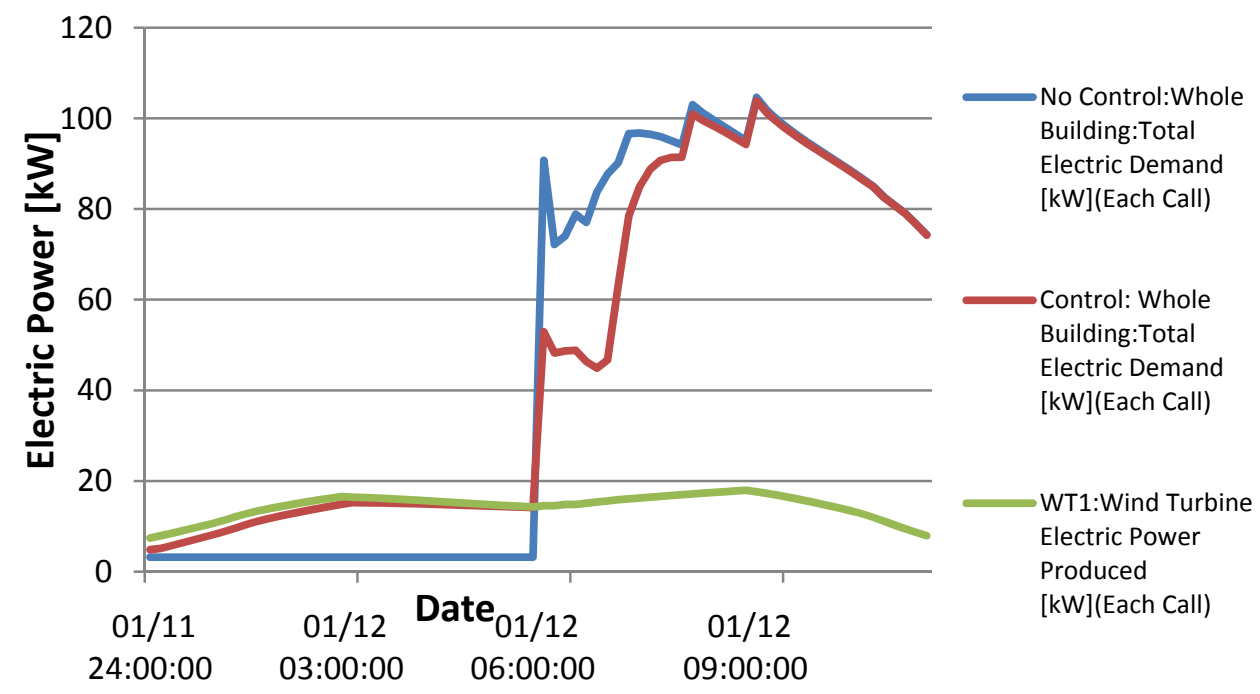

Figure 3.41. Electric Demand and Production of the Medium-Sized Office Building 


\subsubsection{Conclusions Thus Far}

This case study demonstrates that directly use of surplus wind energy to offset next day thermal energy demands is better, in terms of cost to the owner, than selling the surplus back to the grid. The reason for this is directly attributed to utility rates, where the depending on the season the purchase cost of a $\mathrm{kWh}$ is 5 to 10 times the rate the utility will purchase a $\mathrm{kWh}$ generated on the building site. That is, even if money is not earned by selling surplus electricity back the grid, the energy storage allowed electricity savings that completely overshadowed any "losses." Research up to this point has focused on the control strategy for storing the excess generation in the ground via heat transfer. Sensitivity to control setpoints has been explored to ensure that the control strategy is correct. Future research will focus on dynamic control of the charging/discharging rates and the state of the storage. Moving forward there is a number of considerations that can be extracted from the proof-of-concept:

- An optimization routine focusing on life-cycle cost analysis would have to be developed to determine the amount of excess production that would necessitate the purchase of auxiliary equipment such as boilers and fluid coolers.

- Although it is evident that conversion of electricity to thermal storage can reduce the next day's daily electrical demand, it is important to quantify the value this has for the utility.

- Although conversion of the high work potential of electricity to heat is a huge waste of exergy, the preliminary study shows that consumers are aware of the bias in buying/selling utility rates and if/when they purchase renewable energy systems they are inclined to minimize the payback period.

\subsubsection{Summary and Future Work}

This preliminary, proof-of-concept study is the first step toward devising a control system that seeks to store excess, on-site energy generation, in lieu of selling back to the grid, to allow the maximum amount of energy and/or cost savings for and customer's building. Due to the unfavorable selling rate in Des Moines, IA, and using the devised setpoint management system to harness the previous day's wind generation the daily electrical demand could be shifting. Future work will focus on the time period in which the load is shifted in order to maximize whole-system efficiency. Although there were factors that limited the effectiveness of these renewable energy systems for this building in this location, these same strategies could be applied for a similar building in a different location where utility buying rates and selling rates are higher. One key concept that should be taken away from this study is that there are a variety of renewable systems and implementation strategies available. The difficulty is tailoring these systems and strategies to the resources available and the location's environment. This will be a common hurdle to overcome as more buildings strive to become more energy efficient. 


\subsection{References}

BPA, 2008. Makarov, Y.; Ma, J.; Lu, S.; Nguyen, T. Assessing the Value of Regulation Reources Based on Their Time Rsponse Characteristics. PNNL-17632. June 2008. Pacific Northwest National Laboratory. Richland, WA.

CAISO, 2010. Integration of Renewable Resources - Oeprational Requirements and Generation Fleet Capability at 20\% RPS," California Independent System Operator Report, August 31, 2010.

Dam, K. H. v., M. Houwing, et al. (2008). "Agent-Based Control of Distributed Electricity Generation with Micro Combined Heat and Power-cross-sectoral Learning for Process and Infrastructure Engineers." Computers \& Chemical Engineering 32(1-2): 205-217.

de Leon, C. P., A. Frias-Ferrer, et al. (2006). "Redox flow cells for energy conversion." Journal of Power Sources 160(1): 716-732.

Divya, K. C. and J. Ostergaard (2009). "Battery energy storage technology for power systems-An overview." Electric Power Systems Research 79(4): 511-520.

DOE. (2009, March 12, 2010). "Commercial Reference Buildings." version 1.2_4.0. from http://www1.eere.energy.gov/buildings/commercial initiative/reference buildings.html.

DOE. (2010). "EnergyPlus." 5.0. Retrieved July 27, 2010, from http://apps1.eere.energy.gov/buildings/energyplus/.

EIA. (2006). "2003 Commercial Buildings Energy Consumption Survey (CBECS)." from http://www.eia.doe.gov/emeu/cbecs/contents.html.

EIA (2008). Annual Energy Review.

EIA (2009). Annual Energy Outlook 2010.

Energizer. (2010). "Nickel Metal Hydride (NiMH) Handbook and Application Manual." Retrieved 9/24/2010, 2010, from http://data.energizer.com/PDFs/nickelmetalhydride appman.pdf.

Exarchakos, L., M. Leach, et al. (2009). "Modelling Electricity Storage Systems Management under the Invluence of Demand-Side Management Programs." International Journal of Energy Research 33(1): $62-76$.

Gattrell, M., J. Park, et al. (2004). "Study of the mechanism of the vanadium 4+/5+redox reaction in acidic solutions." Journal of the Electrochemical Society 151(1): A123-A130.

Griffith, B., N. Long, et al. (2008). Methodology for Modeling Building Energy Performance across the Commercial Sector, National Renewable Energy Laboratory, U.S. Department of Energy.

Ibrahim, H., A. Ilinca, et al. (2008). "Energy storage systems - Characteristics and comparisons." Renewable \& Sustainable Energy Reviews 12(5): 1221-1250.

ISO (2008). Energy performance of buildings - Calculation of energy use for space heating and cooling. 13790:2008(E). 
Kavgic, M., A. Mavrogianni, et al. (2010). "A Review of Bottom-up Building Stock Models for Energy Consumption in the Residential Sector." Building and Environment 45(7): 1683-1697.

Linden, H. D., Ed. (1995). Handbook of Batteries, McGraw-Hill Professional.

Macal, C. M. and M. J. North (2005). Tutorial on Agent-based Modeling and Simulation. 2005 Winter Simulation Conference.

Millet, J.-R. (2007). The Simple Hourly Method of prEN 13790: a Dynamic Method for the Future. Chima 2007 WellBeing Indoors, Helsinki, Finland.

M. Milligan, B. Parsons 1997. A Comparison and Case Study of Capacity Credit Algorithms for Intermittent Generators, NREL report. National Renewable Energy Laboratory, Golden, CO.

Nielsen, T. R. (2005). "Simple Tool to Evaluate Energy Demand and Indoor Environment in the Early Stages of Building Design." Solar Energy 78: 73-83.

PJM 2007a, PJM Manual 20: PJM Resource Adequacy Analysis, available at http://ftp.pjm.com/ /media/documents/manuals/m20.ashx , PJM Interconnection, 2007. Norristown, PA

Rabl, A. and L. K. Norford (1991). "Peak Load Reduction by Preconditioning Buildings at Night." International Journal of Energy Research 15(9): 781-798.

Swan, L. G. and V. I. Ugursal (2009). "Modeling of End-Use Energy Consumption in the Residential Sector: A Review of Modeling Techniues." Renewable and Sustainable Energy Reviews 13(2009): 1819-1835.

Vytelingum, P., T. D. Voice, et al. (2010). Agent-Based Micro-Storage Management for the Smart Grid. 9th Internaional Conference on Autonomous Agents and Multi-Agent Systems, Toronto, Canada. 


\section{Distribution}

No. of

Copies

\# Name

Organization

Address

City, State and ZIP Code

\# Organization

Address

City, State and ZIP Code

Name

Name

Name

Name

Name (\#)

\# Name

Organization

Address

City, State and ZIP Code
No. of

\section{Copies}

\# Foreign Distribution

\# Name

Organization

Address

Address line 2

COUNTRY

\# Local Distribution

Pacific Northwest National Laboratory

Name

Name

Name

Name

Name
Mailstop

Mailstop

Mailstop

Mailstop

(PDF) 



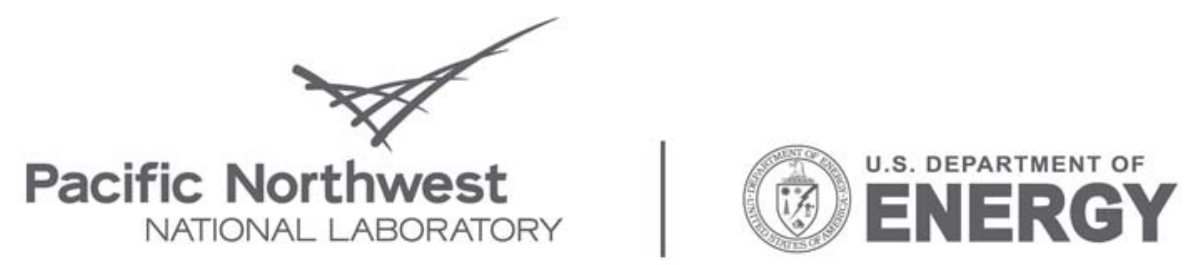

Proudly Operated by Battelle Since 1965

902 Battelle Boulevard

P.O. Box 999

Richland, WA 99352

1-888-375-PNNL (7665)

www.pnl.gov 